\title{
A PROPOSED CONTROL SOLUTION FOR THE CAL POLY WIND ENERGY CAPTURE SYSTEM
}

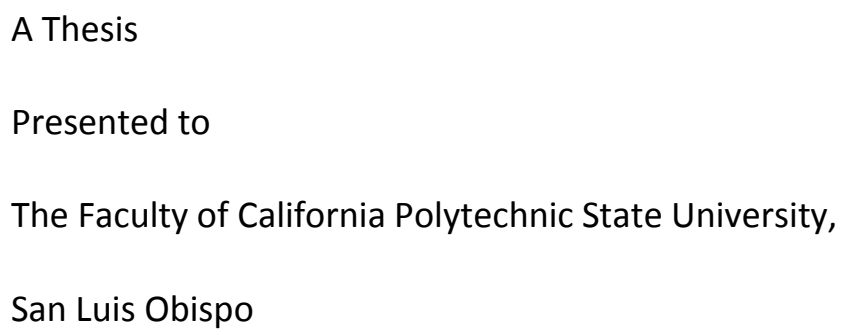

A Thesis

Presented to

The Faculty of California Polytechnic State University,

San Luis Obispo

In Partial Fulfillment

Of the Requirements for the Degree

Master of Science in Electrical Engineering

By

Kent Burnett

June 2012 
(C) 2012

Kent Burnett

ALL RIGHTS RESERVED 


\section{COMMITTEE MEMBERSHIP}

TITLE:

AUTHOR:

DATE SUBMITTED: June 2012

COMMITTEE CHAIR: Dr. Dale Dolan, Assistant Professor Electrical Engineering

A PROPOSED CONTROL SOLUTION FOR THE

CAL POLY WIND ENERGY CAPTURE SYSTEM

Kent Burnett

COMMITTEE MEMBER: Dr. Patrick Lemieux, Associate Professor Mechanical Engineering 


\section{ABSTRACT}

\section{A PROPOSED CONTROL SOLUTION FOR THE}

\section{CAL POLY WIND ENERGY CAPTURE SYSTEM}

Kent Burnett

The focus of this thesis is to research, analyze, and design a reliable and economical control system for the Cal Poly Wind Energy Capture System (WECS). A dynamic permanent magnet generator model is adopted from [1] and [2] and combined with an existing wind turbine model to create a non-linear time varying model in MATLAB. The model is then used to analyze potentially harmful electrical disturbances, and to define safe operating limits for the WECS. An optimal operating point controller utilizing a PID speed loop is designed with combined optimization criteria and the final controller design is justified by comparing performance measures of energy efficiency and mitigation of mechanical loads. The report also discusses implications for a WECS when blade characteristics are mismatched with the generator. Finally, possible ways to improve the performance of the Cal Poly WECS are addressed. 


\section{TABLE OF CONTENTS}

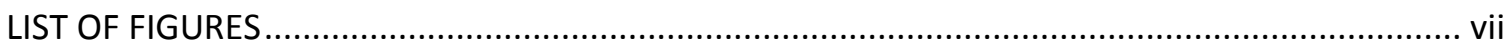

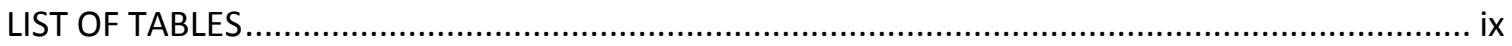

LIST OF SYMBOLS

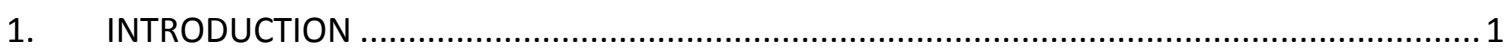

1.1 Statement of Problem and Motivation ...................................................................... 1

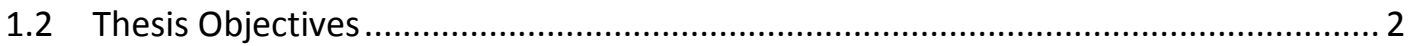

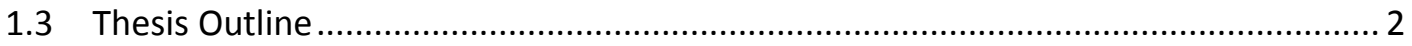

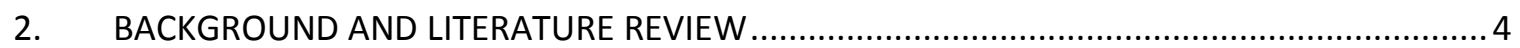

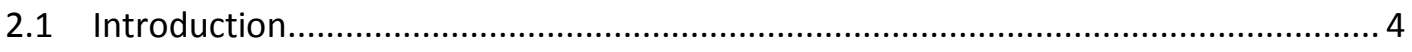

2.2 An Overview of Three Fundamental WECS Systems .............................................. 5

2.3 The Control System - Structure, Objectives, and Strategies …............................. 17

3. DYNAMIC GENERATOR - MODEL DEVELOPMENT AND ANALYSIS ....................................26

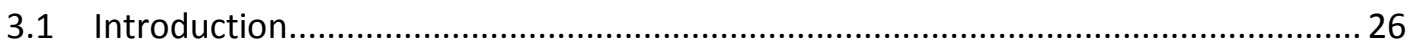

3.2 Determination of Dynamic PMG Model Parameters ............................................... 26

3.3 Torque Oscillations from Bridge Rectifier ......................................................... 31

3.4 Voltage Transients from Step Load Change .......................................................... 40

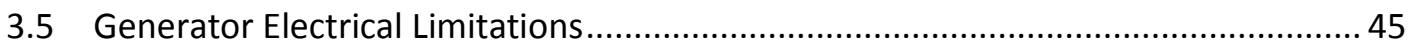

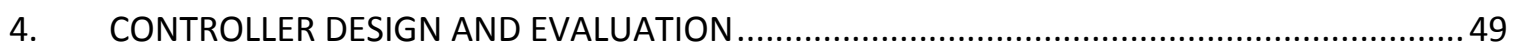

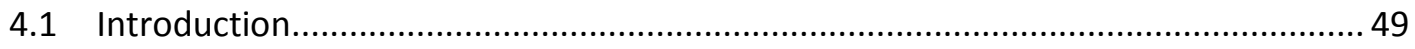

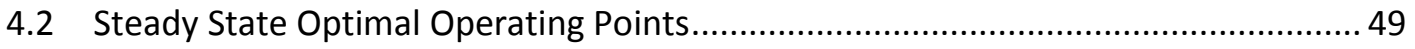

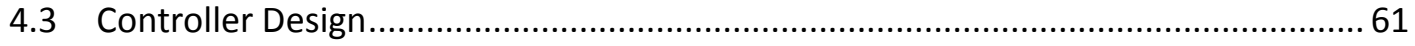

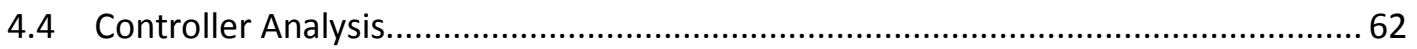

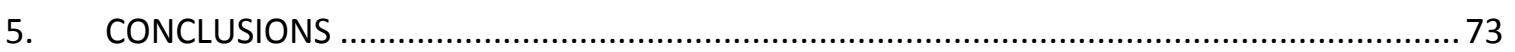

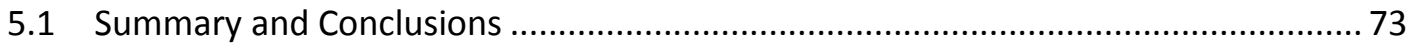

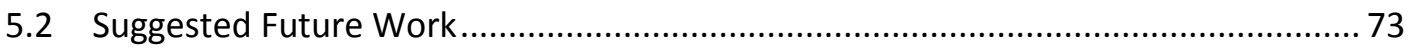




\subsection{Possible Solutions to Improve the Operational Range of the}

Fixed Pitch Cal Poly WECS

APPENDICES 75

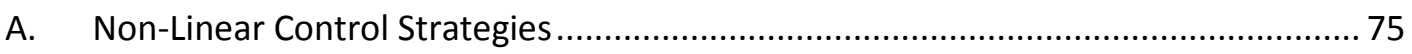

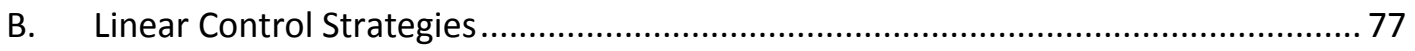

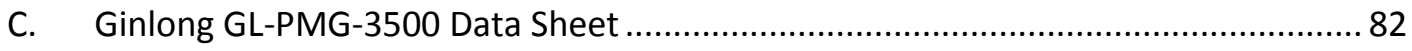

D. Ziegler Nichols Frequency Response Tuning for PID ............................................. 83

E. Classical Method for Determining Aerodynamic Limitations.................................. 86

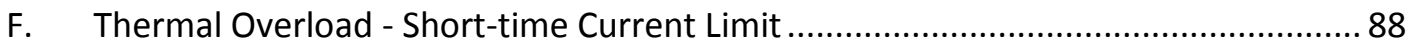

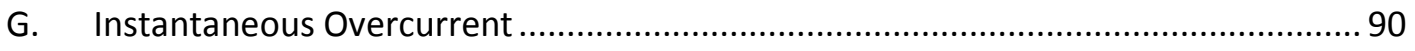

H. MDS60-16B Bridge Rectifier Datasheet ........................................................... 91

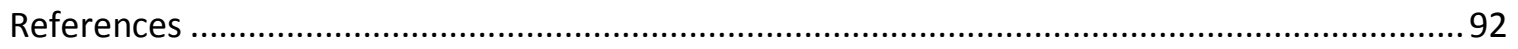




\section{LIST OF FIGURES}

Figure 2.1 Aerodynamic, Mechanical, and Electrical subsystems of the WECS ............................ 5

Figure $2.2 \mathrm{Cp}$-Power Coefficient vs. $\lambda$ for the Cal Poly WECS [4] .............................................. 6

Figure 2.3 Typical Power vs. Rotational speed ( $r / s)$, for given wind speed, with ORC [8].............. 7

Figure 2.4 Aerodynamic MatLab Simulink WECS model [4] .................................................... 8

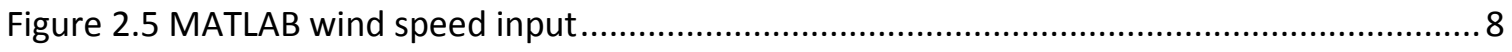

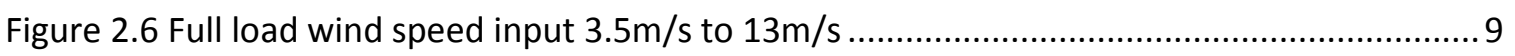

Figure 2.7 Rigid shaft MatLab Simulink WECS model with constant inputs [4] ............................ 10

Figure 2.8 Equivalent per phase model for synchronous generator .......................................... 12

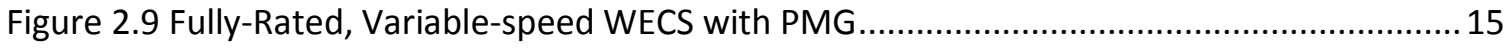

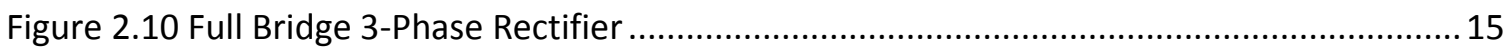

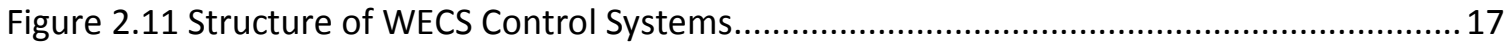

Figure 2.12 Ideal Power Production Curve with Regions of Operation ........................................19

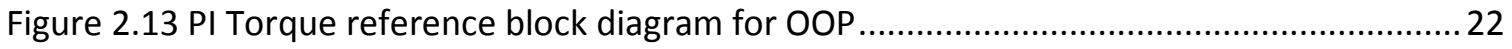

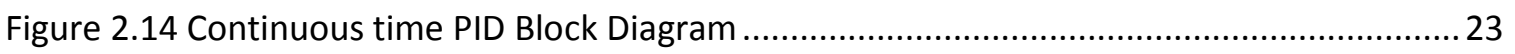

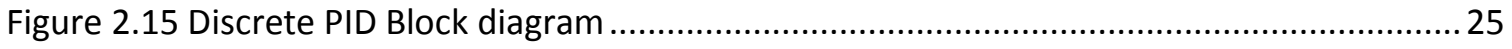

Figure 3.1 MatLab PMG Generator model for parameter determination.....................................2 27

Figure 3.2 MatLab Simulink PMG Parameters ............................................................................ 29

Figure 3.3 Simulated PMG Torque Oscillations from rectifier

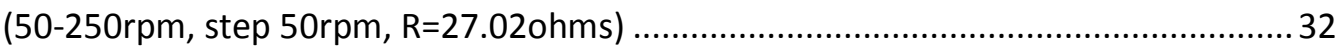

Figure 3.4 Simulated PMG Torque Oscillation (40[Nm_pp]) (250rpm, $R=27.02 \mathrm{ohms}$ ) ................. 33

Figure 3.5 Line Current (labc) at PMG terminals (250rpm, $\mathrm{R}=27.02 \mathrm{ohm}$ ) .................................. 34

Figure 3.6 LT-Spice Steady State generator model and MDS60-16B Rectifier ..............................35

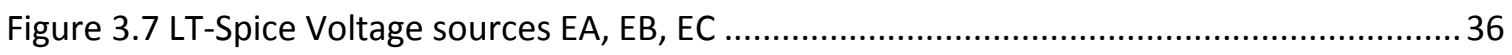

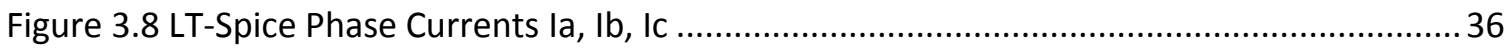

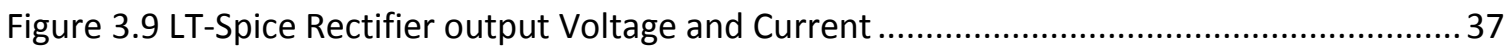

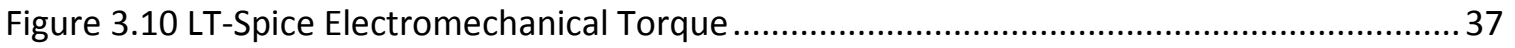

Figure 3.11 PMG Simulation with fixed 3-phase Resistive load................................................. 39

Figure 3.12 Simulated PMG Torque with balanced 3-phase load

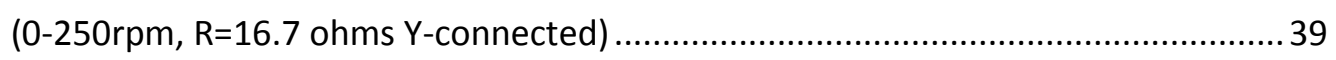

Figure 3.13 Dynamic PMG Simulink model with rectifier and current-source variable load ........ 40

Figure 3.14 Variable resistance load using current source ....................................................... 41

Figure 3.15 PMG step load increase, Vdc, Idc, and torque (250rpm, Rdc=500 to 27) ..................42

Figure 3.16 PMG step load decrease, Vdc, Idc, and torque (250rpm, $\mathrm{Rdc}=27$ to 500) ................. 43

Figure 3.17 PMG stepped load Decrease with capacitor( $C=0.1 \mathrm{mF}), \mathrm{Vdc}$, Idc, and torque

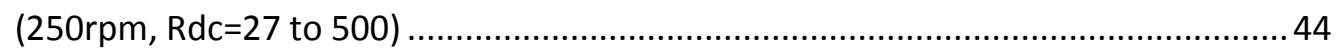

Figure 3.18 Capacitor added across the output of the rectifier to reduce voltage transient ....... 44

Figure 3.19 PMG Input Power vs. Rotor Speed for approximate power Loss=400W ................... 47

Figure 4.1 Available Power vs. Rotor Speed for given wind speeds .........................................50 
Figure 4.2 Limited range of operation - Available Power vs. Wind Speed................................... 51

Figure 4.3 Improved range of operation - Available power vs. wind speed.................................52

Figure 4.4 Rotor Speed vs. Wind speed along safe operating limit ...........................................53

Figure 4.5 Optimal operating points on available power vs. rotor speed ...................................53

Figure 4.6 Controller speed reference signal as a function of wind speed .................................55

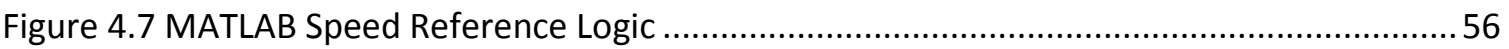

Figure 4.8 Available Power \& Input PMG Power for given Wind Speed and Output Resistance .. 57

Figure 4.9 Approximate Steady State Resistance vs. Desired Rotor speed ..................................57

Figure 4.10 MATLAB Steady State Resistance Equations and Logic ............................................58

Figure 4.11 Combined MATLAB model with Discrete PID Speed Controller

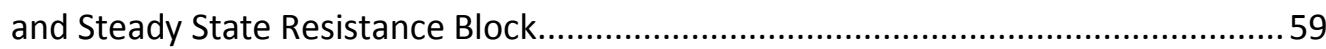

Figure 4.12 Looking inside the WECS block- Aerodynamic, mechanical, electrical,

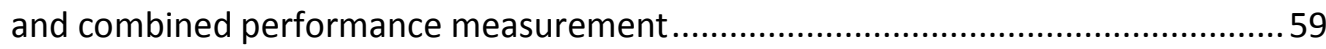

Figure 4.13 Simulink Performance Measurement Block Diagram

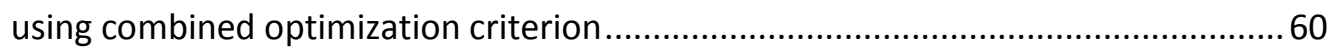

Figure 4.14 System response from steady state resistance input compensator only..................63

Figure 4.15 Rotor Speed vs. Time for with full load wind input - proposed gains ..........................64

Figure 4.16 Resistance control signal connected to the generator .............................................65

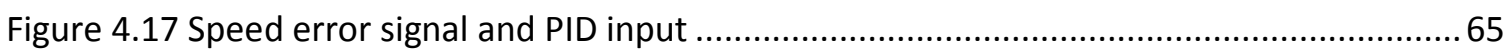

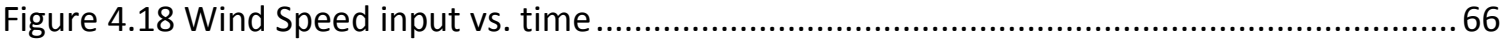

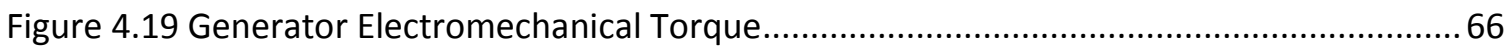

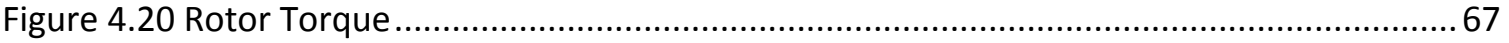

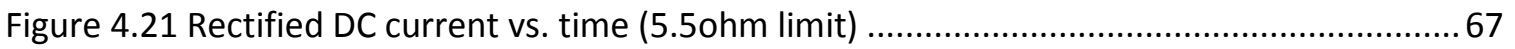

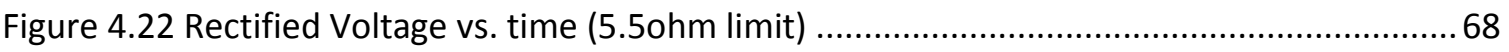

Figure 4.23 Generator Torque spike with minimum resistance limit of $10 \mathrm{ohms} \mathrm{.........................69}$

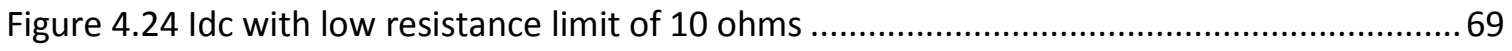

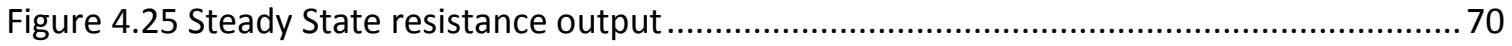

Figure 4.26 Rotor Speed vs. Time for wind speed drop - No PID .............................................. 71

Figure 4.27 Generator torque during wind speed drop - No PID............................................... 71

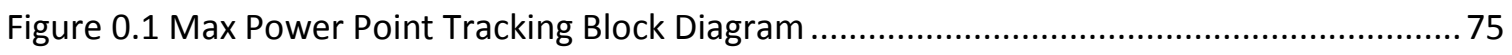

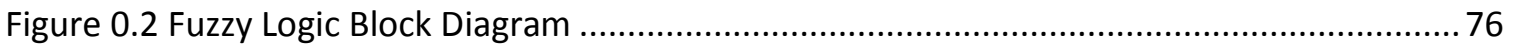

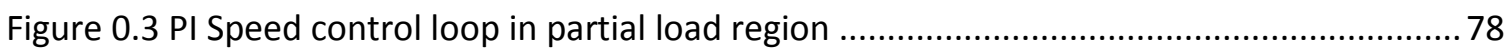

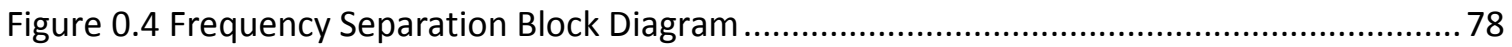

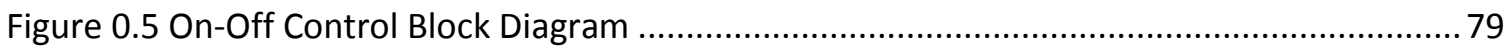

Figure 0.6 Typical Gain Scheduling Controller for overall operation ......................................... 80

Figure 0.7 Marginal stability of rotor speed using discrete controller with Ts=0.01s ................... 84

Figure 0.8 Stator short-time current limit as percent of rated current ....................................... 89

Figure 0.9 Instantaneous and short-time stator current limit for Ginlong PMG-3500.................90 


\section{LIST OF TABLES}

Table 2.1 Aerodynamic system constants for Cal Poly WECS [4] .............................................. 8

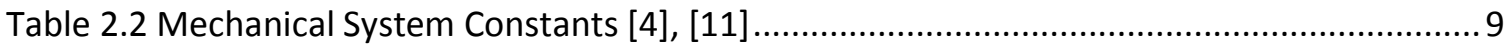

Table 3.1 Simulated and specified Power for the PMG-3500 with $R=27.05$............................... 30

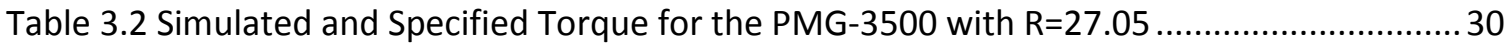

Table 3.3 Simulated and Specified Voltage for the PMG-3500 with $R=27.05$............................. 30

Table 3.4 Simulated MATLAB Ginlong GL-PMG-3500 Parameter Values ...................................... 31

Table 3.5 Simulated PMG 11A Limit Generator Characteristics ................................................... 45

Table 3.6 Simulated PMG Power loss data below rated speed ................................................... 47

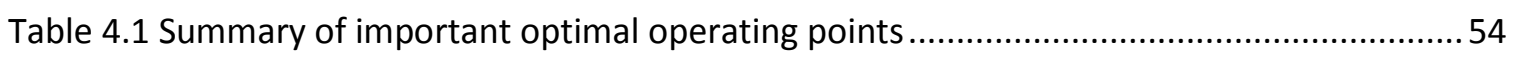

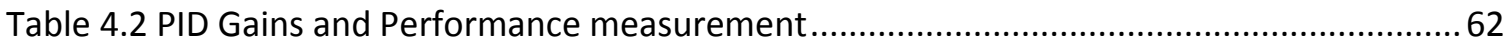

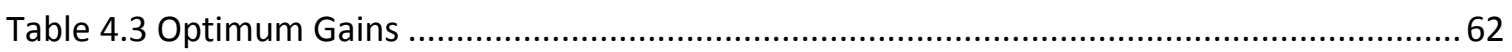

Table 0.1 Ziegler-Nichols Frequency Response Tuning Parameters [17] .................................... 83

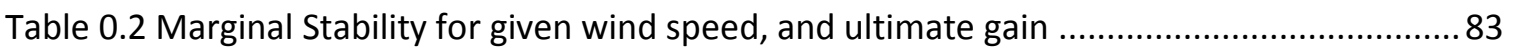

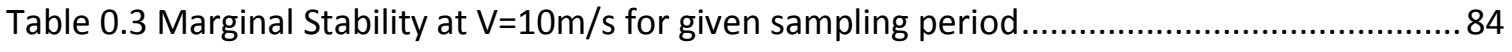

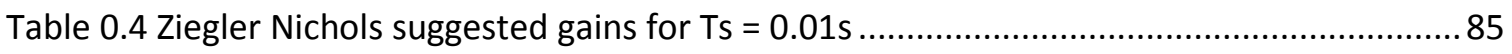

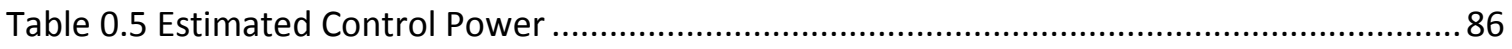

Table 0.6 Selected electrical \& thermal specifications from Ginlong PMG data sheet .................. 88

Table 0.7 Short-time current limit as percent of rated current.................................................. 89 


\section{LIST OF SYMBOLS}

\begin{tabular}{|c|c|c|}
\hline$C_{p}$ & Power Coefficient & [unit-less] \\
\hline$C_{\text {pmax }}$ & Max Power Coefficient & [unit-less] \\
\hline$\lambda$ & Tip Speed Ratio & [unit-less] \\
\hline$\lambda_{o p t}$ & Optimal Tip Speed Ratio & [unit-less] \\
\hline$f_{e}$ & Electrical frequency & {$[\mathrm{Hz}]$} \\
\hline$p_{\text {tot }}$ & Total number of poles & [unit-less] \\
\hline$p$ & Number of pole pairs & [unit-less] \\
\hline$J_{r}$ & Rotor Inertia & {$\left[\mathrm{kgm}^{2}\right]$} \\
\hline$J_{g}$ & Generator Inertia & {$\left[\mathrm{kgm}^{2}\right]$} \\
\hline$J$ & Total Inertia & {$\left[\mathrm{kgm}^{2}\right]$} \\
\hline$\overline{E_{a}}$ & Induced RMS voltage per phase & [V] - complex phasor \\
\hline$X_{S}$ & Equivalent per phase reactance & [ohms] \\
\hline$\overline{I_{a}}$ & RMS per phase current & [A] - complex phasor \\
\hline$R_{a}$ & equivalent per phase resistance & [ohms] \\
\hline$\overline{V_{\phi}}$ & RMS per phase terminal voltage & [V] - complex phasor \\
\hline$N_{p h}$ & Number of series turns per phase & [unit-less] \\
\hline$k_{w}$ & winding factor & [unit-less] \\
\hline$\phi_{p}$ & flux per pole & {$[\mathrm{Wb}],[\mathrm{Vs}]$} \\
\hline$R$ & Stator Resistance & {$[\Omega]$} \\
\hline$L_{d}$ & D inductance & {$[\mathrm{H}]$} \\
\hline$L_{q}$ & $\mathrm{Q}$ inductance & {$[\mathrm{H}]$} \\
\hline$\phi_{m}$ & Constant PMG flux & {$[\mathrm{Wb}],[\mathrm{Vs}]$} \\
\hline$i_{d}(t)$ & Stator d current & {$[\mathrm{A}]$} \\
\hline$i_{q}(t)$ & Stator q current & {$[\mathrm{A}]$} \\
\hline$L_{S}$ & Constant parallel load inductance & {$[\mathrm{H}]$} \\
\hline$R_{S}(t)$ & Variable parallel load resistance & {$[\Omega]$} \\
\hline$V_{D C}$ & Rectifier output voltage & [V] \\
\hline$V_{m}$ & Rectifier input - peak phase voltage (line to neutral) & {$[\mathrm{V}]$} \\
\hline$\tilde{V}_{\phi \_r m s}$ & RMS phase voltage (line to neutral) & {$[\mathrm{V}]$} \\
\hline$I_{m}$ & Rectifier input - peak phase current (line to neutral) & {$[\mathrm{A}]$} \\
\hline$\tilde{I}_{R_{r m s}}$ & RMS phase current (line to neutral) & {$[\mathrm{A}]$} \\
\hline$V_{c u t-i n}$ & Cut-in wind speed & {$[\mathrm{m} / \mathrm{s}]$} \\
\hline$V_{\text {nominal }}$ & Nominal wind speed & {$[\mathrm{m} / \mathrm{s}]$} \\
\hline$V_{\text {cut-out }}$ & Cut-out wind speed & {$[\mathrm{m} / \mathrm{s}]$} \\
\hline$P$ & Power & {$[\mathrm{W}]$} \\
\hline$u(t)$ & PID control action & [unit-less] \\
\hline$K$ & PID common gain & [unit-less] \\
\hline$e(t)$ & PID error signal & [unit-less] \\
\hline$T_{i}$ & PID integration period & {$[\mathrm{sec}]$} \\
\hline$T_{d}$ & PID derivative gain & [sec] \\
\hline$T_{r}$ & Rotor Torque & {$[\mathrm{Nm}]$} \\
\hline$T_{g}$ & Generator Torque & {$[\mathrm{Nm}]$} \\
\hline$\Omega$ & Rotational Speed & {$[\mathrm{rad} / \mathrm{s}]$} \\
\hline
\end{tabular}




\section{INTRODUCTION}

\subsection{Statement of Problem and Motivation}

Wind energy is becoming a more attractive energy source for the future world. Growing concern with the effects of green house gasses and the uncertain future of nuclear energy makes renewable sources such as wind a viable alternative. Wind energy is one of the leading renewable energy sources in the US with over 42GW currently installed, [3] but the average cost of installing Wind Energy Capture Systems (WECS) is still much higher than traditional fossil fuel plants of equivalent energy output. Fortunately, larger production quantities and increasing power output are reducing generation costs for WECS. In addition, technological advances in power electronics and innovative new controller designs are enhancing the popularity of variable-speed WECS which can maintain electrical synchronism with the grid while providing energy at different rotational speeds. These advancements are improving the economic vitality of Wind Energy Capture Systems for power generating entities.

The motivation of this thesis is to design a reliable and economical control system for the Cal Poly WECS. The control system is a fundamental component of the WECS which makes the wind turbine a useful machine to capture energy from the wind. Modern WECS control systems are primarily designed with two broad objectives in mind; reliability and energy efficiency. The objective of reliability is realized by mitigating mechanical loads which incurs minimal maintenance costs and leads to a longer service life. However, the goal of energy efficiency sometimes conflicts with the goal of reliability so a balanced compromise between the two objectives must be achieved by a well designed controller.

One of the many challenges facing a WECS design is the uncontrollable nature of wind. Traditional fossil fuel or steam power plants can easily adjust power output by increasing fuel flow or steam pressure, but wind turbines are limited by a highly variable source of energy. This means the control action must adjust according to the current wind resource. Because the wind resource can change quickly, a dynamic WECS model is required to study the transient effects.

In addition, the rated current of the Ginlong PMG-3500 imposes a restriction on the operational range of the WECS. In literature, the rated power of a generator is usually the primary restriction for the operational range of the WECS, but this is not the case for the WECS in this thesis. This thesis attempts to make the Cal Poly WECS reliable, economical, and as simple as possible. 


\section{$1.2 \quad$ Thesis Objectives}

1. To determine the parameters for a dynamic model of a permanent magnet generator.

2. To simulate a WECS modeled after the Cal Poly wind turbine so that torque variations from the bridge rectifier, and voltage transients from step load changes can be analyzed.

3. To determine generator electrical limitations based on simulation.

4. To determine steady state optimal operating points for the Cal Poly WECS.

5. To design an optimal operating point controller utilizing a PID speed loop based on combined optimization criteria.

6. To analyze the performance of the controller by measuring energy efficiency and torque variations.

\subsection{Thesis Outline}

Chapter 2 is a brief introduction to fully-rated, variable-speed fixed-pitch wind energy capture systems with a literature review covering the current methods used to control WECS. Three systems are defined and explained which make up the WECS model. The aerodynamic and mechanical systems for the Cal Poly WECS were created by [4] as part of a Mechanical Engineering Master's Thesis and these systems are the foundation for the WECS model used in this report. The electrical system is described in detail which includes a dynamic permanent magnet generator model and an ideal load.

The second half of chapter 2 describes the control system structure, objectives, and strategies used for the design of the Cal Poly WECS. Objectives are described in the partial and full load region, and energy efficiency, reliability performance, and combined optimization criteria are defined. The Optimal Operating Point controller (OOP) is described, as well as the PID controller in both continuous and discrete time models.

Chapter 3 first explains how the parameters for the dynamic PMG model were chosen and it also explains assumptions and limitations of the results. The model is then used to investigate torque oscillations produced from the bridge rectifier, and electrical transients which occur during step load changes. Finally, the dynamic generator model is used to analyze potentially harmful electrical disturbances, and to define safe operating limits for the WECS. 
Chapter 4 addresses the design and evaluation of an Optimal Operating Point (OOP) PID speed controller for the Cal Poly WECS. First, the safe operating limits for the generator and the aerodynamic characteristics of the Cal Poly WECS are used to define the optimal operating points for all wind speeds. The dynamic permanent magnet generator model is then combined with the existing state space WECS model to create a non-linear time varying system in MatLab Simulink. Next, an optimal operating point controller utilizing a PID speed loop is designed with the combined optimization criteria. The final controller design is justified by comparing performance measures of energy efficiency and mitigation of excessive mechanical loads. Chapter 4 also discusses implications for a WECS when blade characteristics are mismatched with the generator.

Chapter 5 is a summary and conclusion of the work performed in this thesis. It includes a list of future work possibilities and possible solutions to improve the operational range of the Cal Poly WECS. 


\section{BACKGROUND AND LITERATURE REVIEW}

\section{$2.1 \quad$ Introduction}

This chapter is a brief introduction to fully-rated, variable-speed fixed-pitch wind energy capture systems with a literature review covering the current methods used to control WECS. Three systems are defined and explained which make up the WECS model. The aerodynamic and mechanical MATLAB simulation models used by [4] are also used in this report. The electrical system is described in detail which includes a dynamic permanent magnet generator model and an ideal load.

The second half of this chapter describes the control system structure, objectives, and strategies used for the design of the Cal Poly WECS. Objectives are described in the partial and full load region, and energy efficiency, reliability performance, and combined optimization criteria are defined. The Optimal Operating Point controller (OOP) is described, as well as the PID controller in both continuous and discrete time models.

The Cal Poly WECS is Cal Poly's first ever complete wind energy capture system which is being supervised by the Mechanical Engineering department. The Cal Poly WECS is off-grid, with horizontal fixed-pitch blades, and a variable-speed $3.5 \mathrm{~kW}$ permanent magnet generator. The goal of the project is to provide research and hands on learning for students interested in utility grade wind energy capture systems. Significant progress has been made towards a successful wind turbine design including the work performed by [5], [6]. Additional work is currently underway for the design of a blade pitch regulator and a yaw regulator which will be a significant addition to the project.

In 2010, a mechanical engineering graduate student presented a Thesis for the Cal Poly WECS which is titled "Design, Implementation and Testing of a Control System for a Small, Off-Grid Wind Turbine" [4]. Many objectives were achieved in this thesis including calculations for the mechanical, and aerodynamic performance of the rotor, as well as the development of a MATLAB simulation model. Tests were performed on the generator to develop a steady state look-up table for speed, torque, and resistance. In addition, a control strategy was designed for the partial load region.

A senior project for the Cal Poly WECS was also completed in June 2010. The report is titled "Cal Poly Wind Turbine Speed Controller". The report focuses on the design and implementation of a Programmable Logic Controller which controls the speed of the rotor by regulating the electrical load with a DC chopper [7]. 


\subsection{An Overview of Three Fundamental WECS Systems}

The WECS can be modeled as three fundamental systems which are shown in Figure 2.1. This is a standard practice in WECS control literature and further explanations are given below. $P_{w}$ is the power of the wind, $P_{e}$ is the output power of the generator, $T_{r}$ and $T_{g}$ are the rotor torque and generator torque, $\Omega_{\mathrm{r}}$ and $\Omega_{\mathrm{g}}$ are the rotational speed of the rotor and the rotational speed generator.

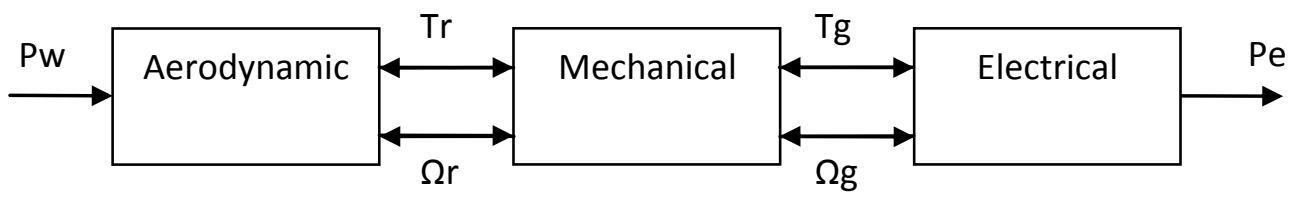

Figure 2.1 Aerodynamic, Mechanical, and Electrical subsystems of the WECS

\subsubsection{Wind Turbine Aerodynamics}

The aerodynamic system converts wind energy into useful mechanical energy. A thorough discussion about wind turbine aerodynamics can be found by reading [8] or [4]. Many other helpful resources exist, but the most important equations to understand are the torque and power captured by the rotor blades. The torque produced by the rotor of a fixed pitch turbine is described by equation (2.1). $\rho$ is the density of air, $R_{t}$ is the radius of the blades, $V$ is the wind velocity, and $C_{Q}$ is the torque coefficient which is a function of the tip speed ratio.

$$
T_{r}=\frac{1}{2} \rho \pi \mathrm{R}_{\mathrm{t}}^{3} \mathrm{C}_{\mathrm{Q}} \mathrm{V}^{2}
$$

The relation for the power captured by the rotor blades is described by equation (2.2). $C_{p}$ is the power coefficient which is also a function of the tip speed ratio.

$$
P_{r}=\frac{1}{2} \rho \pi \mathrm{R}_{\mathrm{t}}^{2} C_{p} \mathrm{~V}^{3}
$$

The tip speed ratio is defined by equation (2.3), where $\Omega_{\mathrm{r}}$ is the rotational speed of the rotor in $[\mathrm{rad} / \mathrm{s}]$ and $\lambda$ is the tip speed ratio.

$$
\lambda=\frac{\Omega_{\mathrm{r}} \mathrm{R}_{\mathrm{t}}}{V}
$$


The aerodynamic design of the blades is such that a maximum power coefficient occurs at an optimal tip speed ratio $\lambda_{\text {opt }}$. The power coefficient depends on the tip speed ratio and is usually in the range of $0 \leq C_{p} \leq 0.45$, but is never greater than the maximum achievable value of $C_{p}$ which is known as the Betz Limit $\left(C_{p}<C_{p_{-} \text {Betz }}=0.593\right.$ ) [8]. Figure 2.2 shows the predicted $C_{p}$ vs. $\lambda$ curve for the Cal Poly WECS which was determined by [4].

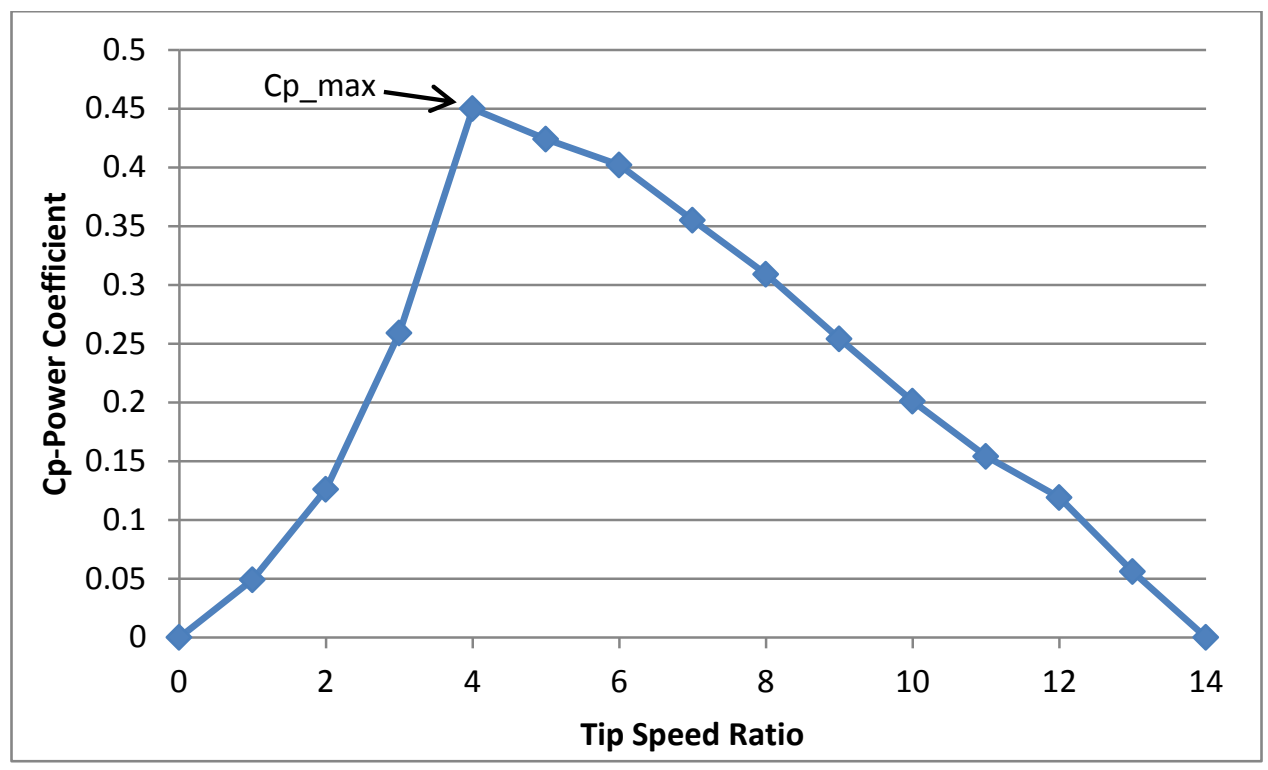

Figure 2.2 Cp-Power Coefficient vs. $\lambda$ for the Cal Poly WECS [4]

As seen in Figure 2.2, the maximum power coefficient occurs at the peak of the graph and corresponds to an optimum tip speed ratio of 4 .

$$
C_{p_{\max }=} C_{p}\left(\lambda_{\text {opt }}\right)
$$

According to equation (2.2) the power extracted by the rotor also depends on the wind velocity. Power is related to wind velocity by the velocity cubed, so the extracted power changes quickly when the wind speed changes. Figure 2.3 shows a family of curves relating the rotor power to wind speed as well as power vs. rotational speed. 


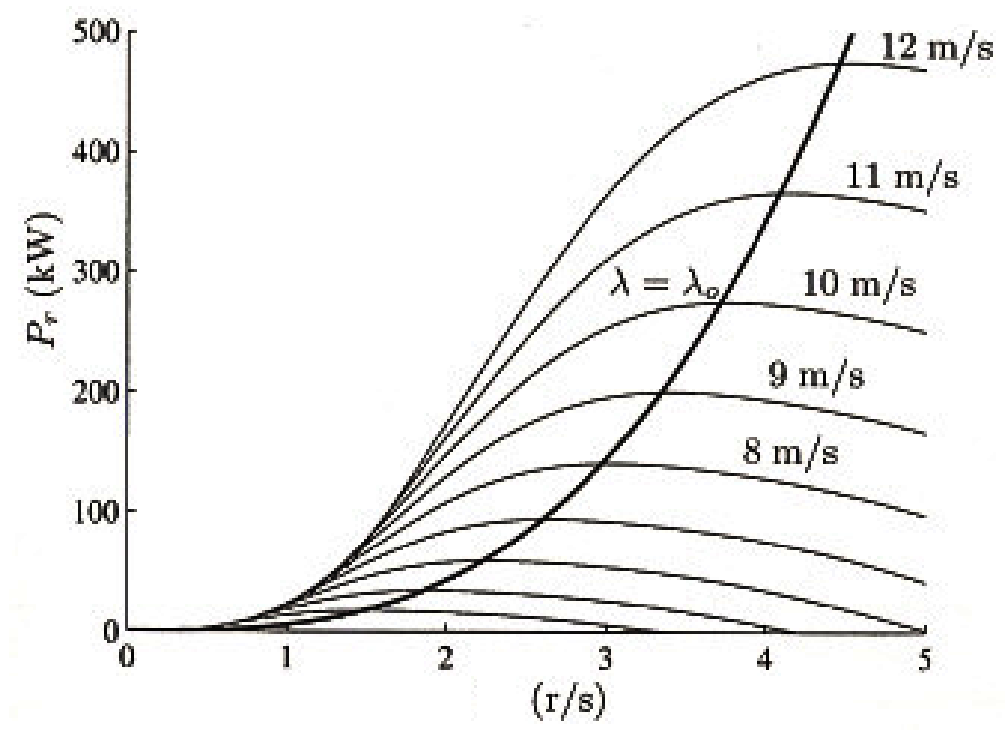

Figure 2.3 Typical Power vs. Rotational speed (r/s), for given wind speed, with ORC [8]

Figure 2.3 also shows the optimal regimes characteristic (ORC) in the partial load region which is the line that intersects the power vs. rotational speed curves at the maximum power point for a given wind speed. The turbine operates on the ORC if the tip speed ratio is held to the optimum tip speed.

$$
\lambda(t)=\lambda_{\text {opt }}
$$

In conclusion, the aerodynamic system is inherently non-linear, most obviously because the power coefficient $C_{p}$ is a non-linear function of the tip speed ratio $\lambda$, and $C_{p}$ is highly dependent on the constructive characteristics of the turbine [9].

\subsubsection{MatLab Aerodynamic Model}

The aerodynamic model developed by [4] is presented in Figure 2.4. This model uses input wind speed, equation (2.1), and a lookup table for $\mathrm{C}_{\mathrm{Q}}$ to calculate the available torque from the wind. 


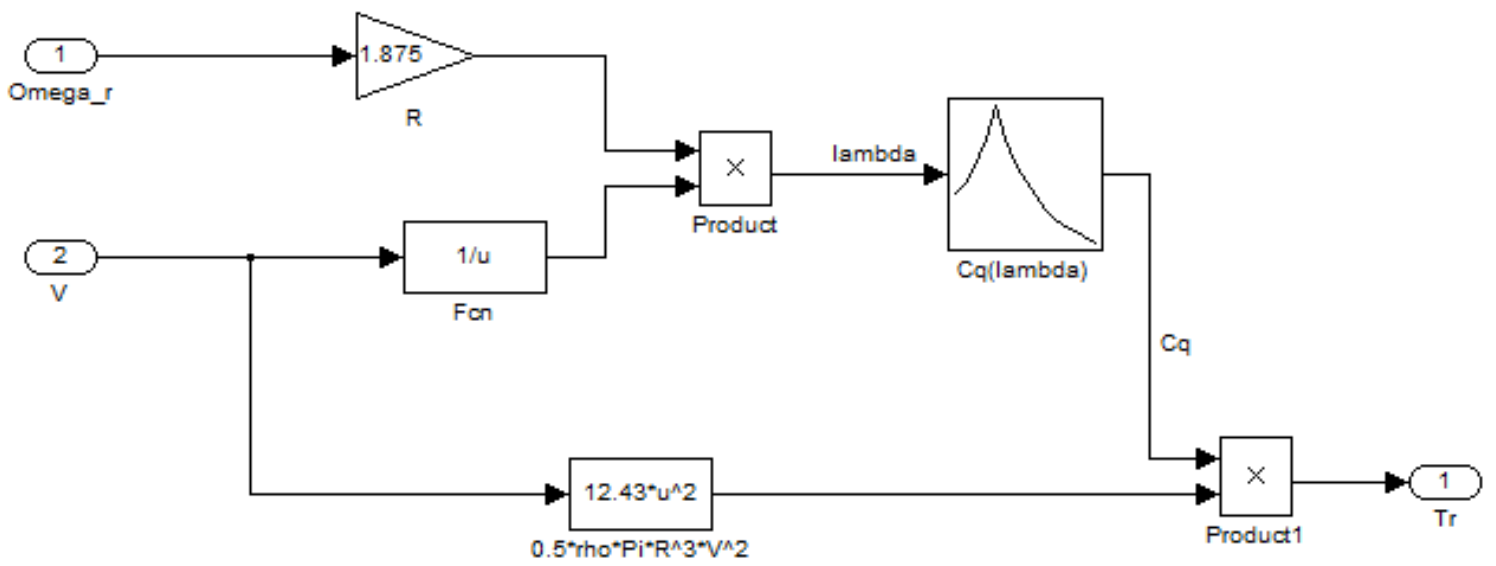

Figure 2.4 Aerodynamic MatLab Simulink WECS model [4]

The model takes inputs from the rotor speed and the wind velocity to calculate the current tip speed ratio. The torque coefficient is represented by a look-up table $\left(C_{q}\right.$ vs. $\left.\lambda\right)$. The parameters in Table 2.1 are the aerodynamic constants for the Cal Poly WECS used in equation (2.1).

Table 2.1 Aerodynamic system constants for Cal Poly WECS [4]

\begin{tabular}{|c|c|c|c|}
\hline Description & Symbol & Value & Units \\
\hline Air density & $\rho$ & 1.22 & $\mathrm{~kg} / \mathrm{m}^{3}$ \\
\hline Radius of blades & $\mathrm{R}_{\mathrm{t}}$ & 1.875 & $\mathrm{~m}$ \\
\hline
\end{tabular}

\subsubsection{Wind Speed Input}

Two basic wind speed inputs were used for this thesis. Both input groups use simple step and ramp functions to represent the wind speed input as shown in Figure 2.5. The full load wind speed input is shown in Figure 2.6.

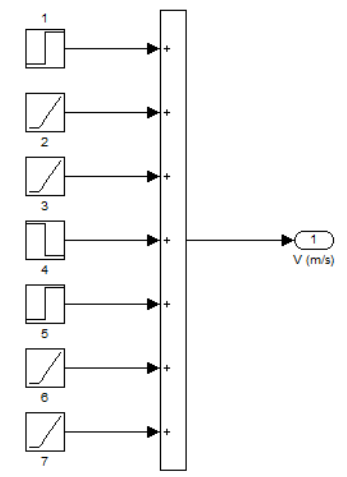

Figure 2.5 MATLAB wind speed input

More complicated models exist, such as the Von Karman wind turbulence model, but they are not considered in this thesis. 


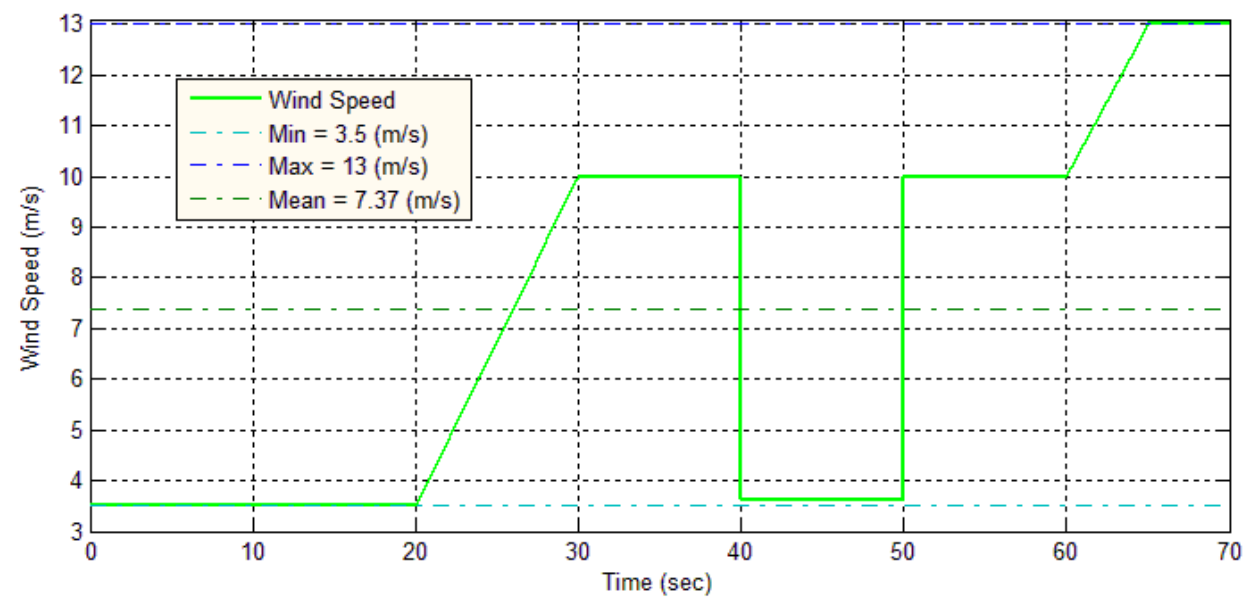

Figure 2.6 Full load wind speed input $3.5 \mathrm{~m} / \mathrm{s}$ to $13 \mathrm{~m} / \mathrm{s}$

\subsubsection{Mechanical System}

The mechanical system considered in this thesis primarily consists of the rotor which transfers energy from the aerodynamic system to the electrical system. It does not include structural considerations such as tower and blade bending although these structural characteristics can play a significant role in WECS dynamics.

The mechanical system of the Cal Poly wind turbine was extensively analyzed by [4] as part of a master's thesis. The inertia constant $\mathrm{J}_{\mathrm{r}}$ was determined by [4], and $\mathrm{J}_{\mathrm{g}}$ comes from [11]. The values are listed in Table 2.2 below.

Table 2.2 Mechanical System Constants [4], [11]

\begin{tabular}{|l|l|}
\hline$J$ & $6.906\left(\mathrm{kgm}^{2}\right)$ \\
\hline$J_{r}$ & $6.84\left(\mathrm{kgm}^{2}\right)[4]$ \\
\hline$J_{g}$ & $0.066\left(\mathrm{kgm}^{2}\right)[11]$ \\
\hline
\end{tabular}

After modeling the system, [4] concluded that the shaft could be modeled as a rigid shaft. In addition, [4] found it acceptable to model the system with a damping coefficient $=0$. The simplified rigid shaft MATLAB model for the mechanical drive train is seen in Figure 2.7 below. 
Rigid shaft

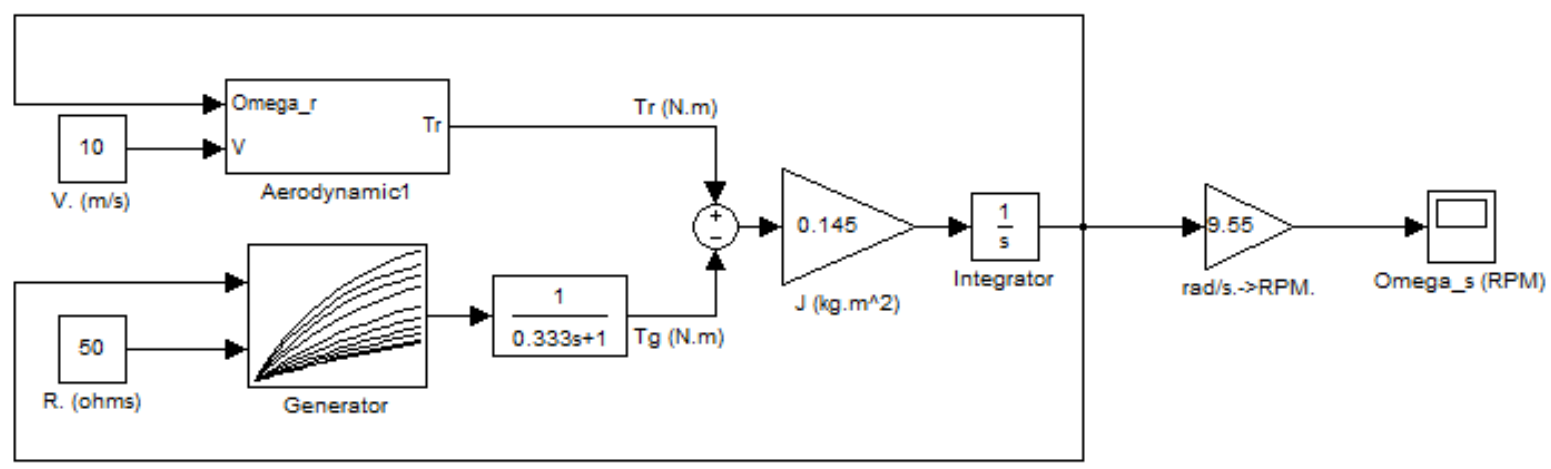

Figure 2.7 Rigid shaft MatLab Simulink WECS model with constant inputs [4]

The equation relating the rotor torque to the input generator torque is represented by equation (2.6). This equation also includes the term $F$ which is the combined viscous friction.

$$
J \frac{d \Omega(t)}{d t}=T_{r}(t)-F \Omega(t)-T_{G}(t)
$$

The model from [4] neglects viscous friction which yields the following equation.

$$
\begin{gathered}
J \frac{d \Omega(t)}{d t}=T_{r}(t)-T_{G}(t) \\
\dot{\Omega}(t)=\frac{1}{J}\left(T_{r}(t)-T_{G}(t)\right)
\end{gathered}
$$

Equation (2.8) represents the accelerating torque which is commonly used to relate the speed acceleration between rigidly coupled torque sources [12]. During steady state operation at a given wind speed, the mechanical torque will be equal to the electrical torque and the turbine will rotate with constant speed. If there is a difference of torques then the system will accelerate based on the inertia and the amount of torque difference. Systems with large measures of inertia will experience smaller speed accelerations for a given accelerating torque. 


\subsubsection{Electrical System}

\subsubsection{Generator - Introduction}

The operation of a WECS is highly dependent on the type of generator used. For example, older style fixed speed WECS typically employed the use of Squirrel Cage Induction Generators (SCIG) which were directly connected to the utility grid. These fixed speed SCIG required a soft starter to operate the generator as a motor during startup. Eventually when the rotational speed of the generator exceeded the synchronous speed of the grid, the generator would begin to produce power. Some SCIG also contain two winding sets ( 8 poles and 4-6 poles) which allow the generator to operate in synchronism with the grid at two different rotational speeds [1].

Synchronous generator are also employed by many variable speed WECS. Both wound rotor and Permanent Magnet Generator (PMG) type are used, but the PMG is the most common synchronous generator for wind turbines [1]. The PMG owes its popularity to the use of the permanent magnets which allow the generator to be self excited. The mechanical gearbox can also be eliminated when using the PMG because a high number of magnetic poles can be used to produce the desired electrical frequency at a slower rotor speed.

Anyone who studies power systems and electric machinery knows there are many different valid models for the synchronous generator. The permanent magnet generator (PMG) is a major component of the WECS and it is important to use the proper simulation model to give the desired simulation results. This thesis briefly discusses 3 models of the PMG; steady state lookup table, equivalent circuit model, and dynamic-state space model.

\subsubsection{Generator - Synchronous Machine Theory}

In order to better understand the origins of different synchronous generator models it is important to understand the general operation of a synchronous generator. When the rotor is turned, the rotating flux density induces a voltage on the armature windings. The flux linkages of the armature winding change with time and create a time varying electrical voltage [12]. The electrical frequency of the voltage induced in the armature is directly proportional to the frequency of the rotor and is synchronized with the mechanical rotor speed. The electrical frequency of the synchronous machine also depends on the number of poles as seen by the following equation (2.9).

$$
f_{e}=\left(\frac{p_{t o t}}{2}\right) \frac{\Omega}{60}
$$

Where $f_{e}$ is the electrical frequency in hertz, $p_{\text {tot }}$ is the total number of poles, and $\Omega$ is the rotor speed in revolutions per minute. 


\subsubsection{Generator - Steady State Lookup Table}

The steady state look-up table can also be used to show the relationship between rotor speed, load resistance and output torque, and is typically obtained by experimental measurement. The look-up table is like the steady equivalent circuit model because it represents the generator during normal operating conditions only. This type of model is sufficient for steady state modeling only.

\subsubsection{Generator - Steady State Equivalent Circuit Model}

The equivalent per phase circuit model for a synchronous generator is a useful tool to shed light on the steady state operation of a generator at rated conditions. The circuit describing the per-phase model for the synchronous generator is described below.

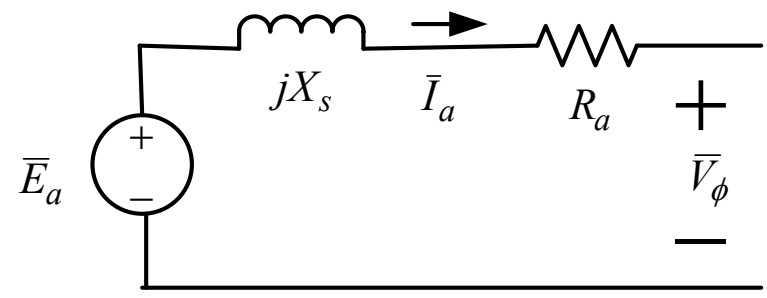

Figure 2.8 Equivalent per phase model for synchronous generator

Where $\overline{E_{a}}$ is the phasor quantity of induced RMS voltage per phase, $X_{S}$ is the equivalent per phase reactance, $\overline{I_{a}}$ is the phasor quantity of RMS current per phase, $R_{a}$ is the equivalent per phase resistance, and $\overline{V_{\phi}}$ is the phasor quantity of RMS terminal voltage per phase. Following $\mathrm{KVL}$, the circuit of Figure 2.8 is described by the following equation.

$$
\overline{V_{\phi}}=R_{a} \overline{I_{a}}-j X_{s} \overline{I_{a}}-\overline{E_{a}}
$$

The voltage induced in the armature winding depends on the frequency of rotation, the effective series turns per phase, and the flux per pole as seen in equation (2.11).

$$
E_{a}=\frac{2 \pi}{\sqrt{2}} f N_{p h} k_{w} \phi_{p}
$$

Where $N_{p h}$ is the number of series turns per phase, $k_{w}$ is the winding factor, and $\phi_{p}$ is the flux per pole. The general point to take away from this simplified equivalent circuit model is that the induced voltage is approximately proportional to the rotational speed and highly dependent on the number of series turns per phase. This equivalent circuit model can effectively model the steady state 
operation of the motor, but it ignores the dynamic characteristics of the motor which are described more thoroughly by the dynamic state space model.

\subsubsection{Generator - Dynamic State Space Model}

A dynamic generator model is a powerful tool to closely represent the actual characteristics of a generator by responding predictably to both steady state conditions and dynamic conditions. In most WECS control designs [1], [14], [2], a dynamic-state space model using differential equations is used. The dynamic state space model is a powerful tool in control theory because it is readily implemented in computer simulation and because it responds accurately to abrupt system changes. The most common model is derived from the $(a, b, c)$ coordinates by means of the Park Transform. The transformation to the direct - and quadrature axis $(\mathrm{d}-\mathrm{q})$ equations allows for a simpler means to analyze AC machines. Details and explanations of the Parks Transformation can be found from many sources including [12]. In addition, it is commonly assumed that the system will operate in balanced 3-phase conditions with no zero sequence components. Equation (2.12) is used to model the dynamic (d-q) current characteristics of the PMG with a parallel R-L load. The model assumes sinusoidal distribution of stator windings, electric and magnetic symmetry, negligible iron losses, and unsaturated magnetic circuit. It must be noted that that equation (2.12) is not valid for short circuit analysis.

$$
\begin{aligned}
& {\left[\begin{array}{l}
\dot{i_{d}} \dot{(}(t) \\
\dot{i_{q}}(t)
\end{array}\right]=} {\left[\begin{array}{c}
\frac{1}{L_{d}+L_{s}}\left(-R i_{d}(t)+p\left(L_{q}-L_{s}\right) i_{q}(t) \Omega(t)\right) \\
\frac{1}{L_{q}+L_{s}}\left(-R i_{q}(t)-p\left(L_{d}+L_{s}\right) i_{d}(t) \Omega_{h}(t)+p \phi_{m} \Omega(t)\right)
\end{array}\right] } \\
&+\left[\begin{array}{cc}
\frac{-1}{L_{d}+L_{s}} & 0 \\
0 & \frac{-1}{L_{q}+L_{s}}
\end{array}\right] \cdot\left[\begin{array}{l}
i_{d}(t) \\
i_{q}(t)
\end{array}\right] \cdot R_{s}(t)
\end{aligned}
$$

Equation (2.12) is adopted from [1], [2] which is the same model presented by [4]. The variables are defined in Table 3.4. In addition, generator torque is described by equation (2.13).

$$
T_{g}(t)=p \phi_{m} i_{q}(t)+p\left(L_{d}-L_{q}\right) i_{d}(t) i_{q}(t)
$$

When the permanent magnets are mounted on the surface of the rotor we assume $L_{d}=L_{q}$ [2]. This simplifies the equation for generator torque.

$$
T_{g}(t)=p \phi_{m} i_{q}(t)
$$


From equation (2.14) the generator torque obviously depends on the pole pairs $p$ which can be found by the following equation relating the rotational speed of the generator to the electrical frequency.

$$
f=p \frac{\Omega}{60}
$$

There are 10 poles pairs in the Ginlong PMG-3500 generator. This result is consistent with [6] and [4] as well as email correspondence with the manufacturer and experimental tests performed by the ME department. One complete turn of the rotor results in 10 electrical cycles. In addition, for a speed of $\Omega=300(\mathrm{rpm})$, and $f=50(\mathrm{hz})$ the pole pairs can be calculated.

$$
p=f \frac{60}{\Omega}=\frac{50 \cdot 60}{300}=10
$$

The load of the PMG model is represented by a variable resistance in equation (2.12) with a fixed inductive load, because it easily approximates a typical power electronics device which could be attached to the generator output. The dynamics of the power electronics are neglected because the switching frequency of most modern devices is significantly faster compared to the dynamics of the WECS and can therefore be neglected when modeling a control system [8], [1], [10], [2]. When the load of the generator is assumed to be a symmetric isolated three phase resistive load, equation (2.12) changes to become the equation shown below, which is the same equation used by the MATLAB model.

$$
\begin{gathered}
{\left[\begin{array}{c}
\dot{i_{d}(t)} \overrightarrow{i_{q}(t)}
\end{array}\right]=\left[\begin{array}{c}
\frac{1}{L_{d}}\left(-R i_{d}(t)+p L_{q} i_{q}(t) \Omega(t)\right) \\
\frac{1}{L_{q}}\left(-R i_{q}(t)-p L_{d} i_{d}(t) \Omega_{h}(t)+p \phi_{m} \Omega(t)\right)
\end{array}\right]} \\
+\left[\begin{array}{cc}
\frac{-1}{L_{d}} i_{d}(t) & 0 \\
0 & \frac{-1}{L_{q}} i_{q}(t)
\end{array}\right] \cdot R_{s}(t)
\end{gathered}
$$

\subsubsection{Power Electronics - WECS Configuration}

The fully-rated variable-speed system is becoming a popular WECS configuration. The power electronics for this type of configuration are rated to the full capability of the generator which is fully decoupled from the grid. All power flows through the power electronics. This configuration allows for the most flexible range of operation. 


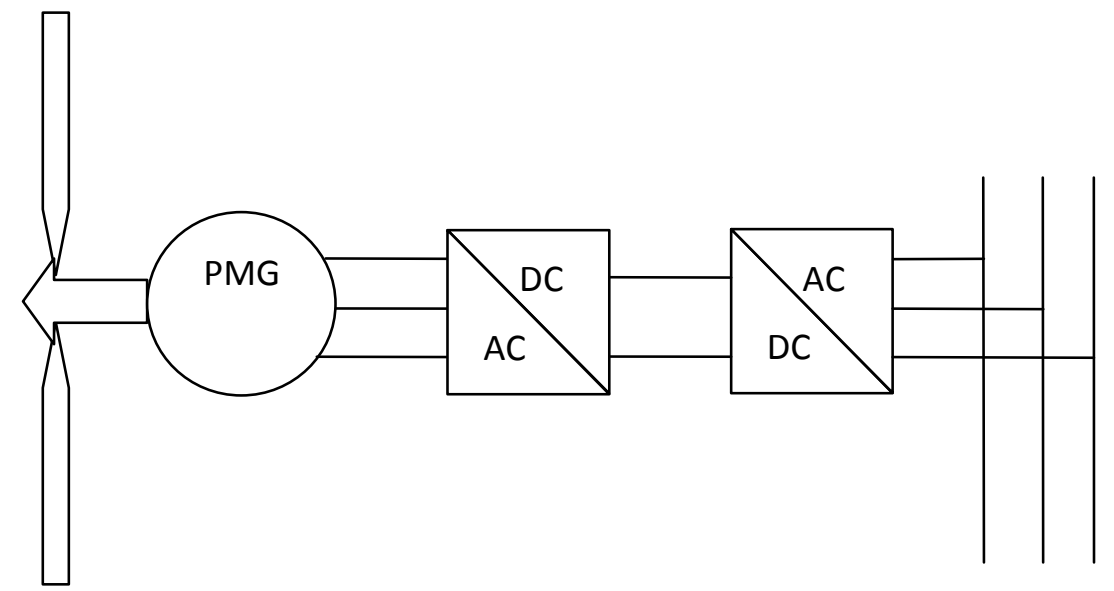

Figure 2.9 Fully-Rated, Variable-speed WECS with PMG

\subsubsection{Power Electronics - Full Bridge Rectifier}

The purpose of the full bridge rectifier is to transform 3-phase AC voltage and current to DC voltage and current. The rectifier connected to the Ginlong PMG is uncontrolled and consists of 6 power diodes. Appendix $\mathrm{H}$ lists the data for the MDS60-16B full bridge rectifier which is connected to the Ginlong PMG-3500. The configuration of the full bridge allows current to pass through in only one direction. The diode with the most positive anode and or the most negative cathode conducts.

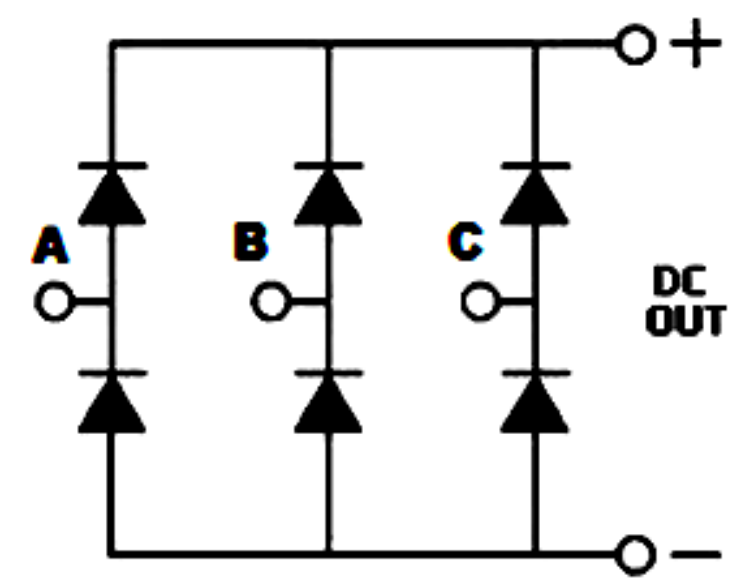

Figure 2.10 Full Bridge 3-Phase Rectifier

The voltage relation for the 3 phase full bridge rectifier is as follows [15]

$$
V_{D C}=1.654 V_{m}
$$


Where $V_{D C}$ is the DC output voltage and $V_{m}$ is the peak phase voltage (line to neutral) from the AC source. For a sinusoidal signal we know that the rms phase voltage $\tilde{V}_{\phi_{-} r m s}$ is related to the peak voltage by

$$
\tilde{V}_{\phi_{-} r m s}=\frac{V_{m}}{\sqrt{2}}
$$

So equation (2.18) becomes

$$
V_{D C}=1.654 \sqrt{2} \cdot \tilde{V}_{\phi \_r m s}
$$

For a purely resistive load the RMS output current of the rectifier $\tilde{I}_{R_{r m s}}$ is related to the peak AC input current $I_{m}$ by equation (2.21) [15].

$$
\tilde{I}_{R_{r m s}}=0.7804 I_{m}
$$

It is also interesting to note that the output current ripple for a 3-phase full bridge rectifier is $6(n)$ times the fundamental input frequency where $n$ is an integer from 1 to infinity. The most apparent output ripple occurs when $n=1$.

$$
f_{\text {out }}=6(n) f=6(1) 50=300(h z)
$$

The input current ripple frequency occurs at $(2 n \pm 1)$ times the fundamental frequency.

$$
f_{\text {input }}=(2 n \pm 1) f=(2 n \pm 1) 50=50(h z) \text { or } 150(h z)
$$




\subsection{The Control System - Structure, Objectives, and Strategies}

This section introduces the structure, objectives and strategies pertaining to fully-rated, variable-speed, fixed-pitch WECS which are most similar to the Cal Poly WECS.

\subsubsection{Structure}

Wind turbine control systems are broad and diverse. The structure of the overall control system is a network of subsystems that perform separate and sometimes parallel tasks. Figure 2.11 summarizes the structure of WECS control systems and lists possible control strategies.

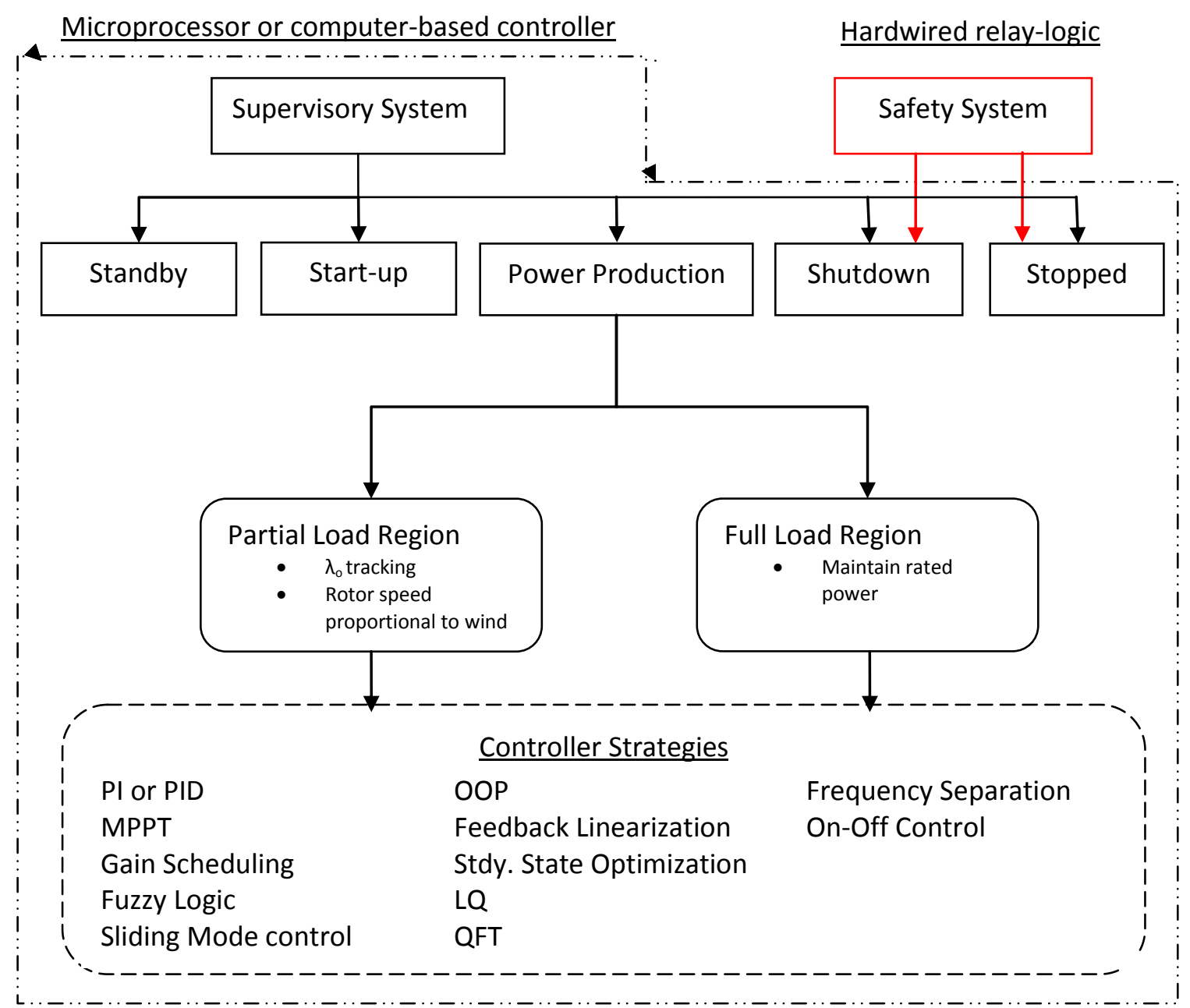

Figure 2.11 Structure of WECS Control Systems 
At the highest level of the control structure there is a safety system, and supervisory system which changes the operational mode of the controller. Supervisory control changes the operational state between standby, startup, power production, shutdown, and stopped with fault [10]. The supervisory system runs in the background during all modes of operation.

\subsubsection{Safety System}

The safety system is usually quite distinct from the main control system because it typically consists of hardwired relay-logic. The safety system prevents the WECS from operating outside its safe operational limits and acts as a back-up if the main control system fails.

Most robust safety systems do not rely exclusively on computer based systems for primary protection, but instead use independently hardwired normally open relay circuits [10]. If any safety relay contact is de-energized, the safety system trips and the WECS stops or returns to a safe operating condition.

Some of the most common safety circuits for typical WECS include the following:

- Rotor over speed - which is typically set higher than software rotor speed limit

- Vibration sensor - which could indicate a major structural failure has occurred

- Controller watchdog timer expired - to indicate if the main controller is active and running

- Other faults - can include high wind speed, generator electrical faults, ect.

The current safety system in the Cal Poly WECS is designed to protect the wind turbine from severe damage. It consists of a rotor over speed shutdown, a high wind speed shutdown, and a yaw/wind direction mismatch shutdown. When any of these conditions is detected by the onboard PLC, the mechanical break is applied to stop the wind turbine.

\subsubsection{Power Production Mode}

The power production mode of operation is most commonly discussed in literature because it is the mode when the WECS generates electricity. This mode is the main focus of this thesis. Within the power production mode there are typically two regions of operation which are defined by the power and wind speed. The controller must satisfy different objectives in each region of operation.

\subsubsection{Objectives}

This section discusses the objectives in the power production mode of operation. First the regions of operation are defined and then objectives are described. Economic performance is arguably 
the most important factor driving all control system objectives. The economic performance of the WECS primarily depends on energy efficiency and reliability performance of the machine.

The ideal power production curve is presented in Figure 2.12 which shows ideal available power for a given wind speed and the regions of operation.

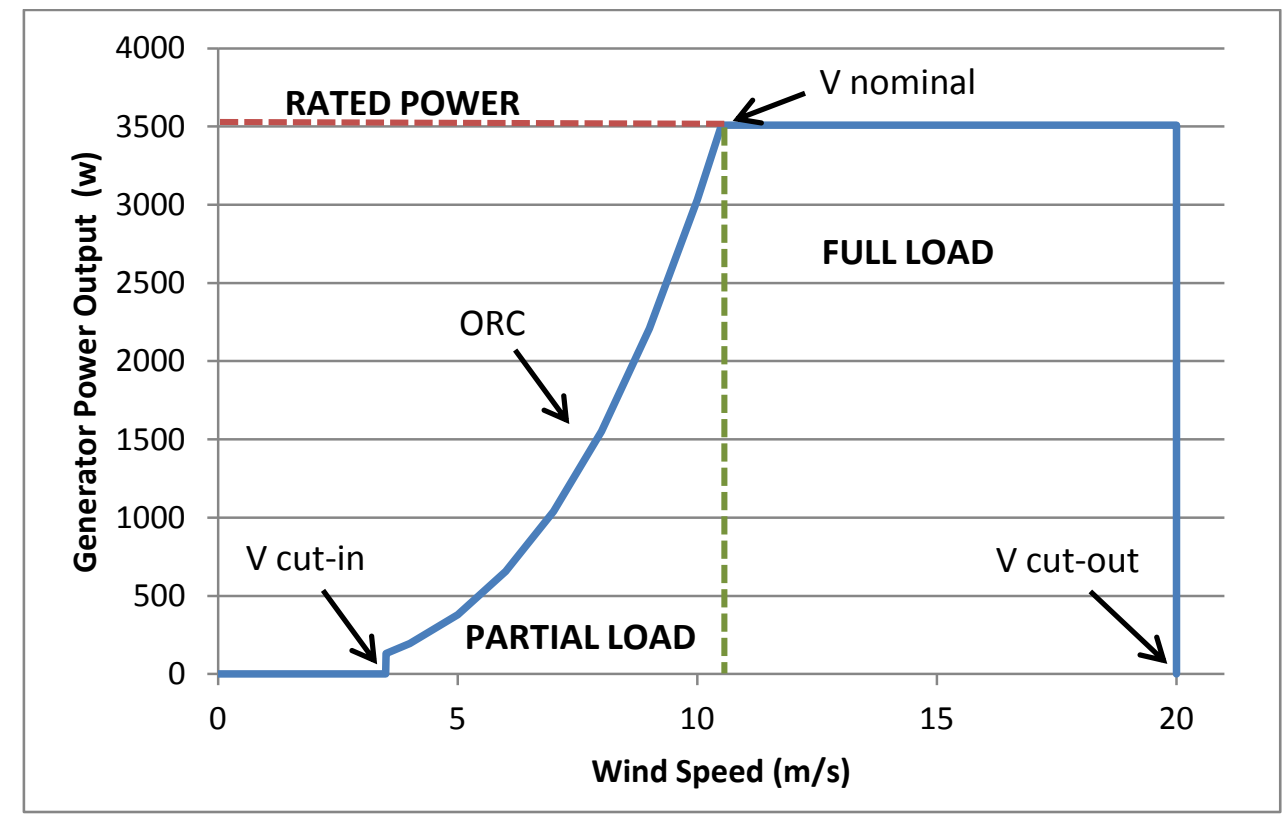

Figure 2.12 Ideal Power Production Curve with Regions of Operation

\subsubsection{Region of Operation - Partial Load}

The partial load region of the ideal power curve is between the cut-in wind speed $V_{\text {cut-in }}$ and the nominal wind speed $V_{\text {nominal }}$ (as defined by the area to the left of the dashed green line in Figure 2.12). When the WECS operates in the partial load region, the power output of the generator is below its nominal rating, so the generation objective is to extract all of the available power from the blades. In other words, the curve in the partial load region is called the Optimal Regimes Characteristic (ORC) which is equivalent to the aerodynamic power equation (2.2) with $C_{p \max }$.

$V_{c u t-i n}$ is usually determined by economic considerations. The cut-in wind speed is required for the WECS to begin delivering useful power which is offset by power consumption from the WECS control hardware. $V_{\text {nominal }}$ is defined as the wind speed which produces the maximum continuous power output rating of the generator. 


\subsubsection{Region of Operation - Full Load Region}

The full load region is between $V_{\text {nominal }}$ and $V_{\text {cut-out }}$. The control objective in this region is to maintain the maximum continuous power rating of the generator for a range of wind speeds. This objective is accomplished by regulating the efficiency of the aerodynamic system. Aerodynamic power efficiency is typically adjusted by changing blade pitch, or by adjusting the tip speed ratio. When the maximum continuous power rating of the generator can no longer be maintained, the WECS must shut down to prevent damage. Shut down occurs at $V_{\text {cut-out }}$.

\subsubsection{Energy Efficiency}

The primary objective in the partial load region is to optimize operation with maximum energy conversion efficiency by extracting the maximum available power from the rotor for any given wind speed. $P_{\text {wind }}$ is the available power from the wind when the power coefficient is a maximum for a given blade set. $P_{\text {out }}$ as defined in the equation below, is the actual power captured by the blade set during operation.

$$
\text { Energy Efficiency }=\frac{P_{\text {out }}}{P_{\text {wind }}}
$$

Energy efficiency can improve the overall economic performance of a WECS because power producers primarily earn revenue based on the total energy supplied to the grid $(k W \cdot h r)$. A WECS with poor energy efficiency will not survive in today's highly competitive energy market.

\subsubsection{Reliability Performance}

The goal of reliability performance is important in both regions of operation. A reliable system operates when called upon, incurs minimal maintenance costs, and has a long service life. The actions from a controller can directly affect the reliability performance of a WECS. A highly compensated controller can impose severe loads on the mechanical system, which over time can lead to mechanical fatigue and broken parts. It has been shown that excessive generator torque variations can lead to mechanical fatigue when energy efficiency is the exclusive objective for a WECS controller [16].

\subsubsection{Mixed Criterion - Energy Efficiency and Reliability Performance}

When energy efficiency and reliability performance become top objectives in the partial load region, a mixed criterion approach is used to measure the overall performance of the WECS. The mixed criterion approach seeks a balance between conflicting goals of energy efficiency and reliability performance. The conflict occurs, because energy efficiency is typically improved by tightly tracking the 
optimum tip speed ratio with high gain controllers, but this can lead to undesirable torque variations. The challenge of measuring the performance of a mixed criteria controller is addressed with the following equation from [16]:

$$
I=E\left\{\alpha\left[\lambda(t)-\lambda_{o p t}\right]^{2}\right\}+E\left\{\Delta \mathrm{T}_{g}^{2}(t)\right\}
$$

Optimum controller performance can be achieved by minimizing the value of $I$. The first average term $(E\{\cdot\}$ is the symbol for the statistical average) is a measure of energy efficiency and the second average term is a measure of torque variations. In addition, numerical scaling between the two terms can be adjusted with the weighting coefficient $\alpha$.

\subsubsection{Strategies}

In order to achieve the objectives listed in section 2.3.2, several strategies can be employed. Control strategies for WECS vary from one methodology to another because of assumptions about known parameters, measurable variables, and type of model used to describe the system. Some of the common issues addressed by WECS control systems include:

1. Variable nature of wind

2. Life service reduction due to mechanical stress

3. Non-linear behavior of WECS

4. Poor reliability of important measurement equipment

5. Unknown parameters/operating characteristics of WECS

After reviewing literature surrounding variable-speed WECS control systems it is apparent that there are many different strategies. Some of the most popular strategies include Gain Scheduling, PI control, and Maximum Power Point Tracking (MPPT). However, most applied WECS control systems use only the most basic control strategies for generator side control and none of the techniques have become classical and widely used. Summary descriptions of the most interesting generator side control strategies used for fully-rated, variable-speed WECS are included in the Appendix.

\subsubsection{Controller Strategy Choice}

The Optimal Operating Point (OOP) controller is the final design strategy proposed by this thesis, but it was not the initial choice. The initial choice for the Cal Poly WECS was a Gain Scheduling controller. The Gain Scheduling controller uses the well known tools of modern linear control theory, but this requires linearization of an inherently non-linear system. The linearization process can be achieved, but results in a large number of linear systems which are only valid for a single operating point (an operating point is defined by two parameters - wind speed and rotational speed). This leads to the 
requirement for the gain scheduling controller which is essentially a group of many controllers, each designed for a specific operating point. The gain scheduling controller can provide a very elegant solution for WECS systems, but this requires powerful controller hardware and a complex design.

The OOP controller was chosen instead, as a simple alternative to the Gain Scheduling controller and it does not require linearization of the WECS system. The gain values are determined as part of an iterative process using the combined optimization criteria. The OOP controller is described below as well as the PID controller which is a key component of the OOP controller.

\subsubsection{Direct Imposing of Optimal Operating Point (OOP)}

The OOP controller forces the WECS to operate at the optimal operating point corresponding to the instantaneous wind speed in the partial load region. The controller obtains a speed reference based on the measured rotor speed and instantaneous wind speed. The torque reference also requires two known constants, $\lambda_{\text {opt }}$ and $C_{\text {pmax }}$. The direct imposing of the optimal operating point can produce large torque variations and high mechanical loads during fast wind speed variations because of turbine inertia. To reduce the influence of turbine inertia and parametric variations, PI filters are commonly used (see Figure 2.13).

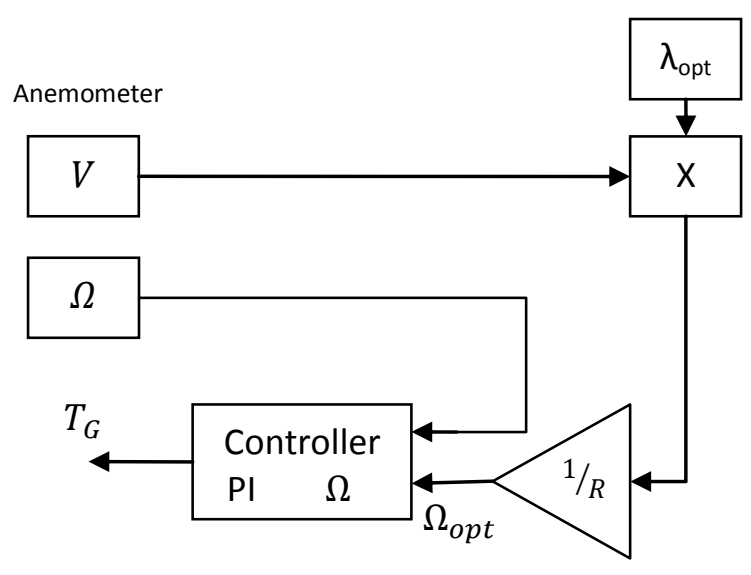

Figure 2.13 PI Torque reference block diagram for OOP

\subsubsection{Continuous PID}

The PID controller is one of the most popular controllers used for industrial control applications and it is the key component in the OOP control strategy. The classic continuous time PID controller is defined by equation (2.26), where $u(t)$ is the control action, $K$ is the common gain, $e(t)$ is the error signal, $T_{i}$ is the integration period, and $T_{d}$ is the derivative gain [17]. 


$$
u(t)=\left(e(t)+\frac{1}{T_{i}} \int_{0}^{t} e(t) d t+T_{d} \frac{d e(t)}{d t}\right)
$$

A block diagram for the classic continuous time PID is presented in Figure 2.14 below.

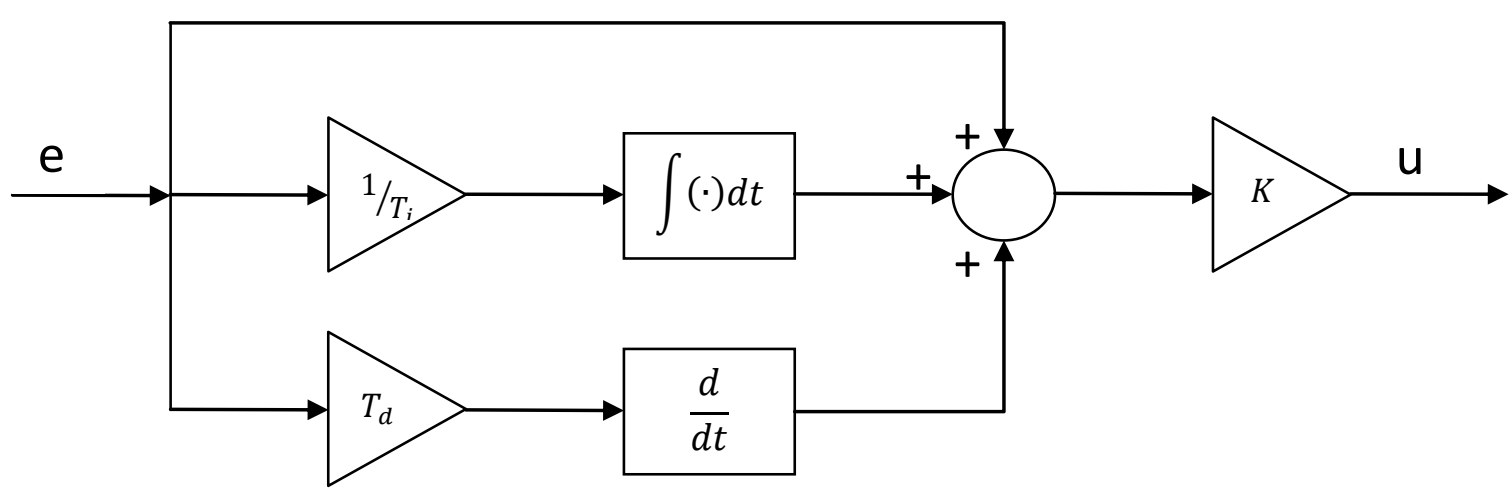

Figure 2.14 Continuous time PID Block Diagram

The proportional term increases the loop gain of the system and therefore reduces its sensitivity to plant parameter variations. The integral makes sure that the plant output agrees with the set point in steady state and increases the system order. The purpose of the derivative action is to improve the closed loop stability by reducing the amount of oscillation on the response. Intuitively, the derivative action predicts the error by multiplying the slope of the error signal by the derivative gain. However, sometimes the derivative term is used sparingly or not at all because the derivative term is sensitive to noise. The transfer function for the derivative term in the frequency domain is as follows

$$
D(s)=s K T_{d}
$$

If the derivative is included in the controller, a first order filter is commonly used to attenuate high frequency noise.

$$
D_{1 s t}(s)=\frac{s K T_{d}}{1+s T_{d} / N}
$$

The entire PID transfer function in the frequency domain with the first order filtered derivative is listed below.

$$
C_{1 s t}(s)=K\left(1+\frac{1}{s T_{i}}+\frac{s T_{d}}{1+s T_{d / N}}\right)
$$


Sometimes it is a better option to filter the measured signal outside the PID. This is commonly done with the use of a $2^{\text {nd }}$ order filter with damping $\zeta=\frac{1}{\sqrt{2}}$ and $T_{f}=T_{d} / N$.

$$
C_{2 n d}(s)=K\left(1+\frac{1}{s T_{i}}+s T_{d}\right)\left(\frac{1}{1+s T_{f}+\frac{\left(s T_{f}\right)^{2}}{2}}\right)
$$

Equation (2.30) is popular because the controller has high frequency roll-off which means the gain goes to zero for high frequencies.

The application of the PID controller is useful when the transfer function of the system is not completely known. In this case it is may be possible to determine the gain constants of the controller with an on-line tuning method such as the Ziegler Nichols frequency method (see appendix D). When the transfer function of a linear time invariant system is known, the gain constants can be determined using a pole placement procedure.

\subsubsection{Discrete PID}

The discrete PID is derived from the continuous PID but it is different because it samples signals at discrete time instances. The differences are significant and the discrete PID must be carefully implemented. The following list outlines the ideal sequence of operation for the PID controller [17]:

1. Wait for clock interrupt

2. Read analog input

3. Compute PID equation

4. Set output

5. Update controller variables

6. Return to step 1.

Another important difference with the discrete PID controller is that the integral and derivative terms must be approximated. There are a variety of approximation methods for the integral and derivative terms, but they all produce the same general result. The block diagram for the discrete PID is shown below. 


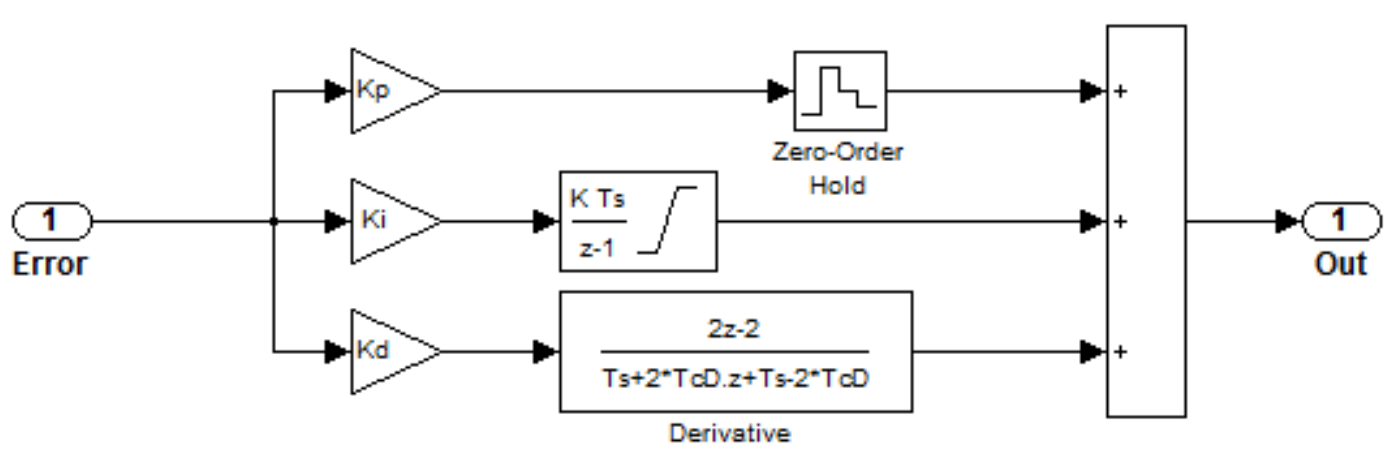

Figure 2.15 Discrete PID Block diagram

The gain constants for discrete PID controllers are slightly different from continuous PID controllers because the gains are not all multiplied by the common proportional gain. The gains for the discrete PID are described in terms of the continuous PID gains below.

$$
\begin{aligned}
K_{p} & =K \\
K_{i} & =\frac{1}{T_{i}} \\
K_{d} & =T_{d}
\end{aligned}
$$




\section{DYNAMIC GENERATOR - MODEL DEVELOPMENT AND ANALYSIS}

\subsection{Introduction}

This chapter first explains how the parameters for the dynamic PMG model were chosen and it also explains assumptions and limitations of the results. The model is then used to investigate torque oscillations produced from the bridge rectifier, and electrical transients which occur during step load changes. Finally, the dynamic generator model is used to analyze potentially harmful electrical disturbances, and to define safe operating limits for the WECS.

\subsection{Determination of Dynamic PMG Model Parameters}

In order to use the dynamic generator model discussed in section 2.2.3.5, certain unknown parameters had to be determined. There were a few options for how to obtain the required generator parameters. One option was to perform additional open circuit and closed circuit tests on the generator as described by IEEE standard 115-2009 for testing synchronous machines [18]. These tests could produce the parameters directly, but would require additional laboratory time with the actual generator which was not pursued. Another method would be to determine the parameters algebraically, but this would be difficult without having more information about the generator. The final option was to determine the parameters from the known steady state characteristics in the generator manufacturer data sheet [11] (steady state - torque vs. speed, and steady state - voltage vs. speed). The steady state characteristics from [11] were also experimentally verified by [4] as part of a Master's Thesis.

The parameters for the MatLab Simulink dynamic generator model were chosen by an iterative process which involved adjusting the parameter values of the dynamic generator model when operating in a known steady state condition. This process assumes the following about the dynamic generator model:

1. The dynamic generator model described in section 2.2.3.5 is valid for both steady state and dynamic operation.

2. The parameter values used in the model are constants.

3. If assumptions $1 \& 2$ are correct, and if parameter values are valid in steady state, then parameter values are assumed to be valid for dynamic operation. 
The process of determining the values of Table 3.4 are outlined in the following section. The final parameter values in the dynamic model are only assumed to be valid. They have not been verified for accuracy.

\subsubsection{Procedure}

The following procedure can be used with MatLab V.7.6 (R2008a).

1. The first step is to build the MatLab Simulink model as seen in Figure 3.1. This simulation model is built around the generic permanent magnet generator from the Power-System library and a variable resistance current source load. The generator takes a speed input (radians/s) and produces an electromechanical torque $(\mathrm{Nm})$, based on the condition of the load (see equation (2.14)). Friction losses are neglected so the input rotor torque applied to the generator equals the output torque in steady state.

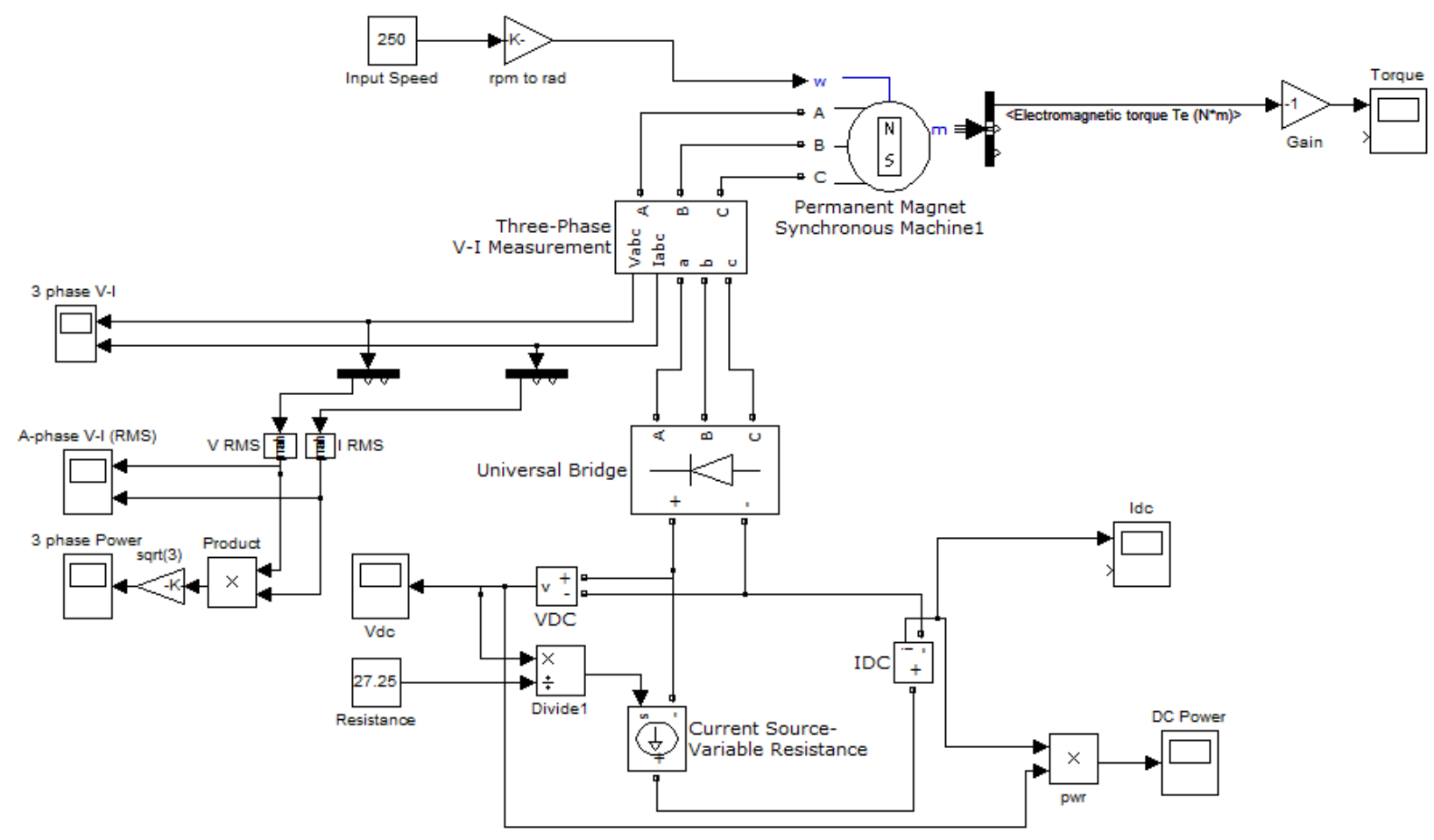

Figure 3.1 MatLab PMG Generator model for parameter determination

2. The parameters for the Simulink PMG are accessed by double clicking on the PMG block. When the parameters tab is selected a window appears as in Figure 3.2. The first step is to specify the voltage constant which is listed as VLL_peak/ $\mathrm{krpm}$. The voltage constant is only a starting point for determining the PMG parameters because it is based on ideal calculations for the open 
circuit-rectified DC voltage vs. speed characteristic which are shown below. The Simulink voltage constant specifies peak AC voltage so equation (2.20) can be used to relate DC voltage to $\mathrm{AC}$ line voltage.

$$
\begin{gathered}
V_{D C}=1.654 \sqrt{2} \frac{\tilde{V}_{L L_{-} r m s}}{\sqrt{3}}=1.654 \frac{V_{L L_{-} p e a k}}{\sqrt{3}}=0.955 V_{L L_{-} \text {peak }} \\
V_{L L_{-} \text {peak }}=1.047 \cdot V_{D C}
\end{gathered}
$$

From [4], when the speed is $250 \mathrm{rpm}$, the DC open circuit voltage $V_{D C / 250 \mathrm{rpm}}$ is 450 volts, therefore the voltage constant for beginning iterations become

$$
\begin{aligned}
\mathrm{V}_{\mathrm{LL} \_ \text {peak } / \mathrm{krpm}}= & 1.047 \cdot \mathrm{V}_{\mathrm{DC} / \mathrm{krpm}}=1.047 \cdot 4 \cdot \mathrm{V}_{\mathrm{DC} / 250 \mathrm{rpm}} \\
= & 1.047 \cdot 4 \cdot 450=1885
\end{aligned}
$$

The calculated voltage constant in equation (3.3) is only a starting value for the iterative procedure The final value for the voltage constant was adjusted to 1575 because it resulted in a lower error calculation when the simulated model was compared to actual terminal voltage under loaded conditions (see Figure 3.3). It is also useful to note that the value for flux linkage depends on the voltage constant. The Simulink model automatically updates the flux linkage value after closing and re-opening the PMG block parameter window. 


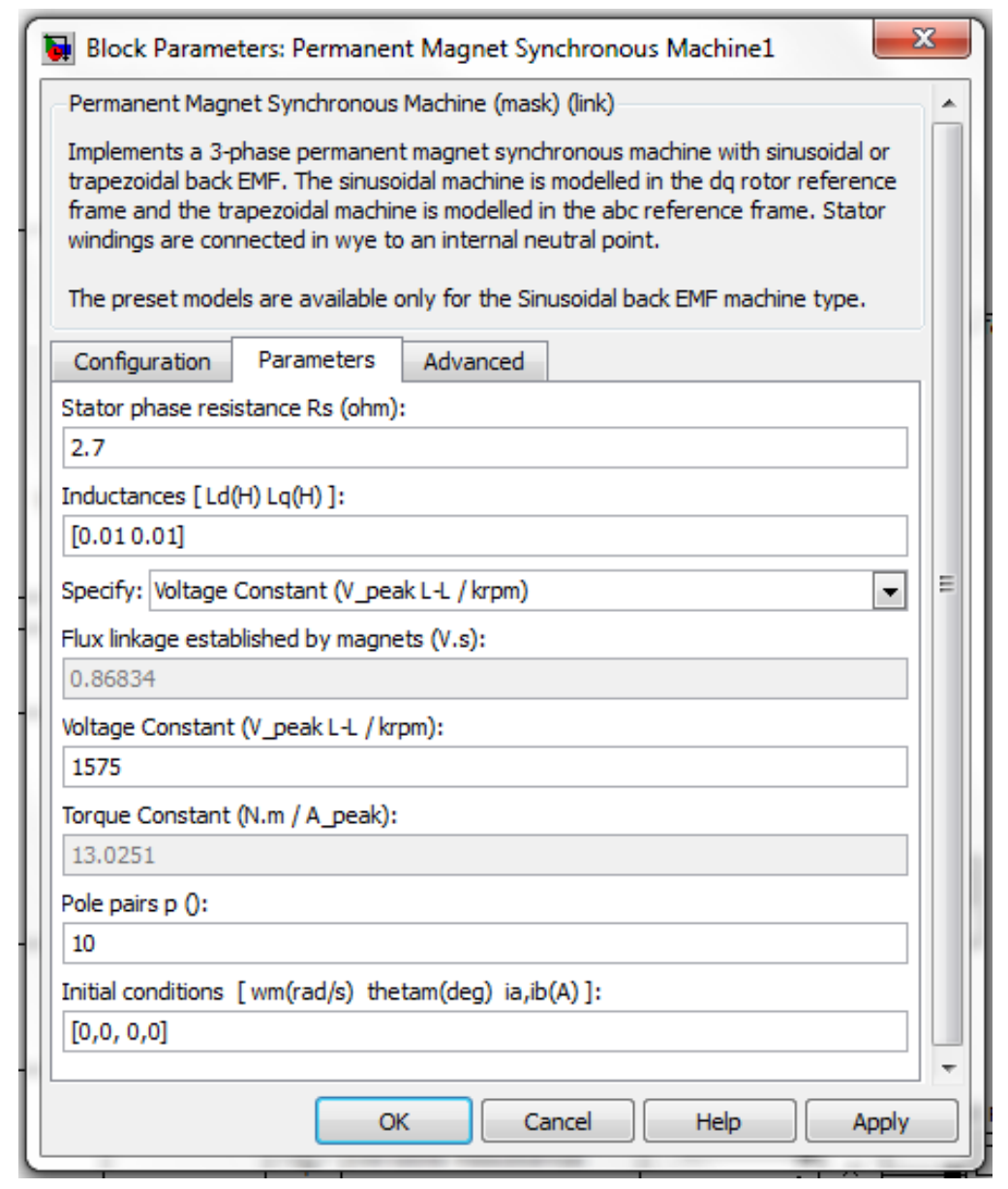

Figure 3.2 MatLab Simulink PMG Parameters

3. The next important parameter to specify is the Ld and Lq inductance. The initial values for these parameters were set between 0.02 to 0.0006 which are typical for a PMG of this size.

4. The number of pole pairs was found previously by equation (2.16), and the stator resistance is known from the data sheet to be 2.7ohms.

5. An iterative process was used to determine actual values. The first step in the iterative procedure is to adjust the voltage constant, and this turns out to be a very important value for the generator. The voltage constant was adjusted many times and the final value was chosen differently than the ideal calculation in equation (3.3).

6. After selecting a voltage constant, the model is simulated at $250 \mathrm{rpm}$ full load. At this data point the generator should require $150 \mathrm{Nm}$ torque to produce $3.5 \mathrm{~kW}$ and $11 \mathrm{~A}$. This is stated in the PMG-3500 datasheet which is also listed in the appendix. In addition, the rectified output should also match the voltage vs. resistance values recorded by [4].

7. After an acceptable combination of parameters is selected at 250rpm full load, the input speed is adjusted down and the corresponding voltage, torque and power are measured and compared to the known steady state values for the PMG. The results are listed in the following section. 


\subsubsection{Data and Results}

Table 3.2 Simulated and Specified Torque for the PMG-3500 with R=27.05

Tables 3.1-3.3 show the simulated and specified values for the PMG using the final parameters of Table 3.4 and a resistance of 27.05 ohms. The Simulated AC power is measured directly at the terminals of the PMG and the simulated torque is the electromagnetic torque which is calculated directly from the generic MATLAB PMG model. The specified values of output power and input torque were taken directly from the PMG data sheet [11], and the specified DC voltage was approximated from experimentally measured values between $240 \mathrm{hms}$ and $36 \mathrm{ohms}$ which was recorded by [4]. The specified voltage was used from [4] because the PMG data sheet only specifies open circuit voltage.

Table 3.1 Simulated and specified Power for the PMG-3500 with R=27.05

\begin{tabular}{|c|c|c|c|}
\hline $\begin{array}{c}\text { Speed } \\
(\mathbf{r p m})\end{array}$ & $\begin{array}{c}\text { Spec-AC- } \\
\mathbf{P}(\mathbf{w})\end{array}$ & $\begin{array}{c}\text { Sim-AC- } \\
\mathbf{P}(\mathbf{w})\end{array}$ & $\begin{array}{c}\mathbf{\%} \\
\text { Error }\end{array}$ \\
\hline $\mathbf{2 5 0}$ & 3500 & 3515 & $0.43 \%$ \\
\hline $\mathbf{2 0 0}$ & 2333 & 2298 & $-1.50 \%$ \\
\hline $\mathbf{1 5 0}$ & 1375 & 1318 & $-4.15 \%$ \\
\hline $\mathbf{1 0 0}$ & 625 & 597 & $-4.48 \%$ \\
\hline $\mathbf{5 0}$ & 125 & 151 & $20.80 \%$ \\
\hline
\end{tabular}

Table 3.2 Simulated and Specified Torque for the PMG-3500 with R=27.05

\begin{tabular}{|c|c|c|c|}
\hline $\begin{array}{c}\text { Speed } \\
\text { (rpm) }\end{array}$ & Spec-T (Nm) & Sim-T (Nm) & $\begin{array}{c}\% \\
\text { Error }\end{array}$ \\
\hline $\mathbf{2 5 0}$ & 150 & 150 & $0.00 \%$ \\
\hline $\mathbf{2 0 0}$ & 126.6 & 123.2 & $-2.69 \%$ \\
\hline $\mathbf{1 5 0}$ & 102 & 94.9 & $-6.96 \%$ \\
\hline $\mathbf{1 0 0}$ & $\mathbf{7 5}$ & 64.83 & $-13.56 \%$ \\
\hline $\mathbf{5 0}$ & 37 & 33.1 & $-10.54 \%$ \\
\hline
\end{tabular}

Table 3.3 Simulated and Specified Voltage for the PMG-3500 with R=27.05

\begin{tabular}{|c|c|c|c|}
\hline $\begin{array}{c}\text { Speed } \\
\text { (rpm) }\end{array}$ & $\begin{array}{c}\text { Spec-DC-V } \\
\text { (V) }\end{array}$ & $\begin{array}{c}\text { Sim-DC-V } \\
\text { (V) }\end{array}$ & $\begin{array}{c}\text { \% } \\
\text { Error }\end{array}$ \\
\hline $\mathbf{2 5 0}$ & 300 & 297.8 & $-0.73 \%$ \\
\hline $\mathbf{2 0 0}$ & 250 & 241.24 & $-3.50 \%$ \\
\hline $\mathbf{1 5 0}$ & 195 & 183.2 & $-6.05 \%$ \\
\hline $\mathbf{1 0 0}$ & 130 & 123.55 & $-4.96 \%$ \\
\hline $\mathbf{5 0}$ & 60 & 62.4 & $4.00 \%$ \\
\hline
\end{tabular}


Table 3.4 Simulated MATLAB Ginlong GL-PMG-3500 Parameter Values

\begin{tabular}{|c|c|c|c|}
\hline Description & Symbol & Value & Units \\
\hline Stator Resistance & $R$ & 2.7 & $\Omega$ \\
\hline d inductance & $L_{d}$ & 0.01 & $\mathrm{H}$ \\
\hline q inductance & $L_{q}$ & 0.01 & $\mathrm{H}$ \\
\hline Constant PMG flux & $\phi_{m}$ & 0.86834 & $\mathrm{~Wb}, \mathrm{Vs}$ \\
\hline Stator d current & $i_{d}(t)$ & - & $\mathrm{A}$ \\
\hline Stator q current & $i_{q}(t)$ & - & $\mathrm{A}$ \\
\hline Number of pole pairs & $p$ & 10 & Unit-less \\
\hline Constant parallel load inductance & $L_{S}$ & 0.0 & $\mathrm{H}$ \\
\hline Variable parallel load resistance & $R_{S}(t)$ & - & $\Omega$ \\
\hline
\end{tabular}

\subsection{Torque Oscillations from Bridge Rectifier}

During the process of determining the generator parameters, an unexpected result occurred to the electromagnetic torque. Figure 3.3 shows significant torque oscillations when using the MATLAB simulation model of Figure 3.1. Figure 3.1 uses equation (2.14) in the generic PMG model to directly calculate the electromechanical torque. The torque oscillations occur when current $i_{q}(t)$ oscillates. $i_{q}(t)$ oscillates because the full bridge rectifier causes non-continuous current in each phase of the generator (see Figure 3.5 Line Current (labc) at PMG terminals (250rpm, R=27.02ohm)). 


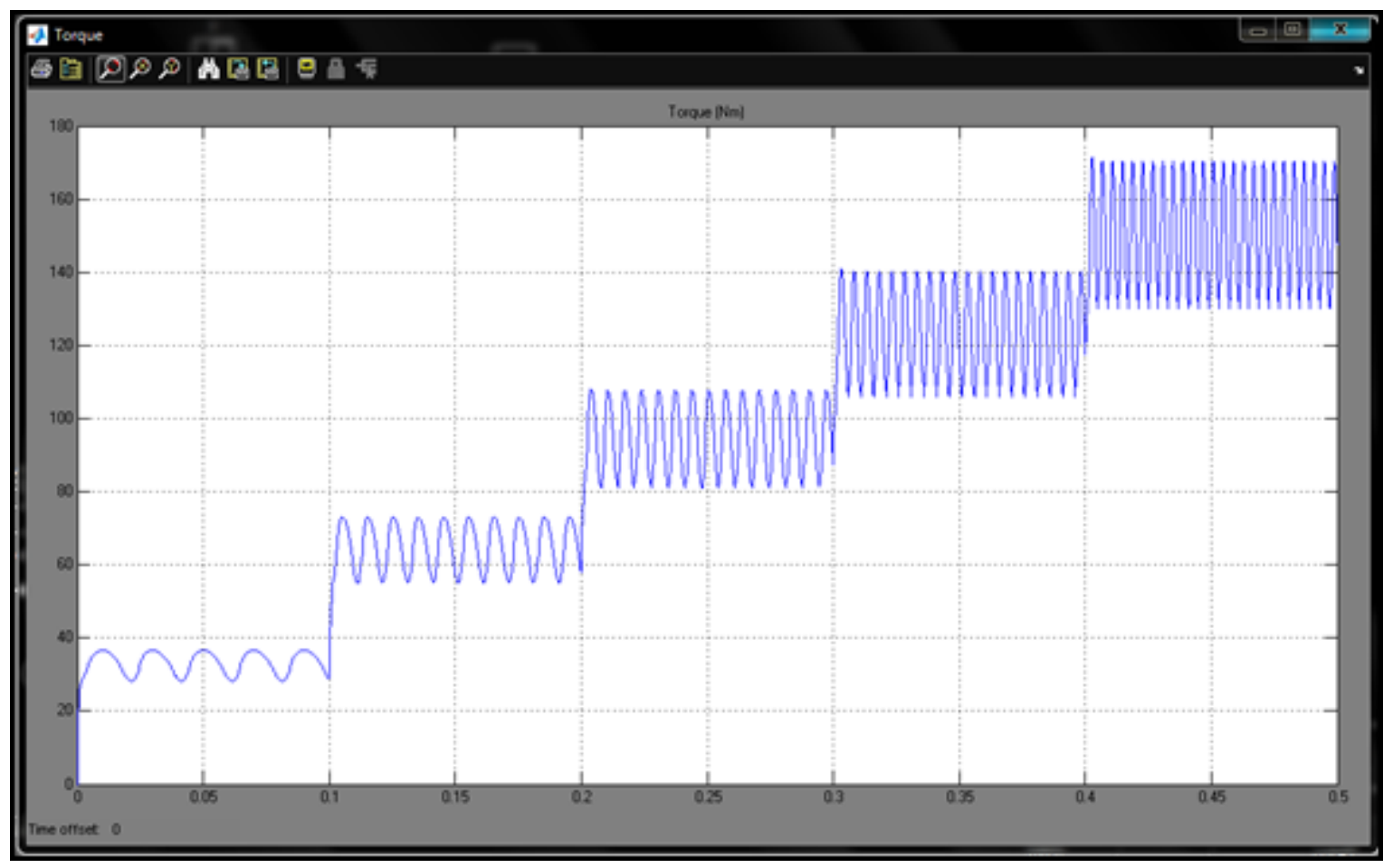

Figure 3.3 Simulated PMG Torque Oscillations from rectifier (50-250rpm, step 50rpm, R=27.02ohms)

Figure 3.3 shows the electromagnetic torque oscillations from the PMG when simulated with a fixed resistive load across the rectifier at speeds stepping up from 50 to $250 \mathrm{rpm}$. The magnitude of torque oscillations increase with speed, and vary from approximately $10 \mathrm{Nm} \_$peak-peak to $40 \mathrm{Nm} \_$peakpeak and occur at a frequency of 6 times the fundamental electrical frequency. At 250rpm the fundamental frequency is $41.66 \mathrm{hz}$ as seen in the calculation below for a 10 pole pair generator.

$$
f_{e}=10 \frac{250 r p m}{60 s}=41.66 h z
$$

The period of torque oscillations at 250rpm can be seen in Figure 3.4 and calculated below

$$
f_{T-\text { osc-250rpm }}=\frac{1}{0.004 \mathrm{~s}}=6 \cdot 41.66 \mathrm{hz}=250 \mathrm{hz}
$$




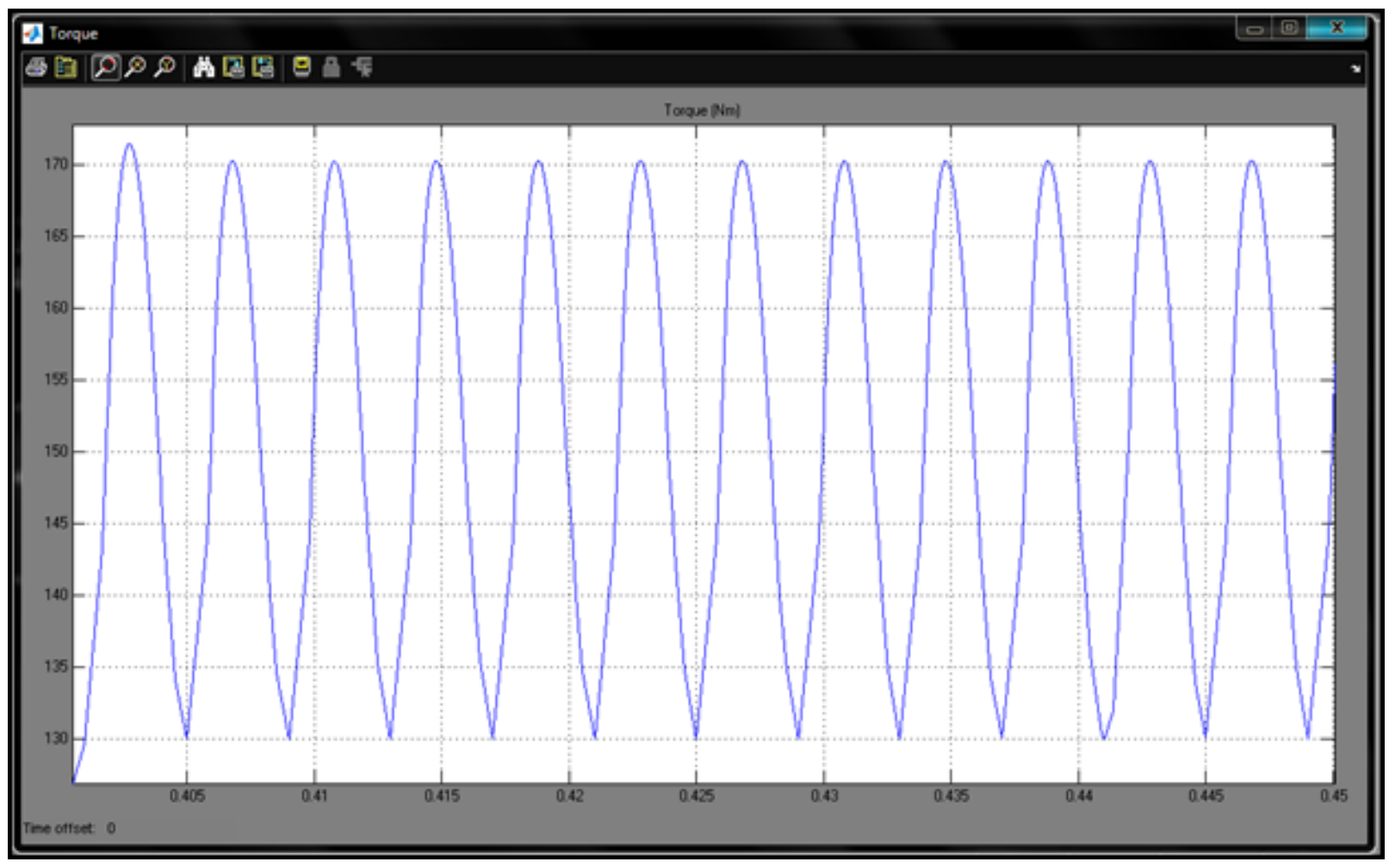

Figure 3.4 Simulated PMG Torque Oscillation (40[Nm_pp]) (250rpm, R=27.02ohms)

The torque oscillations in Figure 3.4 show how the MATLAB PMG model responds to the full bridge rectifier with a fixed resistive load and constant rotor speed. At constant speed, the conservation of power requires that torque oscillations on the output of the generator will also occur on the rotor. The full consequences of the torque oscillations require further experimental investigation, because they could likely hurt the long term reliability performance of the rotor [10].

Simulation and research confirms that the rectifier connection is the source of the torque oscillations on the generator. PMG torque oscillations from a full bridge rectifier have been simulated and experimentally measured in technical papers by [19] and [20].

In [19] the peak to peak generator shaft torque oscillations from a 3-phase full bridge uncontrolled diode rectifier was measured as $31 \%$ of the average torque. The peak to peak torque oscillations occurring in Figure 3.4 are of similar magnitude (\%26) and found by the calculation below.

$$
\text { Peak to Peak Torque Oscillation }=100 \cdot \frac{T_{p p}}{T_{a v g}}
$$

The torque oscillation for the Ginlong PMG in Figure 3.4 are calculated below

$$
100 \cdot \frac{40[\mathrm{Nm}]}{150[\mathrm{Nm}]}=\% 26.6
$$




\subsubsection{Proving the existence of Torque Oscillations}

Torque oscillations in simulation can be attributed to the non-continuous conduction of current through the bridge rectifier. Figure 3.5 shows the MATLAB simulated current at the terminals of the PMG when connected to the full bridge rectifier. In each half cycle of the waveform, the current goes to $\mathrm{OA}$ and stays there for approximately $2 \mathrm{~ms}$ until the diodes allow conduction again.

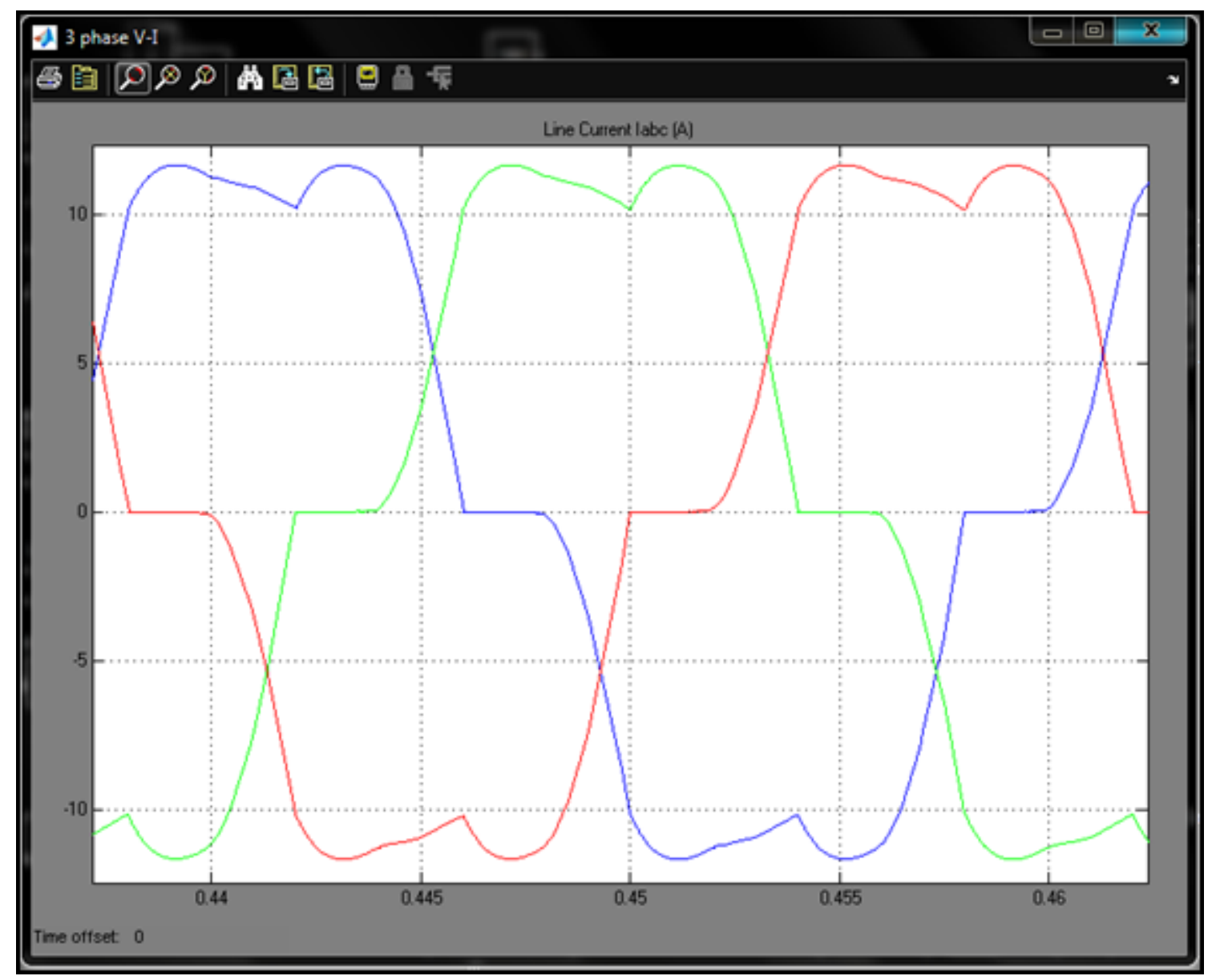

Figure 3.5 Line Current (labc) at PMG terminals (250rpm, R=27.02ohm)

To prove that electromechanical torque oscillations will occur on the generator, a separate simulation was performed with LT-Spice simulation software. The simulation in LT-Spice allows us to create a more precise model for the full bridge rectifier (model MDS60-16B listed in appendix $\mathrm{H}$ ) which is attached to the Ginlong PMG-3500. The LT-Spice simulation uses a steady state model for the generator which consists of 3 ideal voltage sources operating at $250 \mathrm{rpm}$ or $41.66 \mathrm{hz}$. Each phase of the generator model includes the phase resistance $\mathrm{R}=2.7[\mathrm{ohm}]$, and $\mathrm{L}=0.01[\mathrm{H}]$. The voltage sources are set 
to the same voltage specified by the MATLAB PMG model (see Figure 3.2) and are calculated below. The voltage specified in MATLAB is peak line-line voltage per $1000 \mathrm{rpm}$.

$$
V_{p L L / k r p m}=1575[V]
$$

The voltage per phase is calculated as

$$
V_{p \theta / k r p m}=\frac{V_{p L L / r p m}}{\sqrt{3}}=910[V]
$$

The voltage sources in LT-Spice simulation representing operation at 250rpm are calculated as

$$
V_{p \theta / 250 \mathrm{rpm}}=\left(V_{p \theta / \mathrm{krpm}}\right) \frac{250[\mathrm{rpm}]}{1000[\mathrm{rpm}]}=910 \frac{250[\mathrm{rpm}]}{1000[\mathrm{rpm}]}=227.5[\mathrm{~V}]
$$

The LT-Spice simulation model is shown in Figure 3.6 with a fixed resistive load of 27.05 ohms.

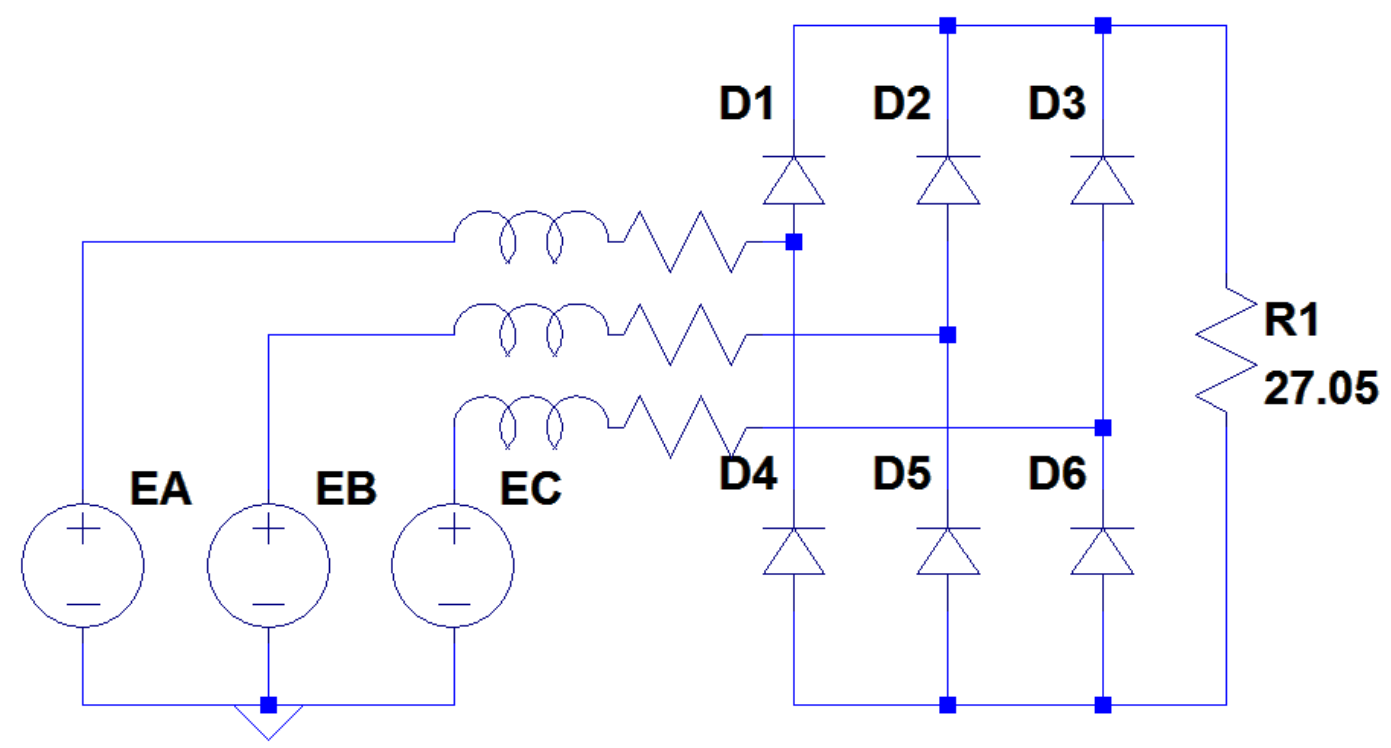

Figure 3.6 LT-Spice Steady State generator model and MDS60-16B Rectifier

The results of the LT-Spice simulation are shown in the Figures below. 


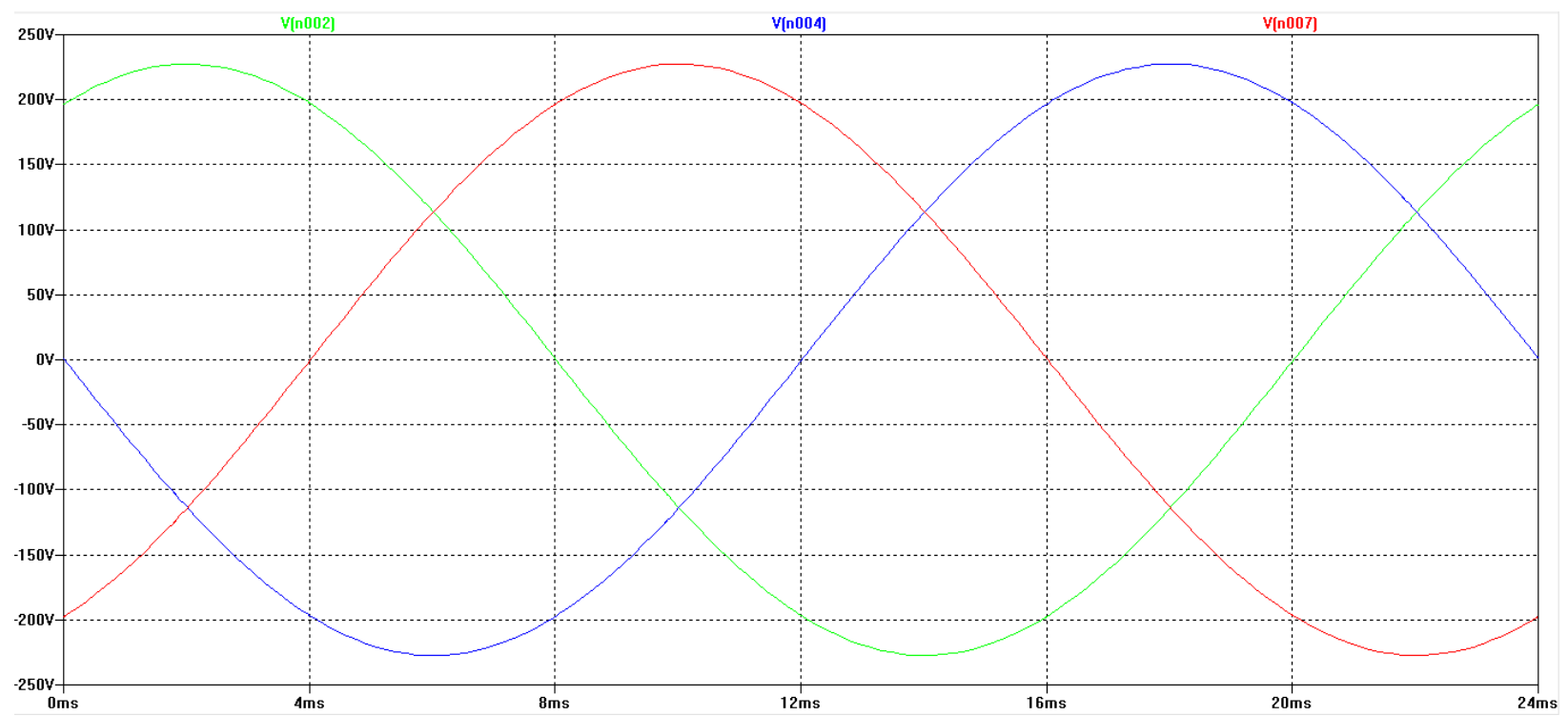

Figure 3.7 LT-Spice Voltage sources EA, EB, EC

The voltages in Figure 3.8 are measured at the positive terminals of Ea, Eb, and Ec with reference to neutral.

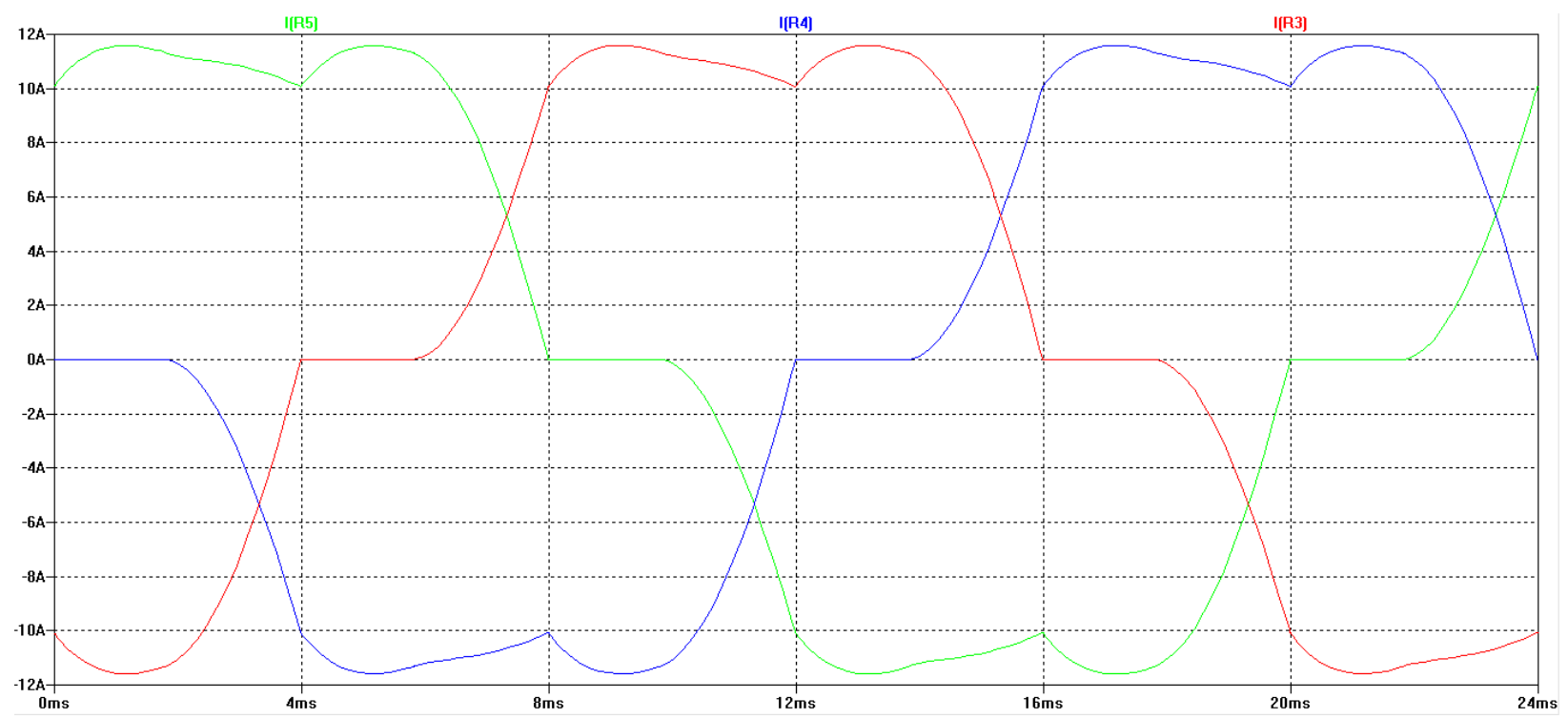

Figure 3.8 LT-Spice Phase Currents la, Ib, Ic

The currents are measured for each phase through the phase resistor and inductor before entering the bridge rectifier. As expected, Figure 3.8 closely matches Figure 3.5. Non-continuous conduction occurs 2 times in each cycle for approximately $2 \mathrm{~ms}$ each cycle. 


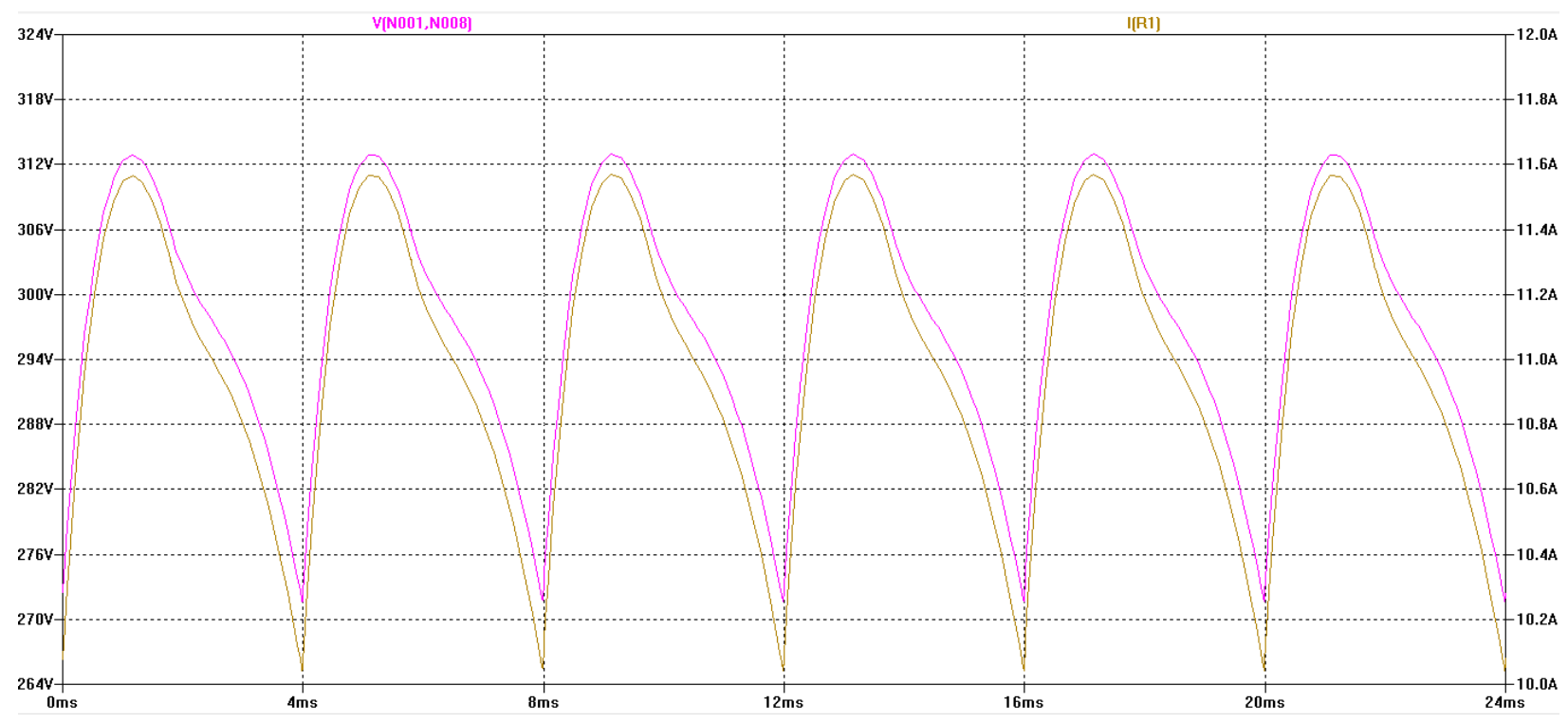

Figure 3.9 LT-Spice Rectifier output Voltage and Current

The output voltage and current of the rectifier is shown in Figure 3.9 with the voltage scale on the left most axis and the current scale on the right most axis. The output voltage oscillates between $313 \mathrm{~V}$ and $272 \mathrm{~V}$ with a peak to peak voltage ripple of $V_{p p}=41[\mathrm{~V}]$. The output current oscillates between $11.6 \mathrm{~A}$ and $10.1 \mathrm{~A}$ for a peak to peak current ripple of $I_{p p}=1.5[A]$.

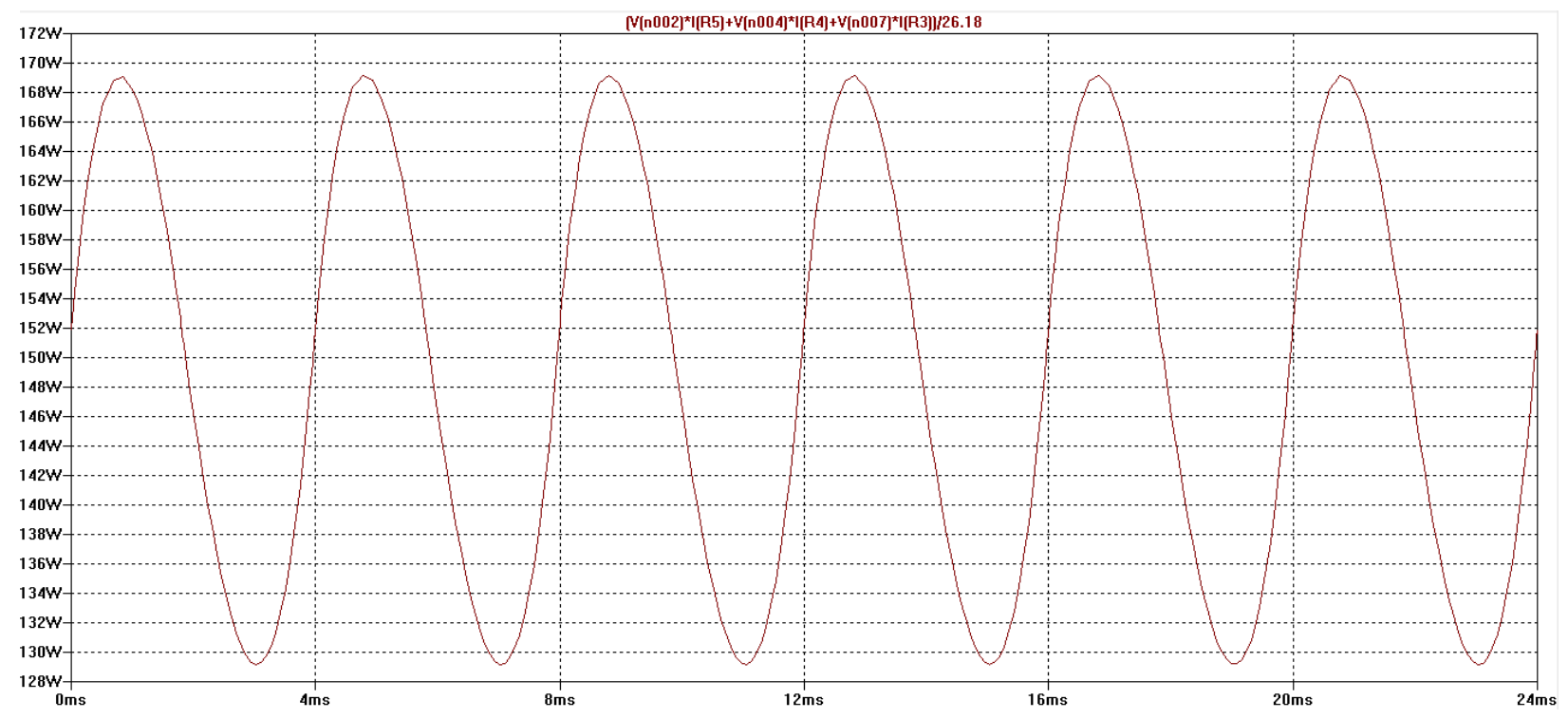

Figure 3.10 LT-Spice Electromechanical Torque

The electromechanical torque is calculated in Figure 3.10 from the following equations for power, torque, and speed. This is a simple alternative method to calculate the torque directly from the phase voltages and currents. 


$$
T_{e}[N m]=\frac{P_{e}[w]}{\Omega\left[\frac{r a d}{s}\right]}=\frac{\left(E_{a} I_{a}+E_{b} I_{b}+E_{c} I_{c}\right)[w]}{\Omega\left[\frac{r a d}{s}\right]}
$$

Figure 3.10 shows the torque oscillations in units of [watts] on the $\mathrm{Y}$-axis but this is misleading because the actual units are $[\mathrm{Nm}]$ because the power is divided by the speed in radians when operating at $250 \mathrm{rpm}$.

$$
\begin{aligned}
\Omega_{250 \mathrm{rpm}}\left[\frac{\mathrm{rad}}{\mathrm{s}}\right] & =250\left[\frac{\mathrm{rev}}{\mathrm{m}}\right]\left[\frac{1 \mathrm{~m}}{60 \mathrm{~s}}\right]\left[\frac{2 \pi \mathrm{rad}}{1 \mathrm{rev}}\right]=250\left[\frac{1}{9.55}\right]\left[\frac{\mathrm{rad}}{\mathrm{s}}\right] \\
& =26.18\left[\frac{\mathrm{rad}}{\mathrm{s}}\right] \\
T_{e}[\mathrm{Nm}] & =\frac{P_{e}[\mathrm{w}]}{\Omega_{250 \mathrm{rpm}}\left[\frac{\mathrm{rad}}{\mathrm{s}}\right]}=\frac{\left(E_{a} I_{a}+E_{b} I_{b}+E_{c} I_{c}\right)[\mathrm{w}]}{26.18\left[\frac{\mathrm{rad}}{\mathrm{s}}\right]}
\end{aligned}
$$

The torque oscillations from the LT-Spice simulation in Figure 3.10 closely match the torque oscillations from the MATLAB simulation in Figure 3.4. The peak to peak torque in Figure 3.10 for a speed of 250rpm and $R=27.020$ hms is found below.

$$
T_{e p p}[\mathrm{Nm}]=169.1[\mathrm{Nm}]-129.2[\mathrm{Nm}]=39.9[\mathrm{Nm}]
$$

The percent ripple for the LT-Spice simulation is found as before

$$
100 \cdot \frac{39.9[\mathrm{Nm}]}{149.2[\mathrm{Nm}]}=\% 26.7
$$

The LT-Spice simulation with actual full bridge rectifier model shows the same electromechanical torque oscillations as the MATLAB simulation which uses a dynamic generator model and a generic full bridge rectifier. This leads us to conclude that the generic rectifier model is acceptable for further simulations and it proves the existence of electromechanical torque oscillations.

Another way to prove that the rectifier is the source of torque oscillations on the generator is by replacing the rectifier with an equivalent balanced 3-phase load (see Figure 3.11) and re-simulating the MATLAB system. The results of the simulation are seen in Figure 3.12, where the torque oscillations are eliminated. 


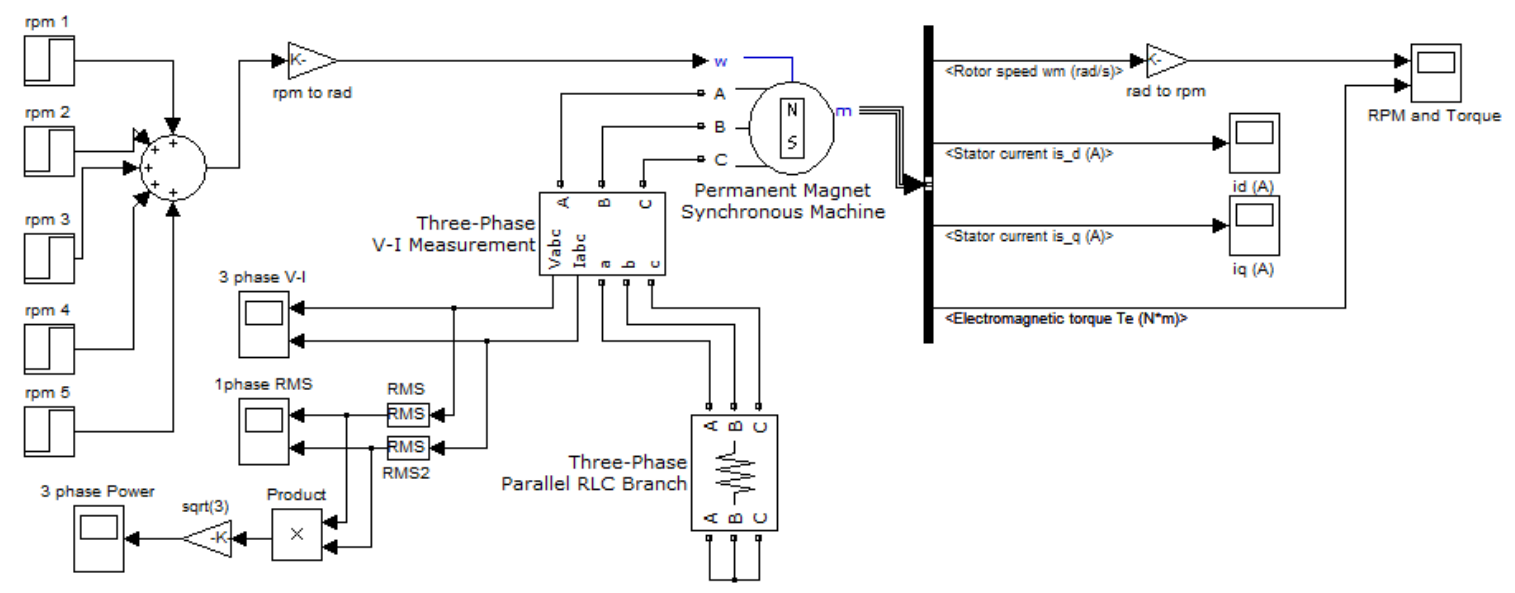

Figure 3.11 PMG Simulation with fixed 3-phase Resistive load

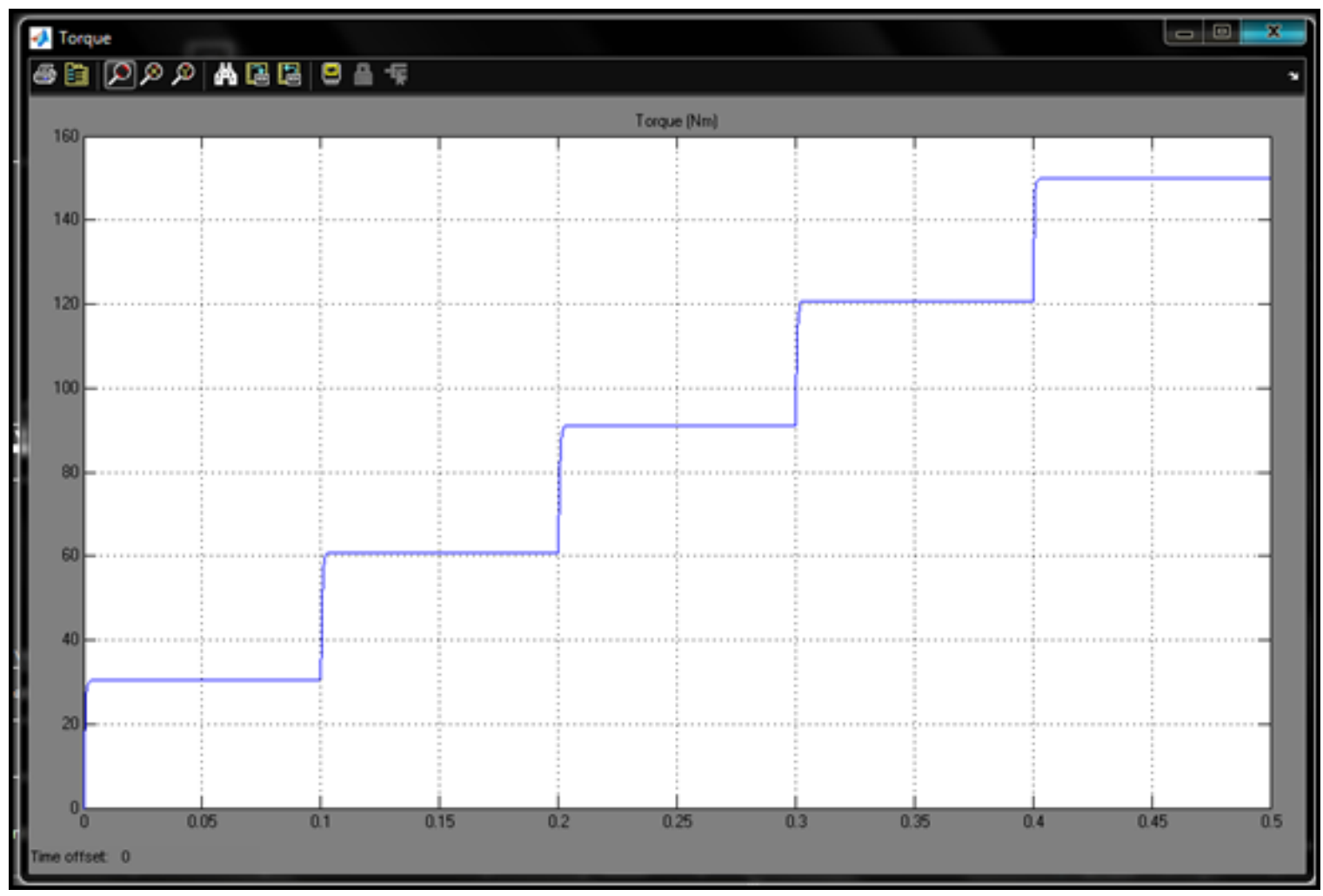

Figure 3.12 Simulated PMG Torque with balanced 3-phase load (0-250rpm, R=16.7 ohms Y-connected) 


\subsection{Voltage Transients from Step Load Change}

Abrupt changes to the load could cause harmful electrical disturbances to the generator. Section 3.4 analyzes potentially harmful electrical transients with occur during step load changes to the PMG. The following simulations use the dynamic PMG Simulink model which is determined in section 3.2 and connected to a full bridge rectifier and variable resistance load. The generator is operated at a constant speed of $250 \mathrm{rpm}$ because the generator speed changes much slower than the electrical load.

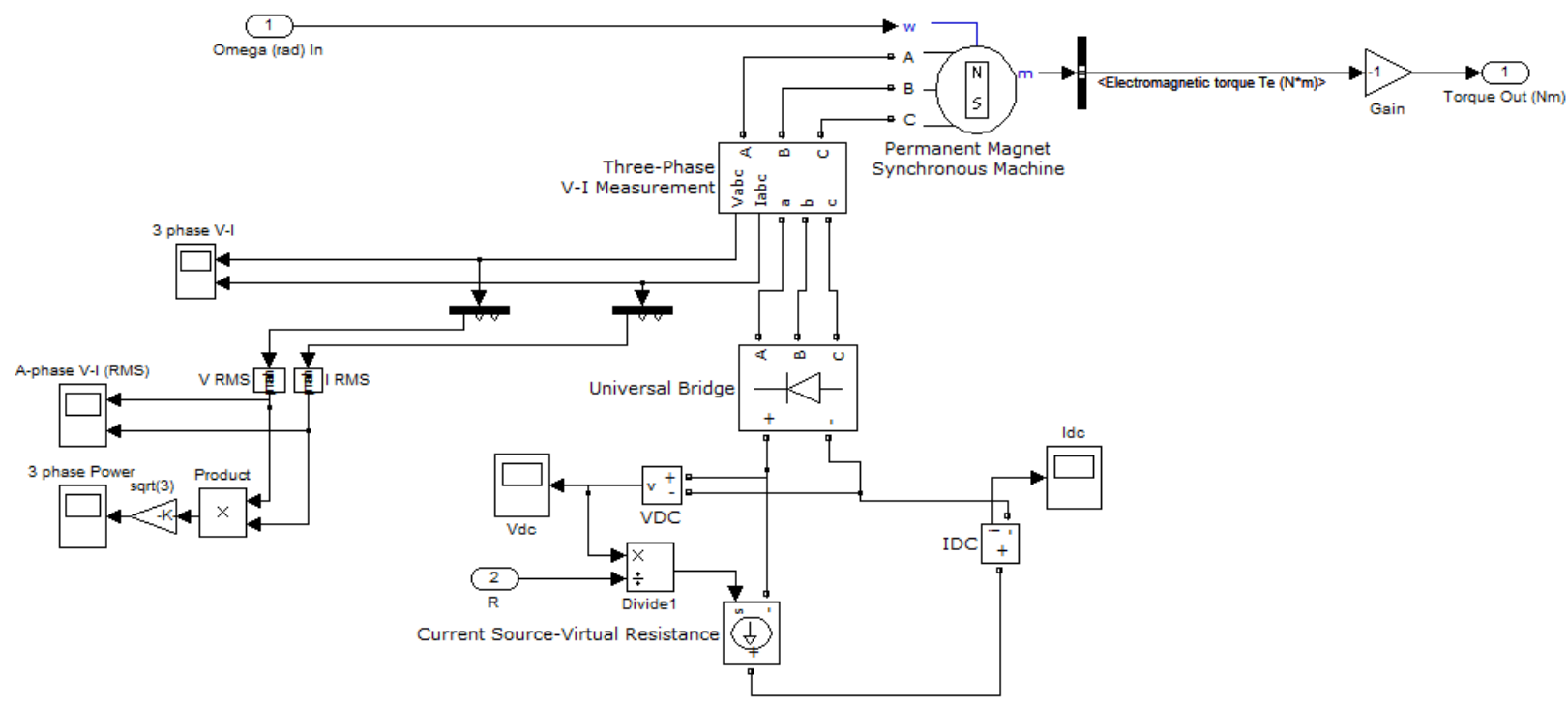

Figure 3.13 Dynamic PMG Simulink model with rectifier and current-source variable load

\subsubsection{Variable Resistive Load}

As with most simulations, some challenges are expected. One such challenge was creating a variable resistance load for the generator. While this task seems simple, it is actually difficult to implement with the MatLab Sim-power system library. There is no simple variable resistance element which is compatible with the generator or rectifier. A dynamic load does exist in the library, but it is designed to function at a constant frequency and voltage, so it does not work with the PMG which operates at variable-frequency and variable-voltage.

To overcome these issues, many solutions were investigated, including the modeling of a PWM DC chopper using an ideal switch, and two different models of switched resistive loads. The best solution was created by using a variable current source to model a dynamic resistive load. This model can produce any resistance value down to the thousandths of an ohm. The model is shown in Figure 3.14 . 


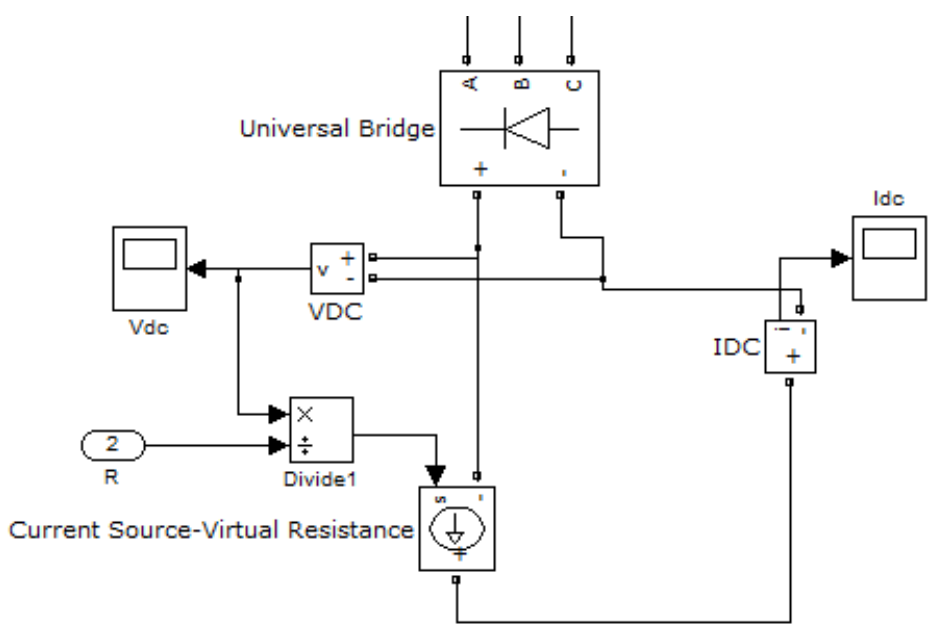

Figure 3.14 Variable resistance load using current source

As seen in Figure 3.14, an ideal current source is used to create a virtual resistance for the generator using ohms law.

$$
I_{d c}=\frac{V_{d c}}{R}
$$

\subsubsection{Step Load Increase}

First the effect of loading the generator from low load to full load was simulated. The variable resistance was adjusted from $500[\Omega]$ to $27[\Omega]$ to represent a change from a light load to full load. 


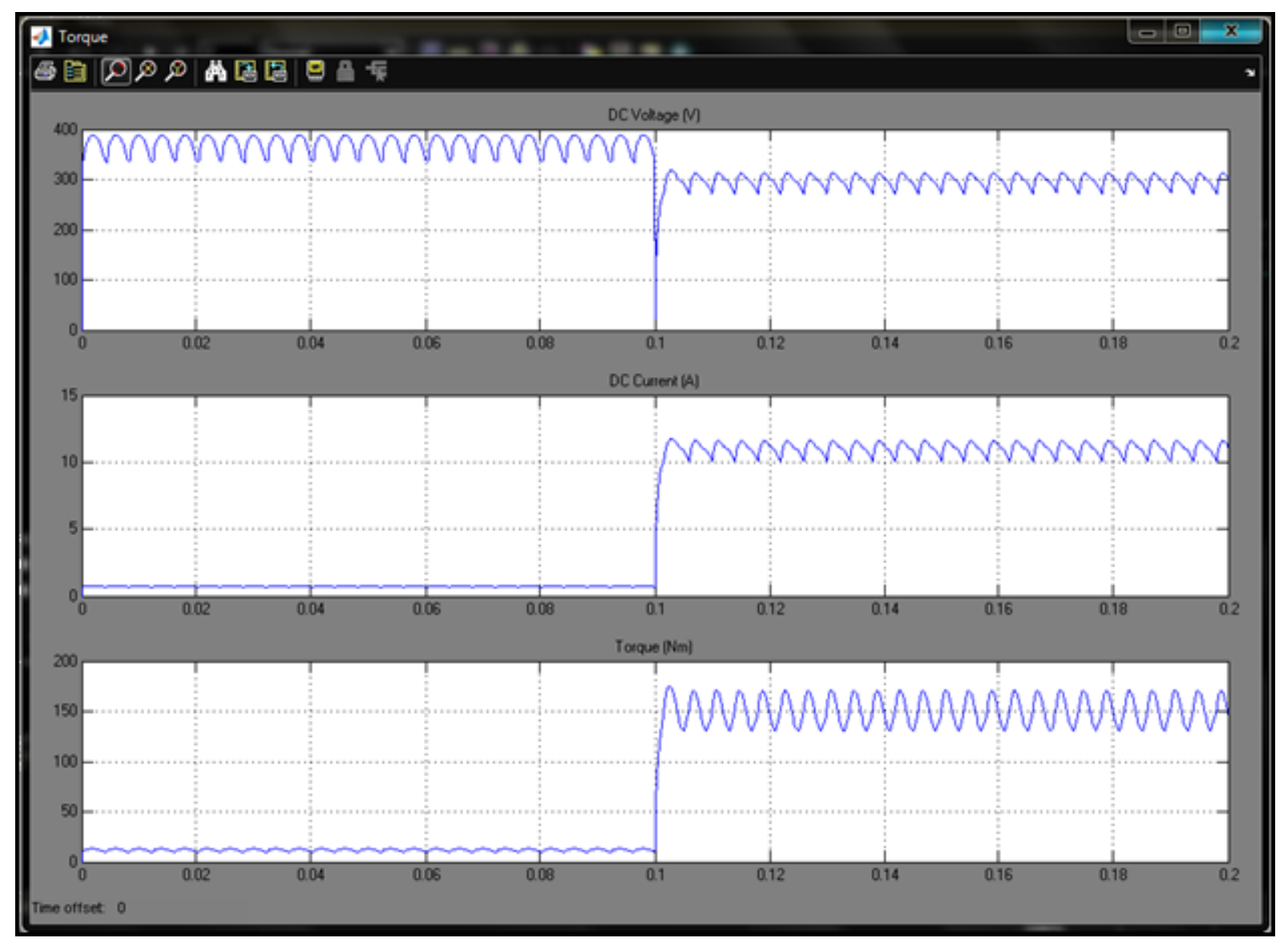

Figure 3.15 PMG step load increase, Vdc, Idc, and torque (250rpm, Rdc=500 to 27)

As seen in Figure 3.15 the Rectified DC voltage has a fast transient spike when the load is increased at timet $=0.1 \mathrm{~s}$. A fast but low energy voltage spike of this magnitude is not likely to harm the generator. In addition, the current does not exceed the continuous rated limit of $11 \mathrm{~A}$ (see Table 0.7 in the Appendix).

\subsubsection{Load Decrease}

This section shows the effect of loading the generator from full load to low load. The variable resistance load was adjusted from $27[\Omega]$ to $500[\Omega]$ and the results are shown below. 


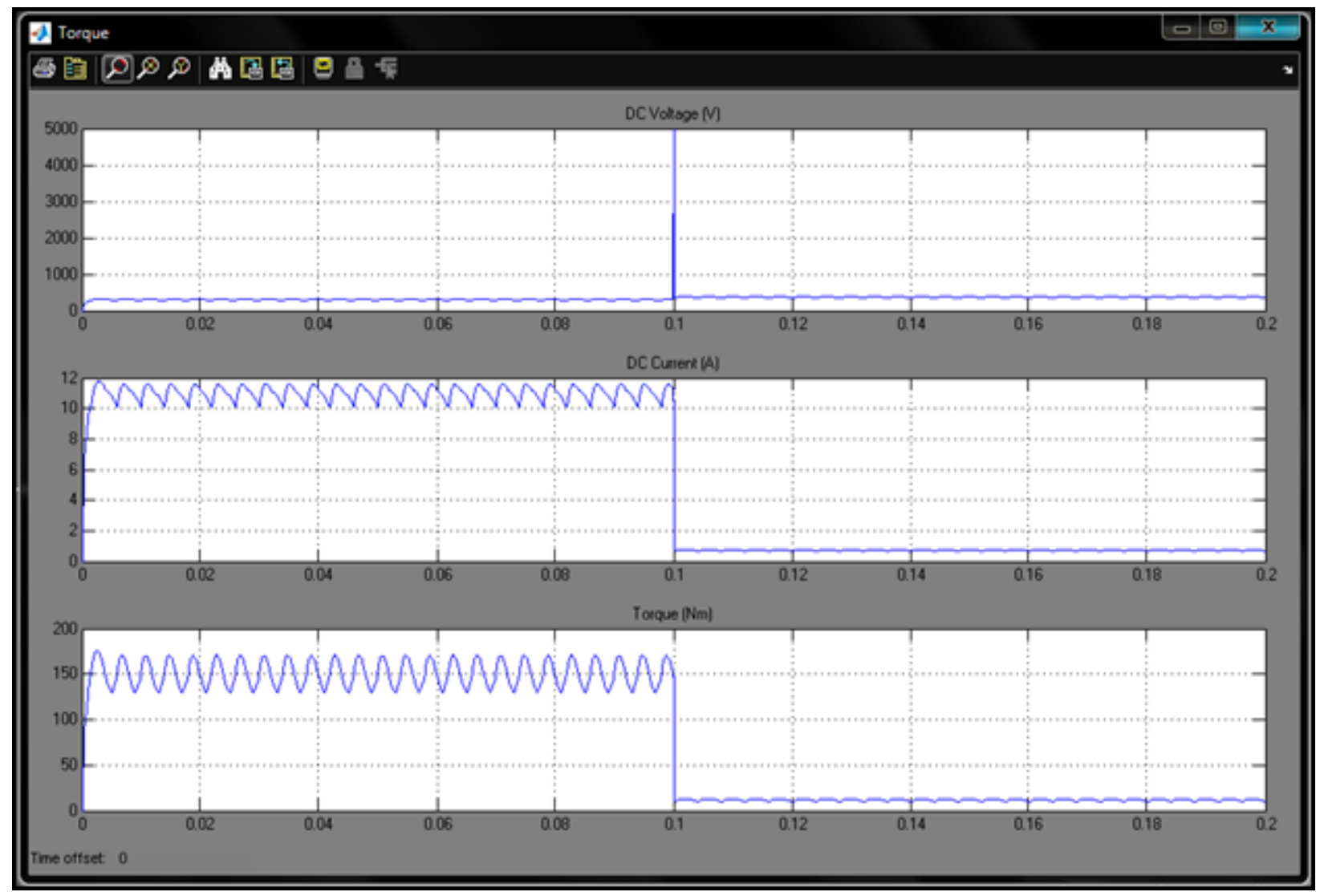

Figure 3.16 PMG step load decrease, Vdc, Idc, and torque (250rpm, Rdc=27 to 500)

Figure 3.16 shows a large voltage transient during the step load decrease. The voltage spike reaches a peak value of $V_{\text {peak }}=5000[\mathrm{~V}]$. This is a concern for the safety of the generator and the rectifier. The voltage spike is due to the relatively large inductance of the generator and the abrupt change of current. An abrupt current change cause a large voltage spike in an inductor because the voltage for an inductor is represented by equation (3.17).

$$
V_{L}=L \frac{d i}{d t}
$$

\subsubsection{Optional Solution for the Voltage Transient}

Adding a capacitor across the DC output of the rectifier reduces the voltage transient as seen in Figure 3.17. The capacitor was chosen as $C=0.1[\mathrm{mF}]$ from a trial and error process. The capacitor reduces the voltage transient to $V_{\text {peak }}=440[\mathrm{~V}]$, and this is within the acceptable limits for the generator. The capacitor also reduces the output $D C$ voltage ripple. 


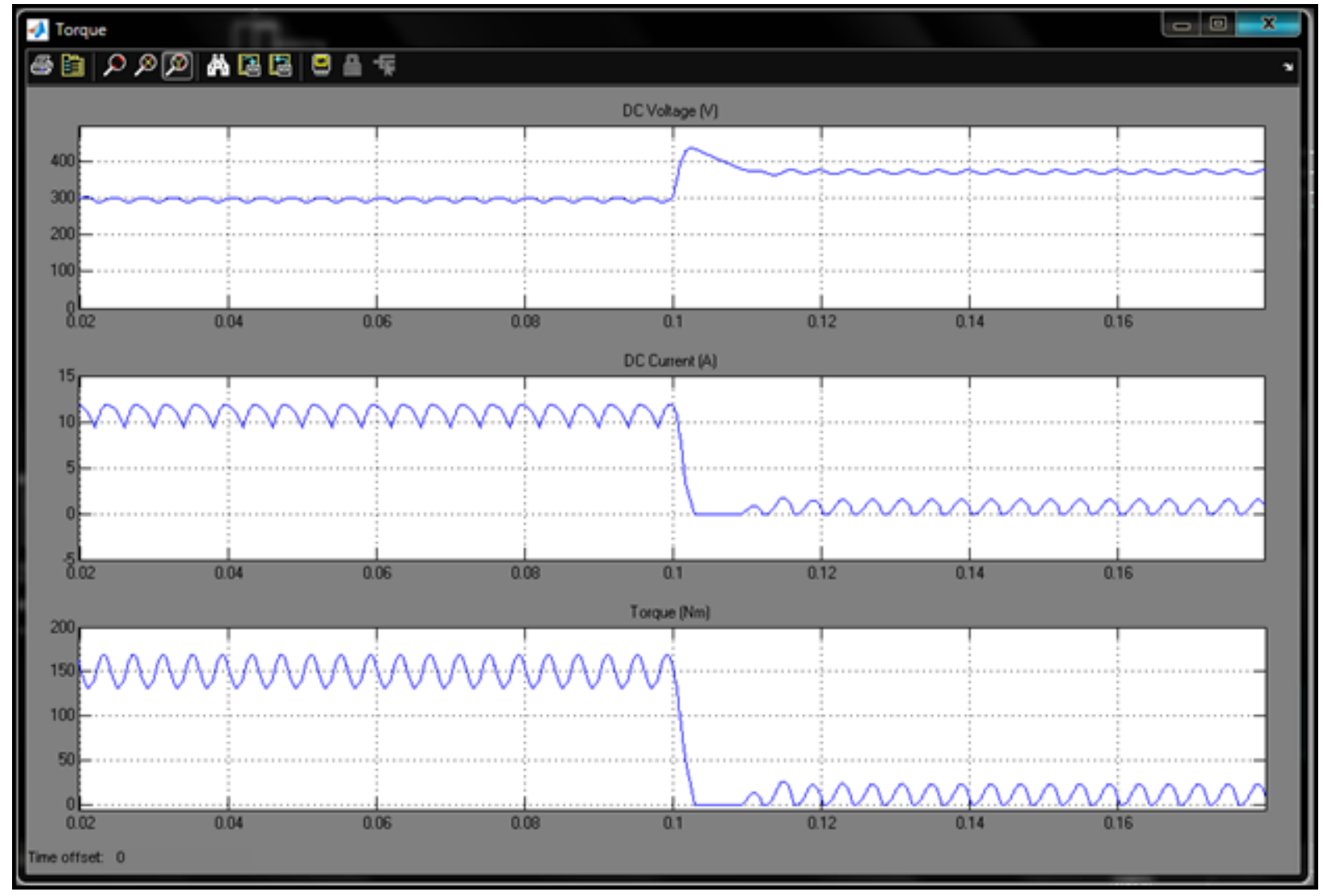

Figure 3.17 PMG stepped load Decrease with capacitor(C=0.1mF), Vdc, Idc, and torque (250rpm, $R d c=27$ to 500 )

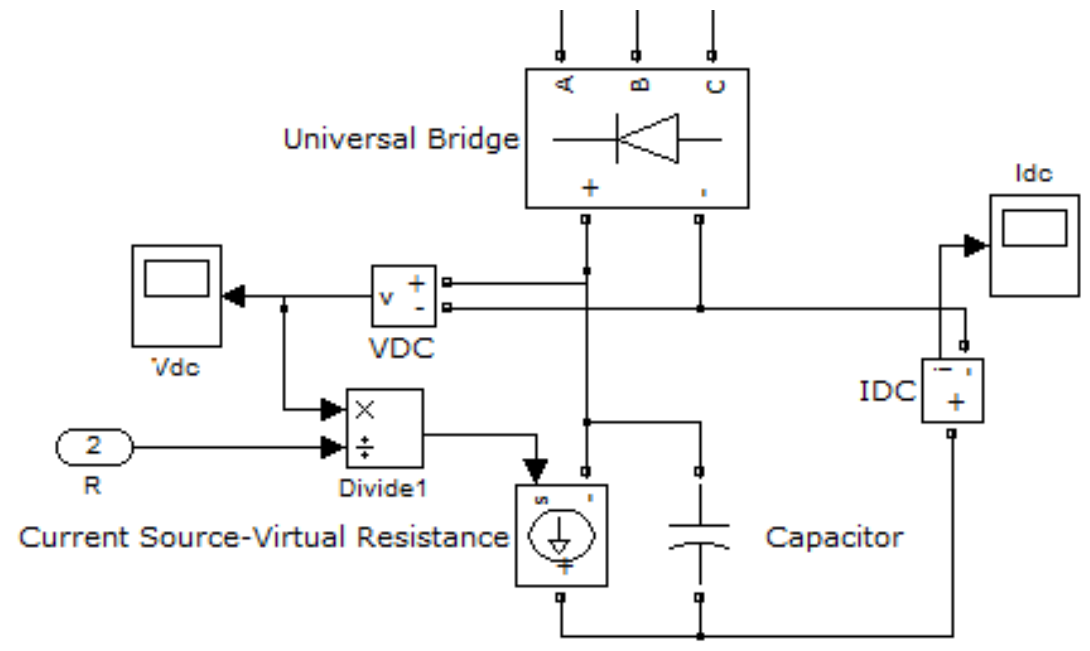

Figure 3.18 Capacitor added across the output of the rectifier to reduce voltage transient 


\subsection{Generator Electrical Limitations}

The electrical limits of the generator must be defined so the controller action does not cause the generator to exceed safe operating limits. A controller driven power electronics load connected to the generator has the ability to cause external disturbances in the form of voltage transients (see section 3.4). It is important to recognize that a properly designed control system is only the first step in ensuring that the generator is protected from electrical hazards.

\subsubsection{Generator Characteristics on the 11A limit line}

As discussed by [4], one of the concerns for the design of a controller is the $11 \mathrm{~A}$ rectified current limit which is specified in the Ginlong PMG-3500 data sheet. This is indeed a valid concern because the maximum current does limit the operation of the generator. Before the optimum operating points for the WECS can be chosen, the generator characteristics along the $11 \mathrm{~A}$ current limit must be further analyzed to determine if it will be acceptable to operate the generator along this line. The simulation model of Figure 3.1 uses the rectifier and the variable resistive load to extract key details about the safe operating limits of the generator. The results are summarized in Table 3.5 below. The generator is run at constant torque and current, and resistance is adjusted to match a desired speed. The input power is calculated from torque and speed, and the output power is measured the 3 phase terminal of the generator. The efficiency measurement includes all losses internal to the generator, including the 2.7ohm/phase internal resistance.

Table 3.5 Simulated PMG 11A Limit Generator Characteristics

\begin{tabular}{|c|c|c|c|c|c|c|c|}
\hline Speed(rpm) & I-DC (A) & Torque(Nm) & Resistance(ohm) & PMG P out(W) & PMG P in(W) & P Loss (W) & Efficiency \\
\hline 300 & 11 & 150 & 33.5 & 4338 & 4712.0 & 374.0 & $92.06 \%$ \\
\hline 250 & 11 & 150 & 27.02 & 3520 & 3926.7 & 406.7 & $89.64 \%$ \\
\hline 200 & 11 & 150 & 20.7 & 2687 & 3141.4 & 454.4 & $85.54 \%$ \\
\hline 150 & 11 & 150 & 14.4 & 1856 & 2356.0 & 500.0 & $78.78 \%$ \\
\hline 100 & 11 & 150 & 8.1 & 1030 & 1570.7 & 540.7 & $65.58 \%$ \\
\hline 50 & 11 & 150 & 1.85 & 230 & 785.3 & 555.3 & $29.29 \%$ \\
\hline
\end{tabular}

Before performing this analysis it was not obvious that torque would be constant for a DC current of $11 \mathrm{~A}$, but this is correct based on the following observations for the PMG. The equation relating torque, power and speed is listed below, and for DC signals, power equals voltage times current.

$$
T=\frac{P}{\Omega\left[\frac{r a d}{s}\right]}=\frac{V I}{\Omega\left[\frac{r a d}{s}\right]}
$$


Speed is proportional to voltage for a PMG with fixed current.

$$
\Omega=\alpha V
$$

So the torque in equation (3.18) becomes

$$
T=\frac{V I}{\alpha V}=\frac{I}{\alpha}
$$

The input torque can also be used to express the $11 \mathrm{~A}$ current limit in terms of power. See equation (3.21).

$$
P_{11 A}(\Omega)=150 \mathrm{Nm} \cdot \Omega\left[\frac{\mathrm{rad}}{\mathrm{s}}\right]
$$

\subsubsection{Power loss and efficiency on 11A current limit}

Another important characteristic in Table 3.5 is the power loss and efficiency calculation. The data shows that power loss increases as speed decreases. This is an unusual relationship because power loss in electric machines is usually dominated by $I^{2} R$ power loss from resistance in the stator winding, so we expect constant power loss when the current is fixed at $11 \mathrm{~A}$. Some other factor must also contribute to increased power loss at low speed. Increased power loss can also be observed when looking at the experimental generator data from [4].

Generator power loss is a concern because thermal damage can occur if the generator continuously operates with large loss. The power lost in the generator will be transformed to heat energy which increases the temperature of the generator. As seen from Table 3.5 the power loss at 250rpm full load rated conditions is $406.7(\mathrm{~W})$ and the power loss at $50 \mathrm{rpm}-11 \mathrm{~A}$ is $555.3(\mathrm{~W})$. This is an additional $150(\mathrm{~W})$ of energy that must be absorbed by the machine at low speed, which may be acceptable if the generator promptly returns to normal operating conditions, but this assumption may not always be valid because of the unpredictable nature of the wind.

A conservative approach to protect the generator is to limit the continuous operation to a fixed power loss. It is safe to assume that power loss of about $400(\mathrm{~W})$ will be acceptable for continuous operation of the generator at any speed. Table 3.6 shows a select list of data for rotor speeds below rated, and with power loss around 400 (W). 
Table 3.6 Simulated PMG Power loss data below rated speed

\begin{tabular}{|c|c|c|c|c|c|c|c|}
\hline Speed(rpm) & Resistance(ohm) & Torque(Nm) & Pin(W) & Pout(W) & P loss(W) & I DC (A) & V DC (V) \\
\hline 50 & 3.00 & 129.25 & 676.70 & 265 & 411.70 & 9.34 & 28.01 \\
\hline 50 & 3.50 & 118.75 & 621.73 & 272 & 349.73 & 8.76 & 30.65 \\
\hline 50 & 4.50 & 112.50 & 589.01 & 278 & 311.01 & 8.80 & 35.09 \\
\hline 50 & 5.00 & 103.40 & 541.36 & 278 & 263.36 & 7.40 & 36.55 \\
\hline 50 & 5.50 & 98.50 & 515.71 & 278 & 237.71 & 7.03 & 36.68 \\
\hline 50 & 6.50 & 90.00 & 471.20 & 274 & 197.20 & 6.41 & 41.65 \\
\hline 100 & 10.00 & 133.25 & 1395.29 & 974 & 421.29 & 9.64 & 96.38 \\
\hline 100 & 10.50 & 129.15 & 1352.36 & 958 & 394.36 & 9.33 & 97.98 \\
\hline 100 & 11.00 & 125.30 & 1312.04 & 943 & 369.04 & 9.04 & 99.45 \\
\hline 150 & 16.00 & 140.2 & 2202.09 & 1770 & 432.09 & 10.21 & 163.3 \\
\hline 150 & 17.00 & 134.25 & 2108.64 & 1718 & 390.64 & 9.75 & 165.70 \\
\hline 150 & 18.00 & 129.00 & 2026.18 & 1669 & 357.18 & 9.35 & 168.30 \\
\hline 200 & 22.00 & 143.80 & 3011.52 & 2598 & 413.52 & 10.51 & 231.30 \\
\hline 200 & 23.00 & 139.2 & 2915.18 & 2532 & 383.18 & 10.15 & 233.1 \\
\hline
\end{tabular}

From the simulated data we can select data points to get an approximate relation for the input power to the PMG as a function of rotor speed when the power loss is about $400(\mathrm{~W})$.

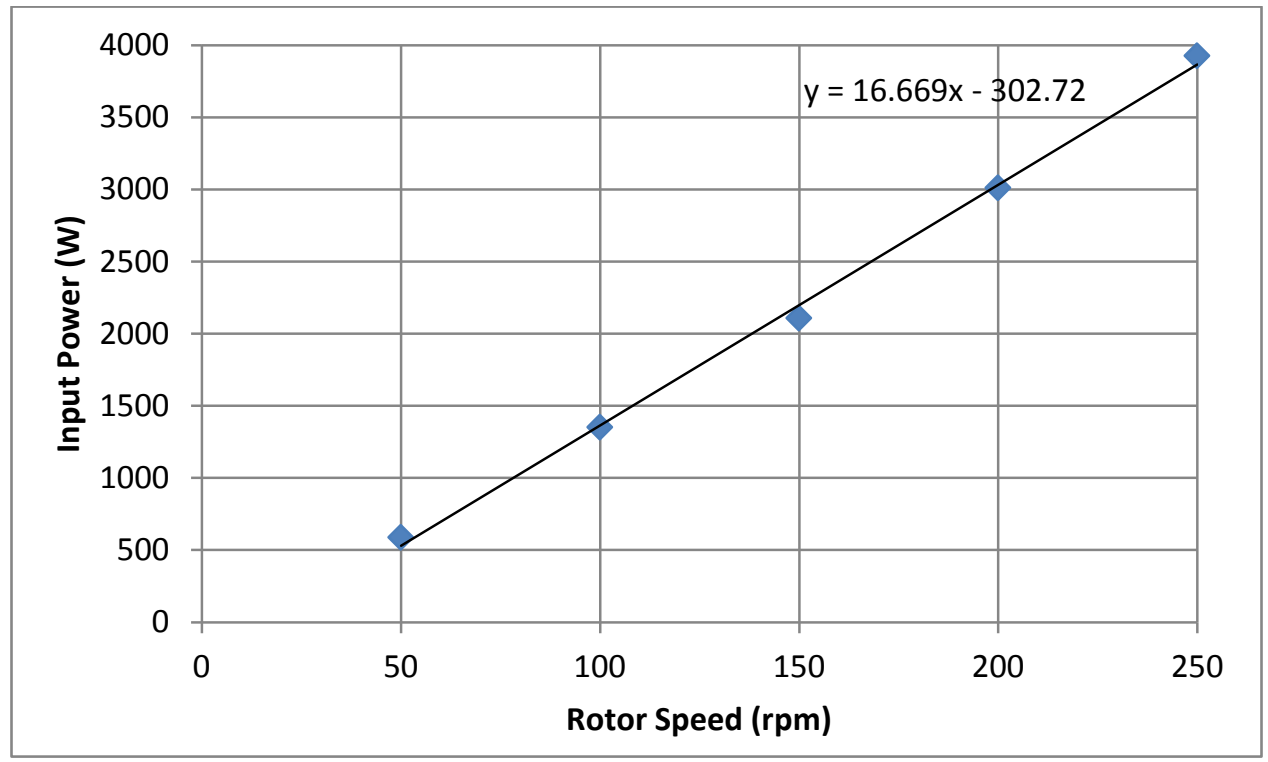

Figure 3.19 PMG Input Power vs. Rotor Speed for approximate power Loss=400W

Equation (3.22) represents the safe continuous operating limit of the generator below rated speed. The equation is represented by a linear approximation of the data points in Figure 3.19).

$$
P_{\text {safe }}(\Omega)=16.669 \Omega-302.71
$$




\subsubsection{Low Resistance Limit}

Table 3.6 also shows an interesting characteristic of the generator at low speeds. When the speed is $50[\mathrm{rpm}]$, decreasing the resistance does not always lead to larger power outputs as we would intuitively expect. For example, when speed is $50[\mathrm{rpm}]$ and output resistance is $5.5[\mathrm{ohm}]$, the power output is $278[\mathrm{w}]$. When the speed is $50[\mathrm{rpm}]$ and resistance is dropped to $4.5[\mathrm{ohm}]$ the power stays at $278[\mathrm{w}]$, and when resistance decreases again to 3.5[ohm], the output power actually decreases. At these low values of resistance the voltage decreases by a larger amount than the current can increase, so output power drops.

From an energy efficiency perspective, there is no reason to operate the generator with a resistance lower than $5.5[\mathrm{ohm}$ ] because the generator produces less power as resistance decreases below this point. Decreasing resistance always requires more input power to the generator, and at 5 [ohm] the power losses become approximately equal to the output power. A low resistance limit of $5.5[\mathrm{ohm}]$ will be used in future sections to help define the controller action. 


\section{CONTROLLER DESIGN AND EVALUATION}

\subsection{Introduction}

This chapter addresses the design and evaluation of an optimal operating point PID speed controller for the Cal Poly WECS. First, the safe operating limits for the generator and the aerodynamic characteristics of the Cal Poly WECS are used to define the optimal operating points for all wind speeds. The dynamic permanent magnet generator model is then combined with the existing state space WECS model to create a non-linear time varying system in MatLab Simulink. Next, an optimal operating point controller utilizing a PID speed loop is designed with the combined optimization criteria. The final controller design is justified by comparing performance measures of energy efficiency and mitigation of excessive mechanical loads. Lastly, this chapter discusses implications for a WECS when blade characteristics are mismatched with the generator.

\subsection{Steady State Optimal Operating Points}

The steady state optimal operating points for the Cal Poly WECS are the points describing the control reference signal. The reference signal is the desired rotor speed, which depends on the wind speed, and the actuator signal sent to the generator is the desired output resistance. Figure 4.1 below shows a family of curves describing the available power from the rotor blades for a given wind speed. The dashed lines describe the ORC in the partial load region (see section 2.3.2.1) and the safe operating limit of the PMG (see section 3.5). The 11A current limit is also shown on the graph with the safe operating limit directly below it. 


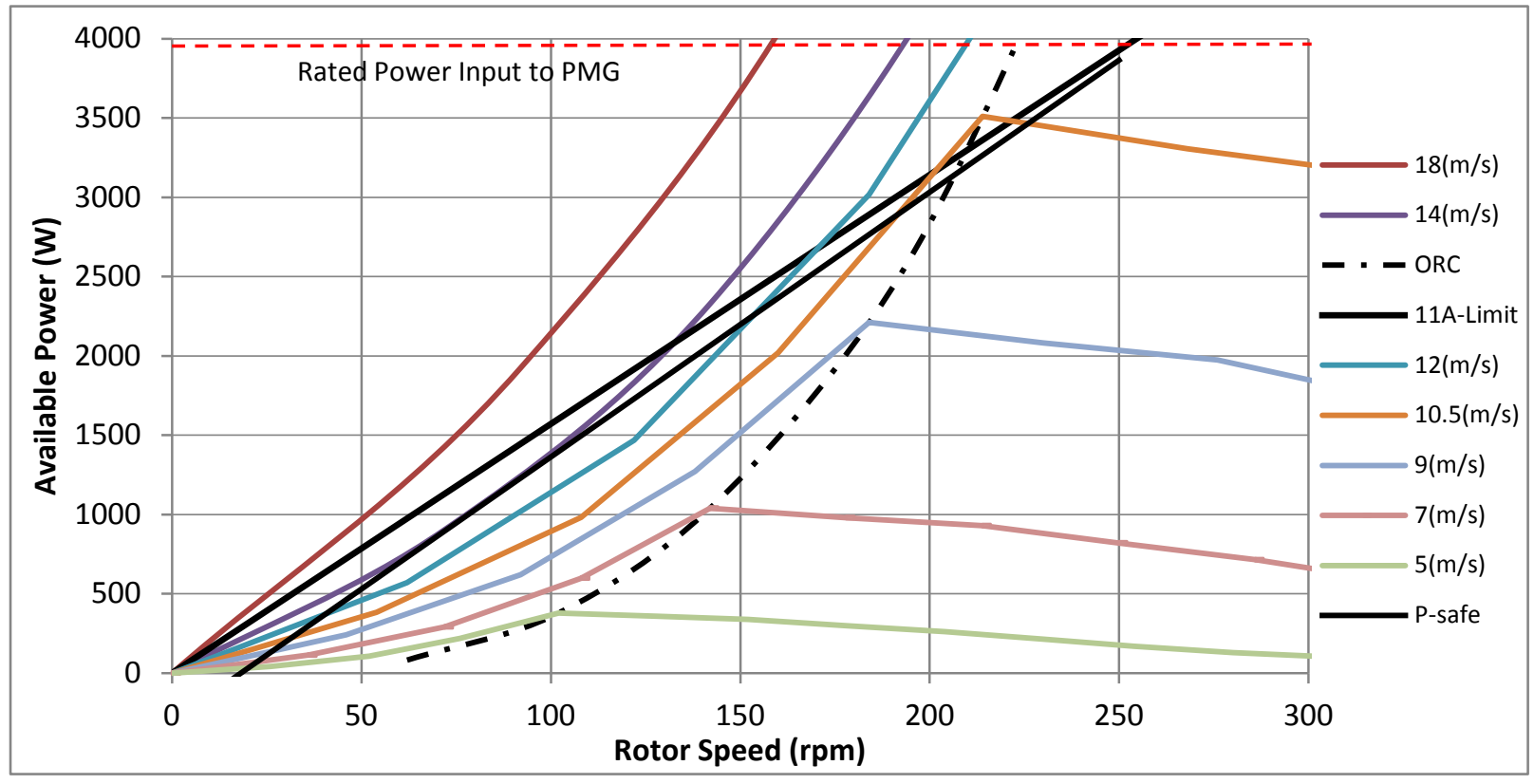

Figure 4.1 Available Power vs. Rotor Speed for given wind speeds

The $11 \mathrm{~A}$ current limit and more importantly, the safe operating limit (P-safe) create a unique challenge for the selection of the optimal operating points, because most WECS are only limited by the rated power and rotor speed (see Appendix E for the classical method of determining aerodynamic limitations).

Available power regulation for a fixed pitch WECS can be accomplished by slowing down or speeding up the rotor. As discussed in section 2.2.1, the power coefficient $\left(C_{p}\right)$ depends on the tip speed $\operatorname{ratio}(\lambda)$, which depends on the wind speed and rotor speed. The rotor speed is dependent on the electrical load of the generator, so by regulating the electrical load of the generator, the available power captured by the blades can also be regulated.

The most effective way to reduce available power from the blades is to reduce the rotor speed. This is the preferred method because the rotor speed should not increase without limit. Additionally, the $C_{p} v s$. $\lambda$ characteristic is non-symmetrical (see Figure $2.2 \mathrm{Cp}$-Power Coefficient vs. $\lambda$ for the Cal Poly WECS) because the slope to the left of $C_{p M a x}$ is much steeper than the slope to the right of $C_{p M a x}$. 


\subsubsection{Limited Range of Operation up to Rated Power and Speed}

One possible option is to follow the ORC until it intersects the safe operating limit and then travels along the safe operating limit until the WECS reaches rated power and speed (see Figure 4.2).

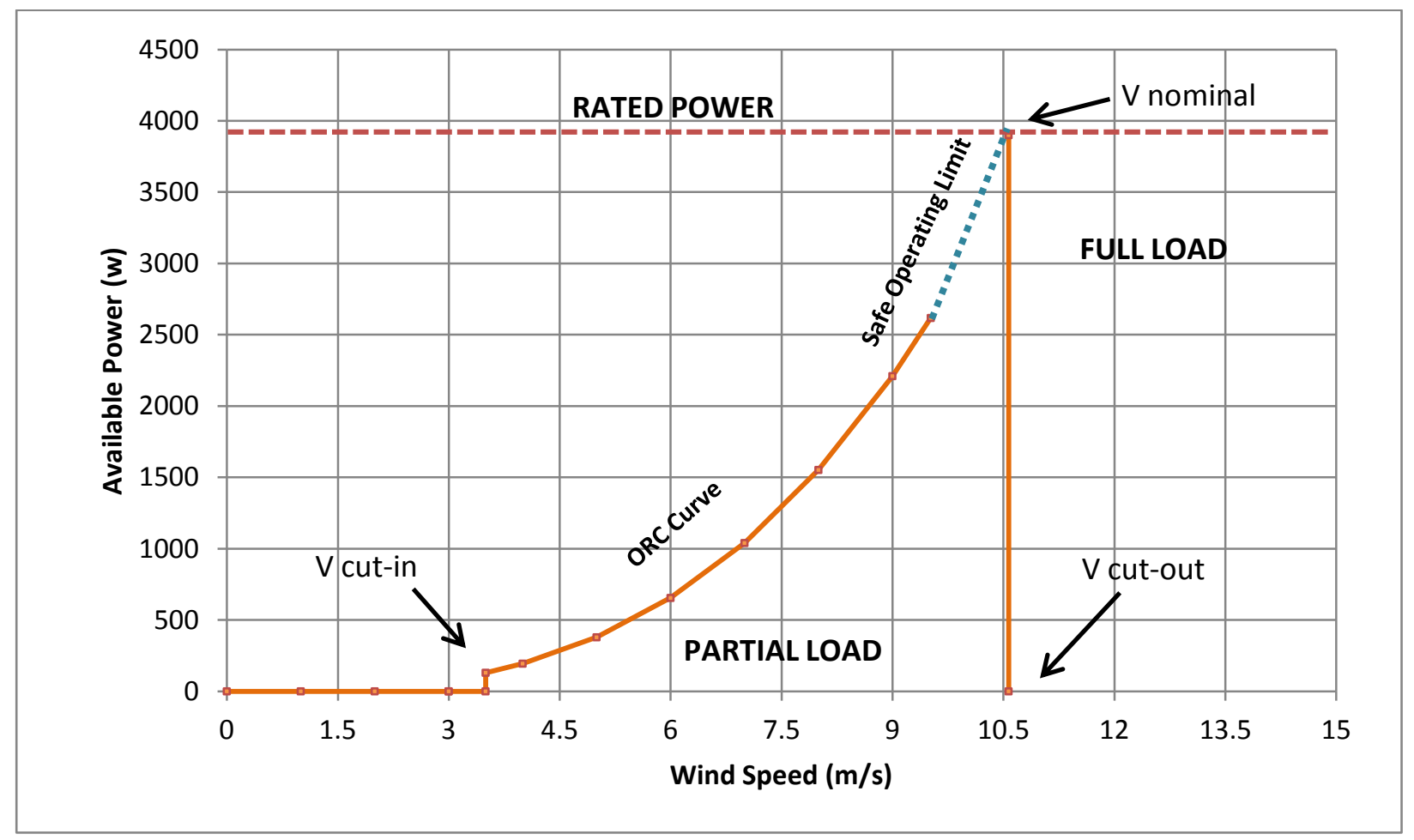

Figure 4.2 Limited range of operation - Available Power vs. Wind Speed

This selection of points would allow one operating point at the full load rating of the generator, but it would be very difficult to maintain operation at wind speeds above $10.5 \mathrm{~m} / \mathrm{s}$ because the speed reference signal would be a discontinuous function of the wind speed. Consider the following example; the WECS is operating at nominal wind speed and rotor speed when the wind increases above $10.5 \mathrm{~m} / \mathrm{s}$. As shown in Figure 4.1 the rotor would have to decelerate back through the ORC to the leading edge of the wind speed where the safe operating limit intersects the available power from the wind. The WECS would experience a large power and torque spike before settling at the new operating point. This is not a reasonable action for the WECS. 


\subsubsection{Improved Range of Operation Below Rated Power and Speed}

Another strategy to capture energy over a wider range of wind speeds is to limit power capture below rated power and speed. The optimal operating points for this scenario again follow the ORC curve until intersecting the safe operating limit, but this strategy does not reach rated power and speed (see Figure 4.3).

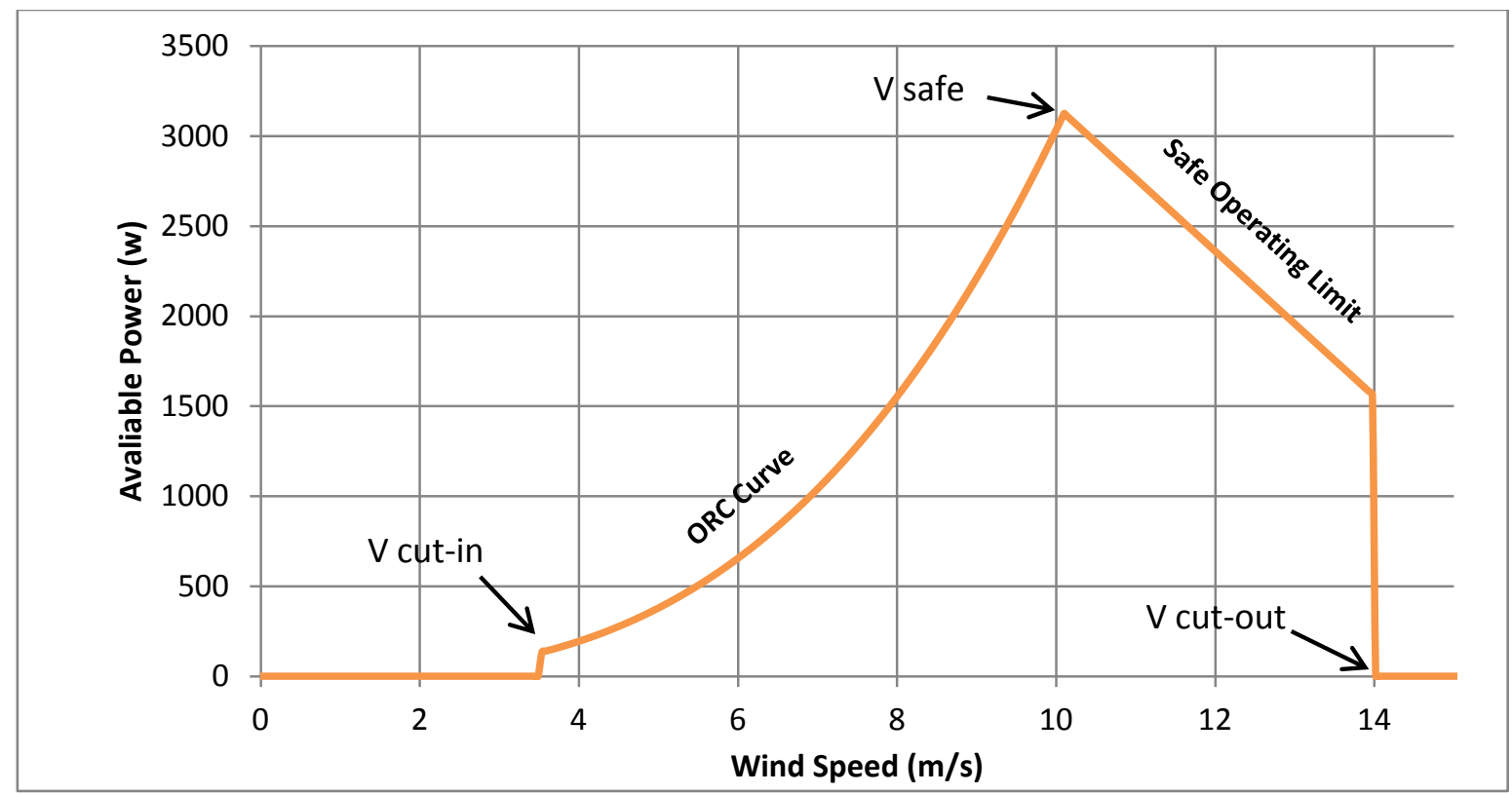

Figure 4.3 Improved range of operation - Available power vs. wind speed

Improved range of operation is possible with this scenario because the control reference signal is continuous from cut in wind speed to cut out wind speed. In this scenario the cut out wind speed is determined by the limit of the linear approximation in Figure 4.4. 


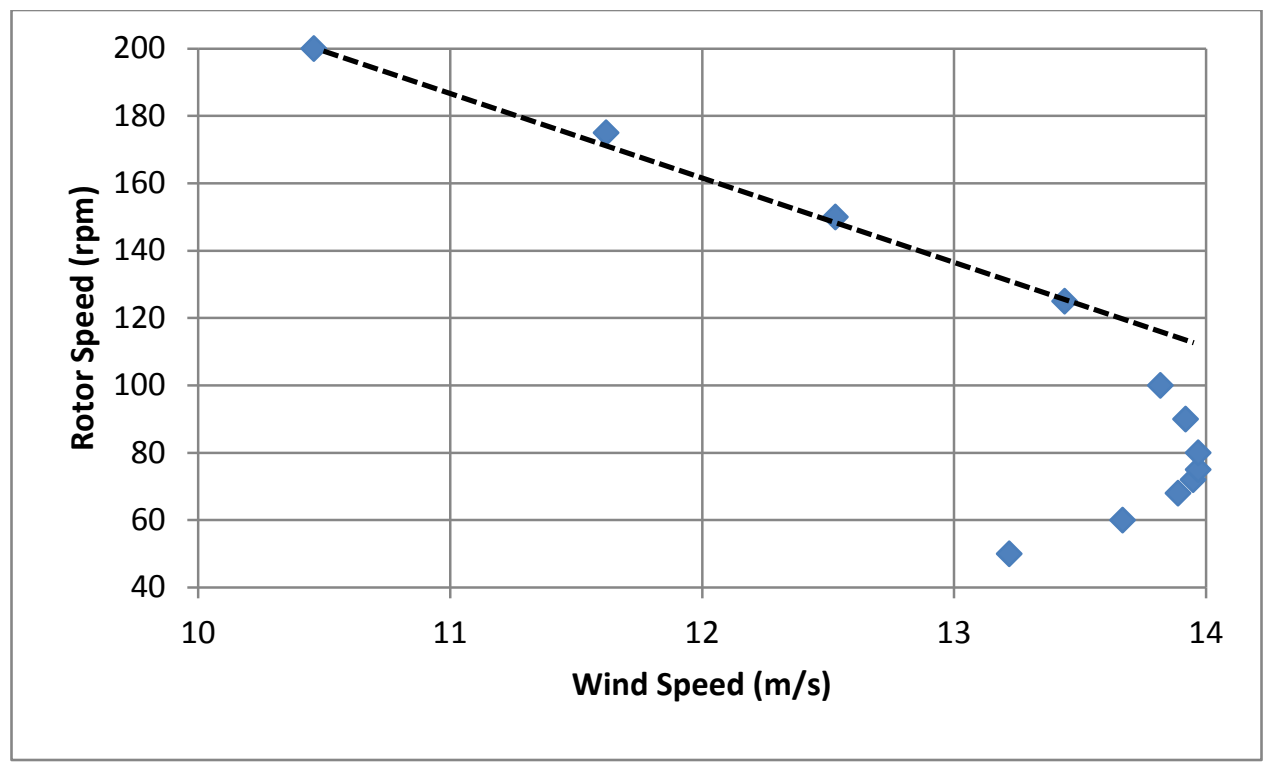

Figure 4.4 Rotor Speed vs. Wind speed along safe operating limit

The linear approximation of Figure 4.4 was determined by fitting two points to a line. The first point intersects the ORC $\left(10.1\left[\frac{\mathrm{m}}{\mathrm{s}}\right], 205.78[\mathrm{rpm}]\right)$ and the second point $\left(13.44\left[\frac{\mathrm{m}}{\mathrm{s}}\right], 125[\mathrm{rpm}]\right)$ was chosen from Figure 4.4 .

$$
\Omega_{\text {safe }}(V)=(-24.186 V+450.055)[\mathrm{rpm}]
$$

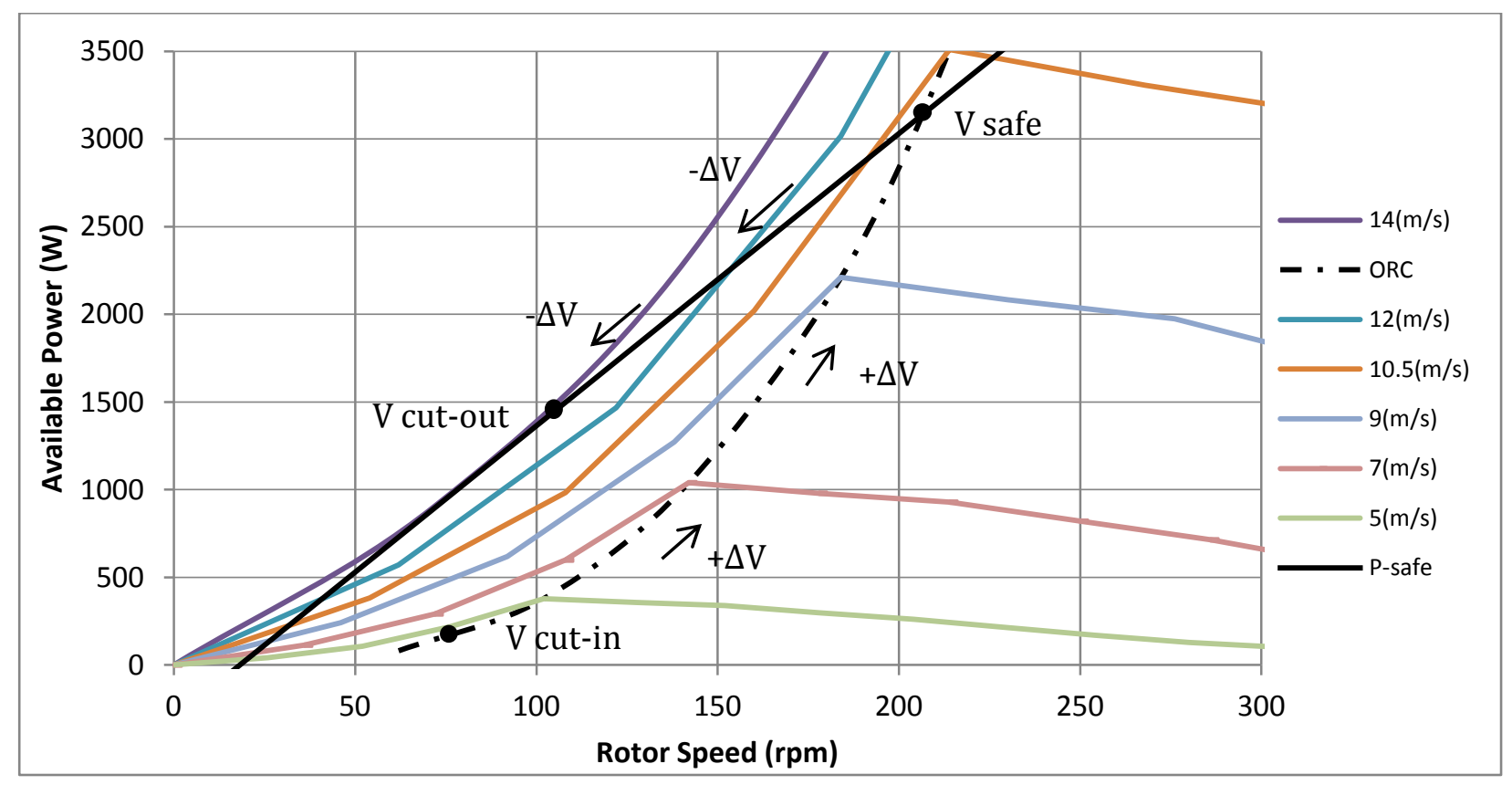

Figure 4.5 Optimal operating points on available power vs. rotor speed 
Table 4.1 lists the values for the important optimal operating points as shown in the Figure above. The following section 4.2.2.1 shows example calculations for the safe limits. Appendix E shows the calculation for cut in speed. The cut out speed was determined by the limit of the linear approximation in Figure 4.4.

Table 4.1 Summary of important optimal operating points

\begin{tabular}{|c|c|}
\hline $\mathrm{V}_{\text {cut-in }}$ & $3.5 \mathrm{~m} / \mathrm{s}$ \\
\hline $\mathrm{V}_{\text {safe }}$ & $10.1 \mathrm{~m} / \mathrm{s}$ \\
\hline $\mathrm{V}_{\text {cut-out }}$ & $14 \mathrm{~m} / \mathrm{s}$ \\
\hline
\end{tabular}

\begin{tabular}{|c|c|}
\hline$\Omega_{\text {cut-in }}$ & $71.3 \mathrm{rpm}$ \\
\hline$\Omega_{\text {safe }}$ & $205.85 \mathrm{rpm}$ \\
\hline$\Omega_{\text {cut-out }}$ & $111.45 \mathrm{rpm}$ \\
\hline
\end{tabular}

\subsubsection{Example Calculation of $\mathrm{V}_{\text {Safe }}$ and $\Omega_{\text {safe }}$}

$\mathrm{V}_{\text {safe }}$ can be calculated by setting the available power along the ORC equal to equation (3.22). The power along the ORC is found by substituting the maximum power coefficient and optimal tip speed ratio into equation (2.2).

$$
\begin{gathered}
P_{\text {safe }}=\frac{1}{2} \rho \pi R_{t}{ }^{2} C_{P \max }\left(\frac{\Omega R_{t}}{\lambda_{\text {opt }}}\right)^{3} \\
\frac{16.669 \Omega_{\text {safe }}\left[\frac{\mathrm{rad}}{\mathrm{s}}\right]-302.71}{9.55}=\frac{1}{2} \rho \pi R_{t}{ }^{2} C_{\text {Pmax }}\left(\frac{\Omega_{\text {safe }} R_{t}}{\lambda_{\text {opt }}}\right)^{3}
\end{gathered}
$$

Graphically solving for the intersecting rotor speed gives

$$
\Omega_{\text {safe }}=21.55\left[\frac{\mathrm{rad}}{\mathrm{s}}\right]
$$

It is important to note that the rotational speed in equation (2.2) has units of ( $\mathrm{rad} / \mathrm{s}$ ) and the rotational speed in equation (3.21) has units of (rpm). Conversion between the two is possible by:

$$
1\left[\frac{\mathrm{rad}}{\mathrm{s}}\right]=\frac{1}{9.55}[\mathrm{rpm}]
$$

The wind speed can be found from the tip speed ratio

$$
V_{\text {safe }}=\frac{\Omega_{\text {safe }} R_{t}}{\lambda_{\text {opt }}}=10.1\left[\frac{\mathrm{m}}{\mathrm{s}}\right]
$$




\subsubsection{Implementing the Optimal Operating Points as the Speed Reference Signal}

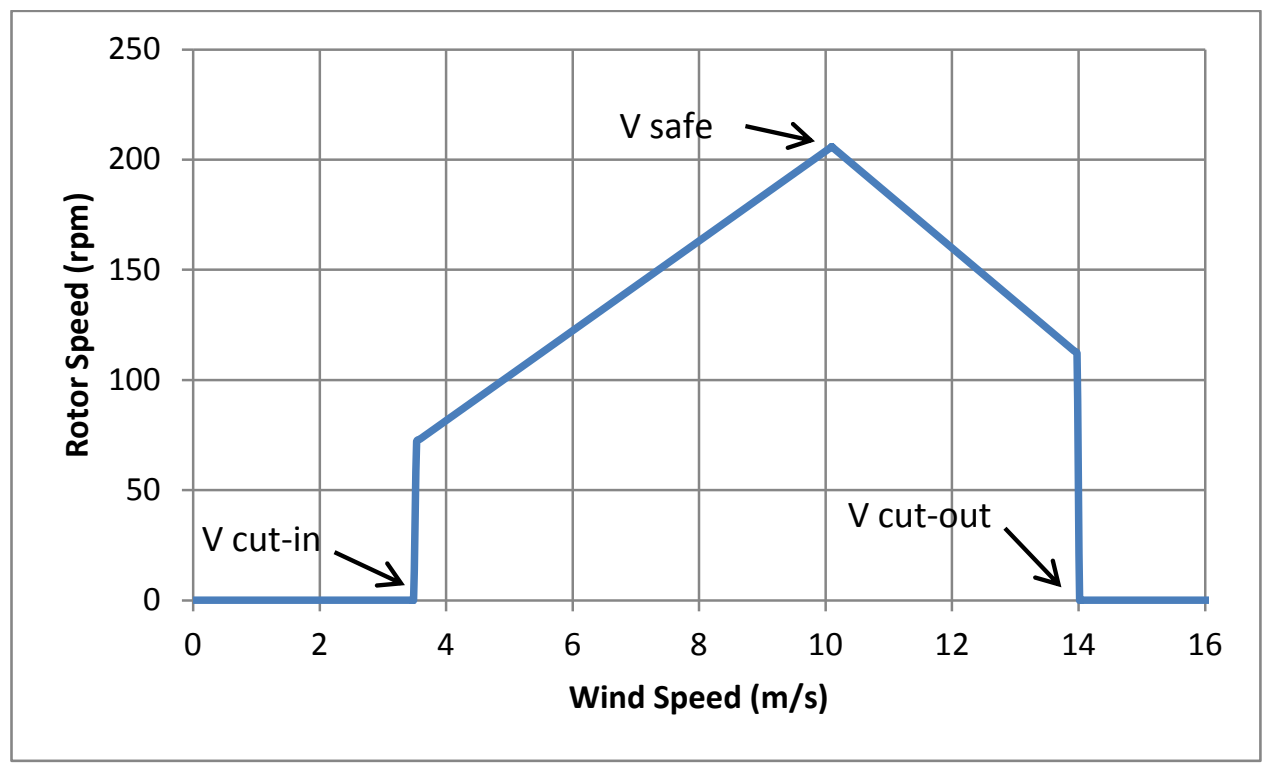

Figure 4.6 Controller speed reference signal as a function of wind speed

The optimal operating points define the speed controller reference signal. Below $\mathrm{V}_{\text {Safe }}$ the ORC is tracked so rotor speed is proportional to wind speed. Above $\mathrm{V}_{\mathrm{Safe}}$, the reference follows equation (4.1). MATLAB simulation accomplishes the speed reference with the use of simple logic statements seen in the Figure below. 


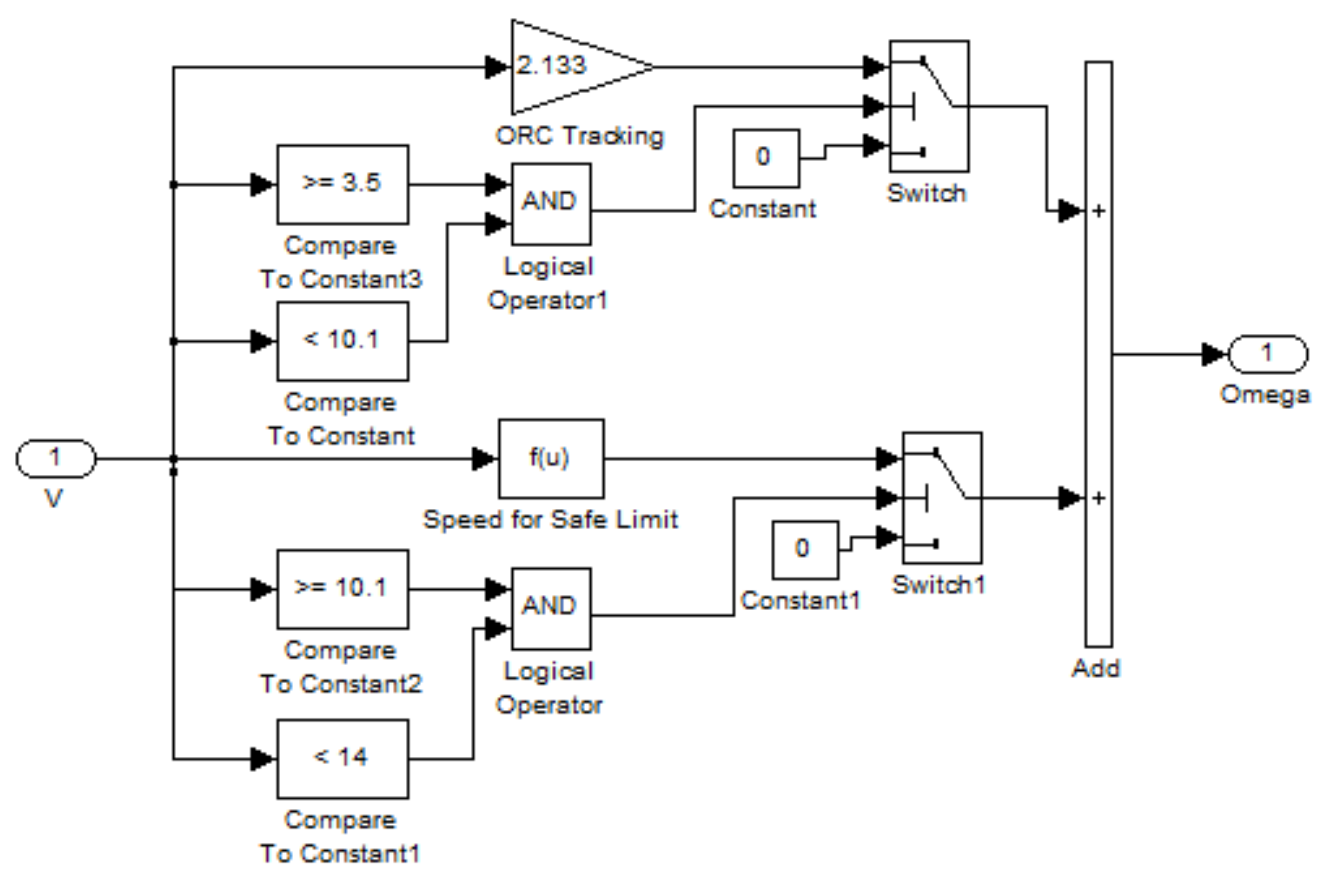

Figure 4.7 MATLAB Speed Reference Logic

\subsubsection{Implementing the Steady State Resistance Signal}

The optimal operating points for the controller are defined in terms of wind speed and rotor speed, but the generator load is adjusted in units of output resistance. A relationship between output resistance and desired rotor speed must be determined as part of the controller design. Experience has shown that a PID controller without proper unit conversion can lead to unusual gain values and questionable stability characteristics.

It is possible to view the relationship between output resistance and desired rotor speed by graphing the input generator power on Figure 4.5. The result is shown in Figure 4.8 below. In addition, an approximation can be made for the relationship between rotor speed and resistance when operating along the optimal operating points. Figure 4.9 shows the simulated steady state resistance in terms of the control reference speed. The Figure also shows the approximate equations which have been fit to match the graph. 


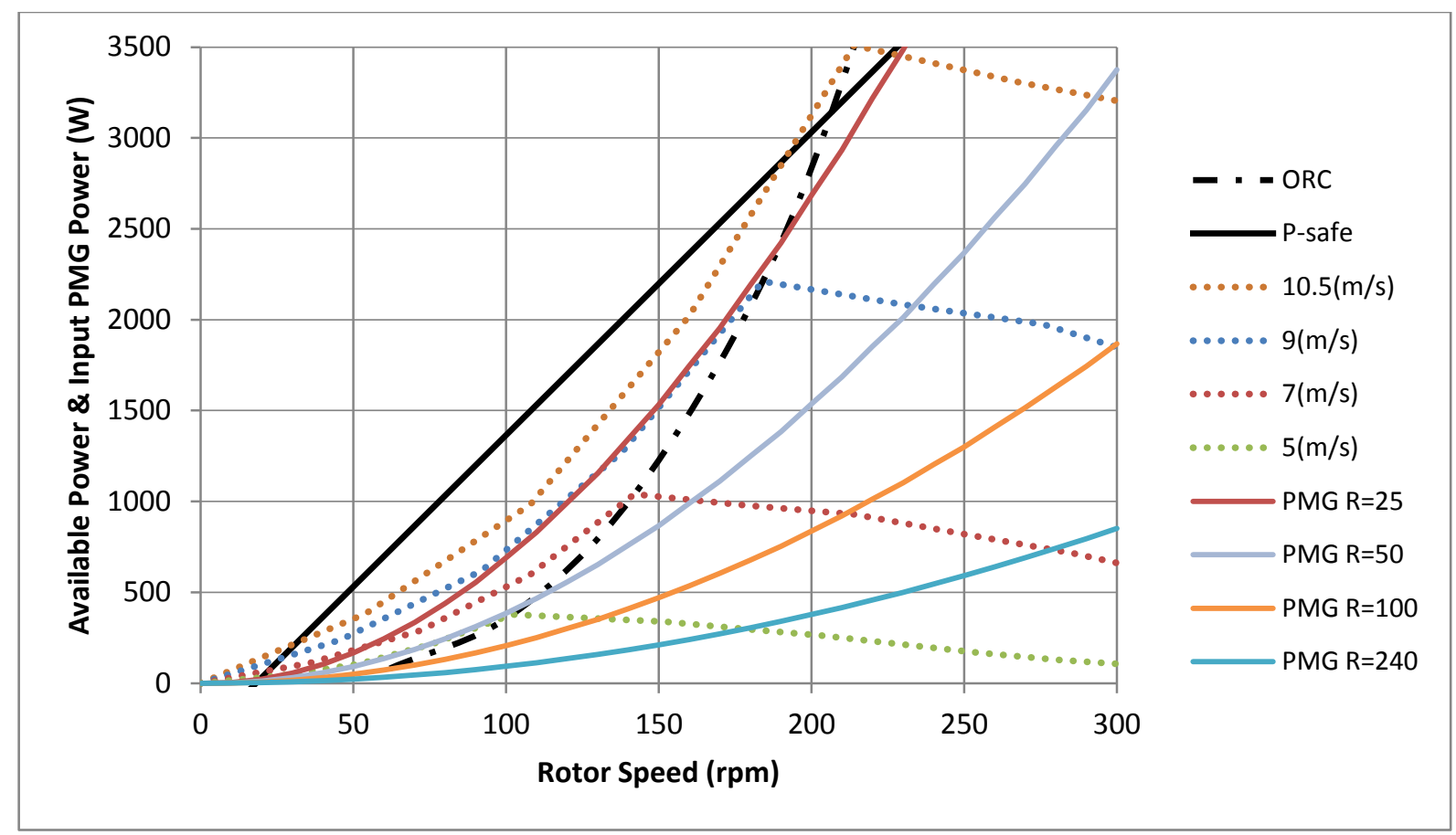

Figure 4.8 Available Power \& Input PMG Power for given Wind Speed and Output Resistance

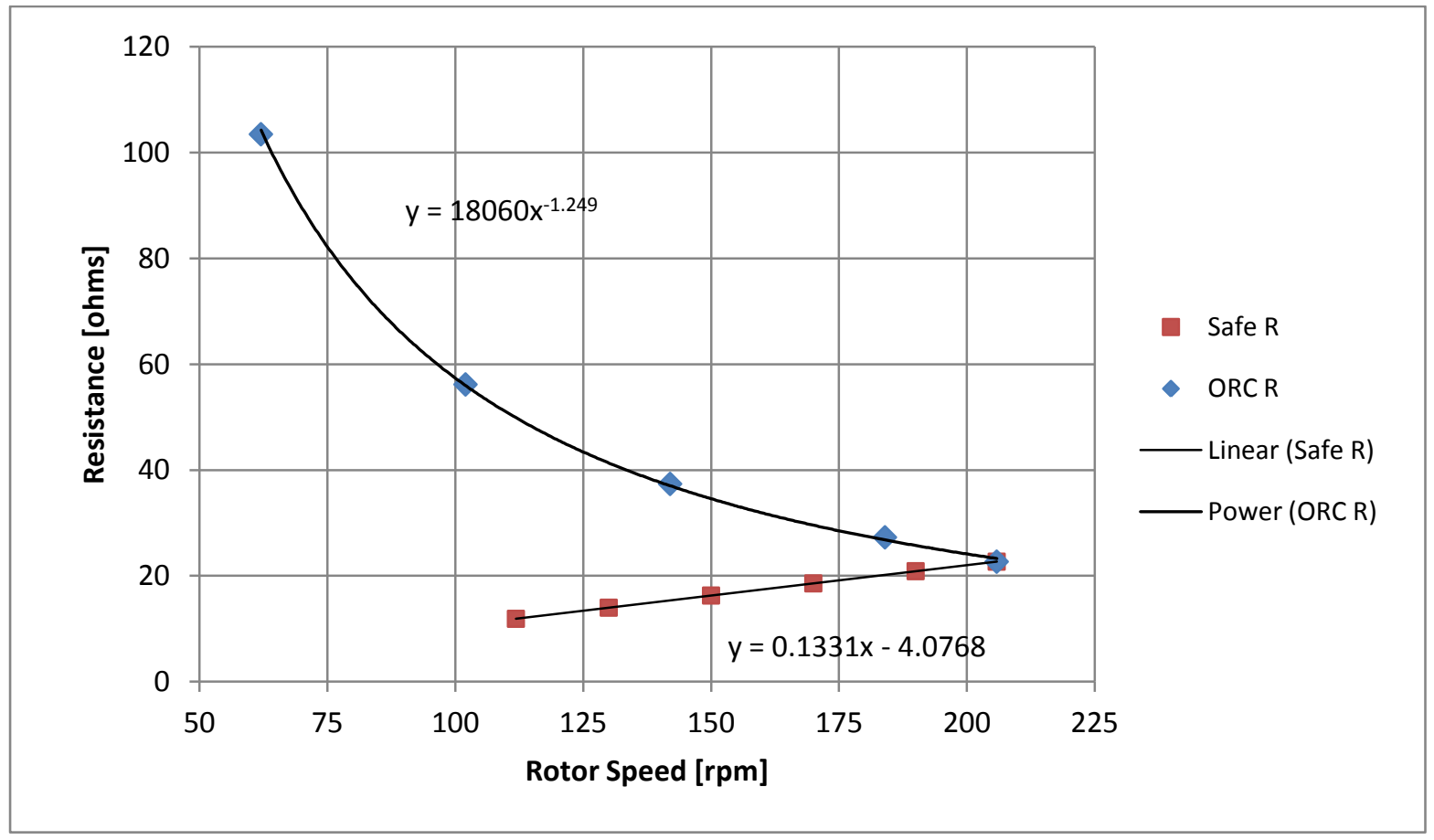

Figure 4.9 Approximate Steady State Resistance vs. Desired Rotor speed 
The equations in Figure 4.9 are used as part of the control signal to the generator. When the desired operation of the WECS is along the ORC (wind speeds between $3.5[\mathrm{~m} / \mathrm{s}]$ and $10.1[\mathrm{~m} / \mathrm{s}]$ ) the steady state resistance should be made to follow the approximated $O R C$ resistance equation.

$$
O R C_{\text {resistance }}[\mathrm{ohms}]=18060 \Omega[\mathrm{rpm}]^{-1.249}
$$

When the desired operation of the WECS is along the safe limit (wind speeds between $10.1[\mathrm{~m} / \mathrm{s}$ ] and $14[\mathrm{~m} / \mathrm{s}]$ ) the steady state resistance should be made to follow the approximated linear Safe resistance equation.

$$
\text { Safe } \text { resistance }[\mathrm{ohms}]=0.1331 \Omega[\mathrm{rpm}]-4.0768
$$

MATLAB is able to implement the steady state resistance equations using the same logic from the speed reference block of Figure 4.7. Figure 4.10 uses the wind speed input and rotor speed reference to determine the desired steady state output resistance.

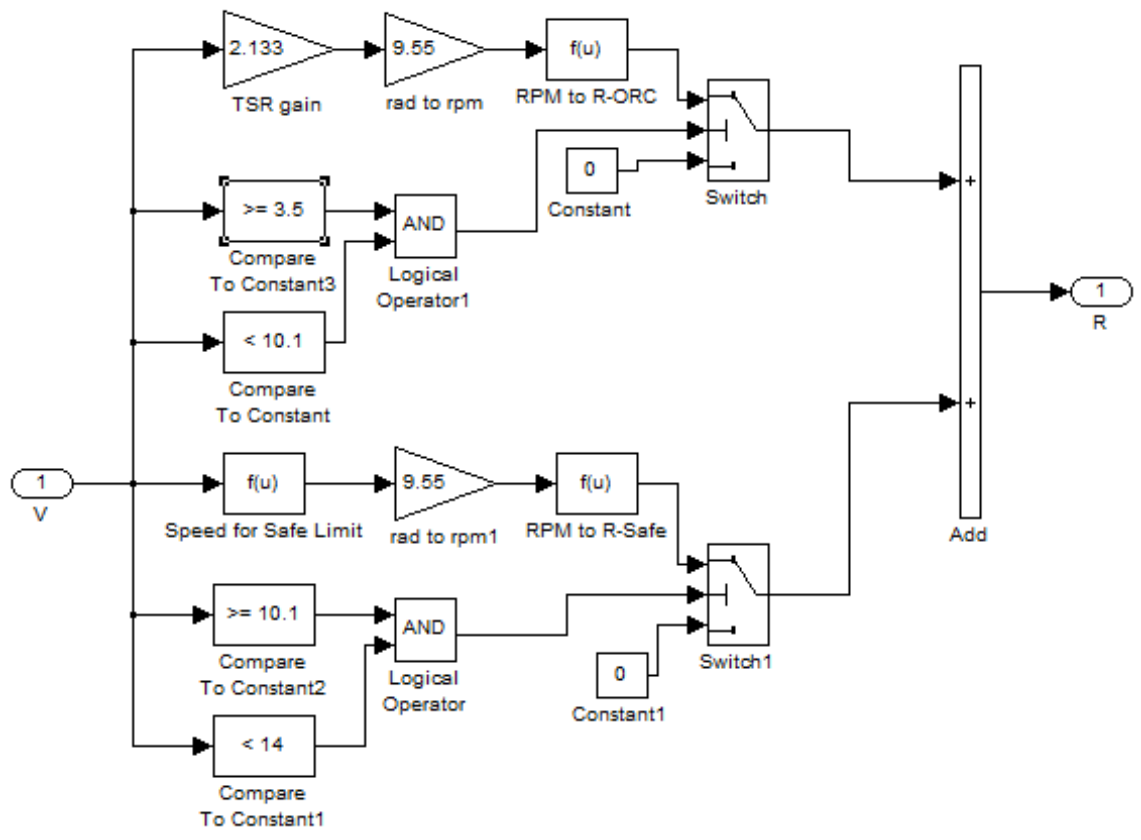

Figure 4.10 MATLAB Steady State Resistance Equations and Logic

\subsubsection{Combined Non-Linear, Time-Varying Model}

Before the controller gains can be designed, the mechanical, aerodynamic, and electrical systems are combined to form a non-linear time varying system. The gains for a discrete PID speed loop controller are determined by simulation because the WECS plant is a nonlinear time varying system that does not convert easily to a useful Linear Time Invariant (LTI) form. The base simulation model was also 
used by [4] which is explained in chapter 2. The combined simulation model is presented in Figure 4.11 below.

The control system shown below consists of a discrete PID speed loop controller and a steady state input compensator. The speed reference signal is defined in section 4.2.3, and the steady state resistance input compensator is defined in section 4.2.4. When the WECS reaches steady state, the speed error goes to zero and the PID output also goes to zero. The PID speed loop controller governs the transient operation of the WECS based on the optimal speed reference and rotor speed feedback.

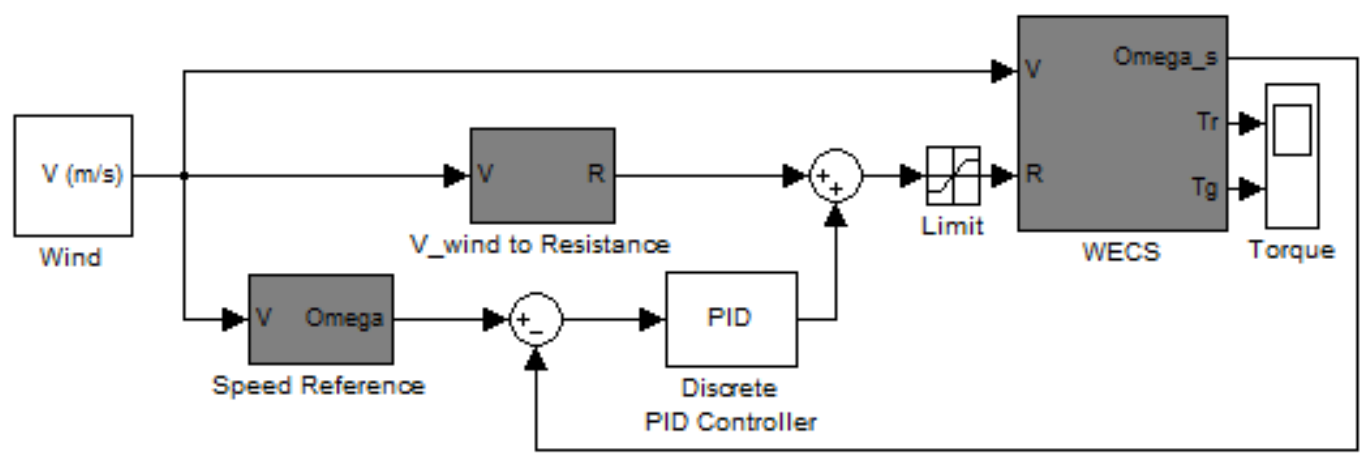

Figure 4.11 Combined MATLAB model with Discrete PID Speed Controller and Steady State Resistance Block

The combined performance measurement block is also added inside the WECS block to measure performance and to aid with the selection of gain constants.

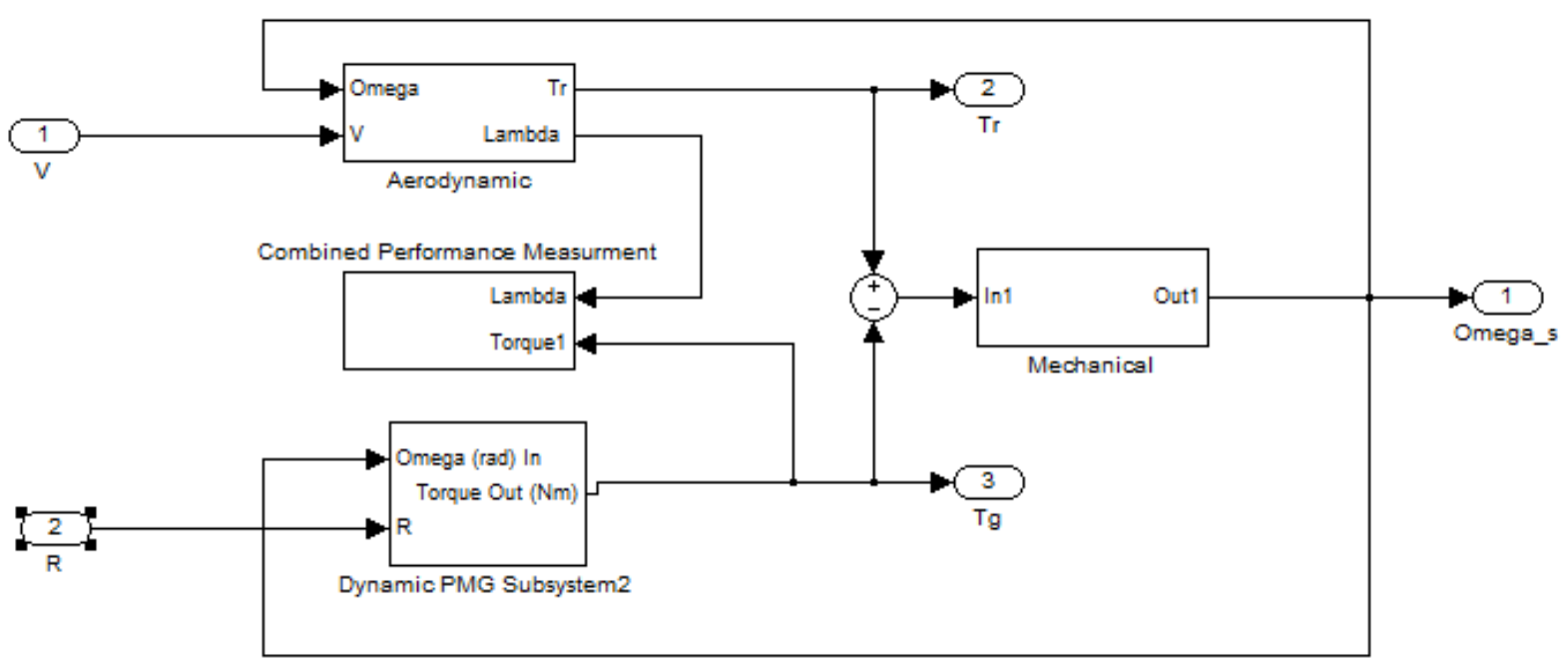

Figure 4.12 Looking inside the WECS block- Aerodynamic, mechanical, electrical, and combined performance measurement 


\subsubsection{Combined Optimization Measurement Block}

The combined optimization criterion established by equation (2.25) is used as a measure of performance and as a controller design constraint. The Simulink block diagram for the performance measurement is shown in the Figure below.

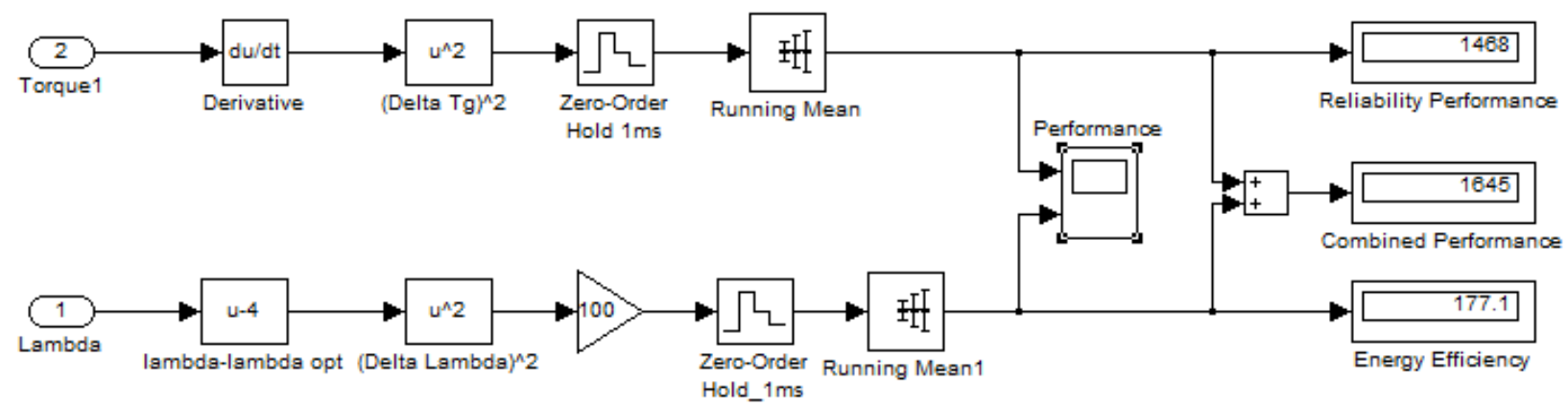

Figure 4.13 Simulink Performance Measurement Block Diagram using combined optimization criterion

The combined performance takes a look at 2 measures of performance. The measure of energy efficiency is measured by how well the WECS tracks the optimum tip speed ratio, and reliability performance is a measured in torque variations from the generator. The performance measurements are summed together to form a combined performance measurement which is represented by the Simulink display in Figure 4.13. As discussed earlier, smaller values of the combined performance measurement $(I)$ are desired.

In addition, the scaling factor $\alpha$ from equation (2.25) is set to 100 , so the numerical value of tip speed ratio and torque are of the same general magnitude. From previous simulations and from the Ginlong data sheet, the magnitude of torque is about $150(\mathrm{Nm})$ at full load and the optimum tip speed ratio is 4 . Setting $\alpha=100$ in equation (2.25) leads to a more even balance of energy efficiency and reliability performance as represented by the following equation

$$
I=E\left\{100\left[\lambda(t)-\lambda_{o p t}\right]^{2}\right\}+E\left\{\Delta \mathrm{T}_{g}^{2}(t)\right\}
$$




\subsection{Controller Design}

The initial gains were determined with the Ziegler Nichols frequency tuning method as described in appendix D. Table 4.2 below summarizes the performance of proportional, integral, and derivative gains when driven by the "partial load wind input" described in section 2.2.1.2. Reliability performance, energy efficiency and combined performance are calculated with MATLAB Simulink as shown in Figure 4.13. The "partial load input" is used for determining the controller gains because the combined optimization measurement is only useful in the partial load region. Optimal tip speed ratio tracking is only an objective for wind speeds below rated wind speed. The final gains are shown in the in the highlighted row in Table 4.2.

The general trend found during this assessment was that low gains generally lead to improved reliability but decreased energy efficiency. This is not hard to understand, because a less abrupt control signal with low gain takes longer to settle and imposes less abrupt torque changes. This is the trade off discussed in earlier chapters. Setting the integral and derivative terms to zero generally improved reliability performance. Integral gain did reduce the steady state error, but overall did not improve performance. The derivative term hurt reliability performance and did not significantly improve energy efficiency. 
Table 4.2 PID Gains and Performance measurement

\begin{tabular}{|c|c|c|c|c|c|}
\hline $\mathbf{P}$ & $\mathbf{I}$ & $\mathbf{D}$ & $\begin{array}{c}\text { Reliability } \\
\text { Performance }\end{array}$ & Energy Efficiency & $\begin{array}{c}\text { Combined } \\
\text { Performance }\end{array}$ \\
\hline 182.5 & 0 & 0 & 803700 & 86.76 & 803787 \\
\hline 146 & 62.5 & 0 & 686400 & 87.46 & 686487 \\
\hline 219 & 100 & 0.0025 & 780300 & 87.07 & 780387 \\
\hline 219 & 100 & 0.025 & 781400 & 87.07 & 781487 \\
\hline 219 & 100 & 0.25 & 775200 & 87.07 & 775287 \\
\hline 219 & 100 & 2.5 & 92820000 & 87.03 & 92820087 \\
\hline 146 & 30 & 0 & 835300 & 87.68 & 835388 \\
\hline 146 & 100 & 0 & 804600 & 87.27 & 804687 \\
\hline 100 & 0 & 0 & 652600 & 86.9 & 754388 \\
\hline 50 & 0 & 0 & 754300 & 87.8 & 579794 \\
\hline 25 & 0 & 0 & 579700 & 93.55 & 637621 \\
\hline 10 & 0 & 0 & 637500 & 121.3 & 762410 \\
\hline 10 & 5 & 0 & 762300 & 110.4 & 786813 \\
\hline 10 & 2.5 & 0 & 786700 & 112.8 & 788213 \\
\hline 10 & 2.5 & 0.001 & 788100 & 112.8 & 560606 \\
\hline 15 & 0 & 0 & 560500 & 105.8 & 661898 \\
\hline 20 & 0 & 0 & 661800 & 98.06 & 658912 \\
\hline 12.5 & 0 & 0 & 658800 & 111.9 & 775108 \\
\hline 14 & 0 & 0 & 775000 & 108 & 788604 \\
\hline 16 & 0 & 0 & 788500 & 103.8 & 823202 \\
\hline 15 & 1 & 0 & 823100 & & \\
\hline & & & & & \\
\hline
\end{tabular}

Table 4.3 Optimum Gains

\begin{tabular}{|l|l|l|l|}
\hline $\mathbf{P}$ & $\mathbf{I}$ & $\mathbf{D}$ & Ts \\
\hline 15 & 0 & 0 & 0.010 \\
\hline
\end{tabular}

\subsection{Controller Analysis}

Closed loop simulation with the steady state input compensator and discrete proportional controller is analyzed in this section. The selected gains are listed in table 4.3. The speed loop controller governs the transient operation of the WECS, and the steady state resistance input compensator provides the WECS with the proper steady state resistance. 


\subsubsection{Steady State Resistance Input Compensator Analysis}

The control action of the steady state resistance input compensator can be seen in Figure 4.14. This Figure shows the response of the WECS when the speed loop controller is removed. The WECS starts at zero speed and accelerates to the desired rotor speed of 72[rpm] (based on cut in wind speed = $3.5 \mathrm{~m} / \mathrm{s}$ ) and the WECS takes over 3 minutes to reach steady state. The output is stable but it takes a long time for the WECS to reach steady state.

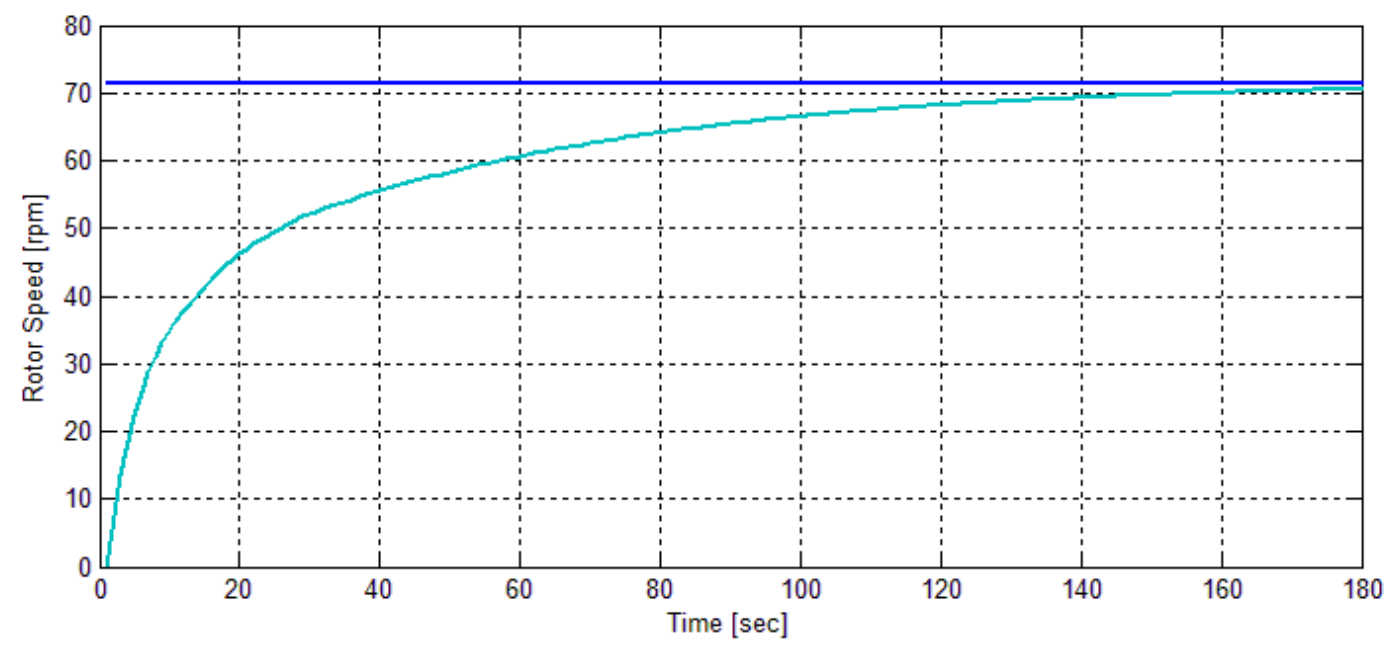

Figure 4.14 System response from steady state resistance input compensator only

\subsubsection{Combined Control System Analysis}

When the speed loop controller is included with the proportional gain (listed in table 4.2) the transient system response is greatly improved. Figure 4.15 shows the actual rotor speed in light-blue, the control reference signal in yellow, and the plus-minus $2 \%$ reference signal in purple and red. In Figure 4.15 it takes approximately $15(\mathrm{sec})$ for the WECS to accelerates to $72[\mathrm{rpm}]$ and at higher wind speeds the WECS is able to closely track the desired rotor speed. At time $t=40(\mathrm{sec})$ the rotor decelerates from $204[\mathrm{rpm}]$ to $72[\mathrm{rpm}]$ in approximately $5(\mathrm{sec})$ and reaches steady state. At $\mathrm{t}=50$ (sec) the wind speed jumps up to $10(\mathrm{~m} / \mathrm{s})$, and the WECS accelerates to steady state in about $3(\mathrm{sec})$. 


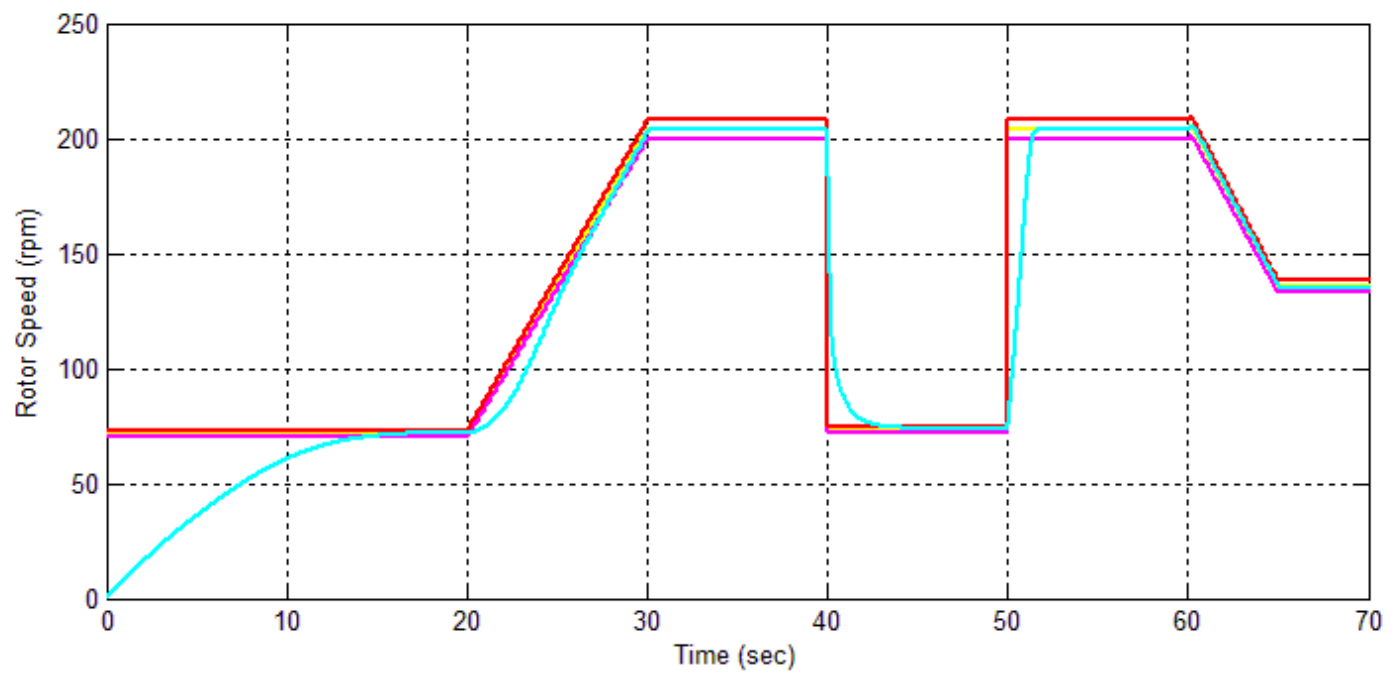

Figure 4.15 Rotor Speed vs. Time for with full load wind input - proposed gains

The next three graphs show the resistance control signal, the error signal, and the wind speed input. Figure 4.16 shows the resistance signal which is fed into the generator. The resistance signal stabilizes and stops changing between time $t=15(\mathrm{sec})$ and time $t=20(\mathrm{sec})$ which corresponds to the steady output speed of $72[\mathrm{rpm}]$ seen at the same time in Figure 4.15.

Sudden wind speed changes cause the most trouble for the controller and WECS. When the wind speed decreases from $10(\mathrm{~m} / \mathrm{s})$ to $3.5(\mathrm{~m} / \mathrm{s})$ at $\mathrm{t}=40(\mathrm{sec})$, the speed error suddenly drops to (13.6[rad/s]) because the wind changes faster than the rotor speed. A negative speed error means the WECS is going too fast so the speed loop controller quickly lowers the resistance at $t=40(\mathrm{sec})$ to the minimum resistance value of 5.5 (ohms). However, when the speed error approaches zero a few seconds later (see Figure 4.17) the resistance increases because there is less energy from the wind and the steady state resistance is higher. This is not a desirable control action because a large electromechanical torque is produced during the quick deceleration. 


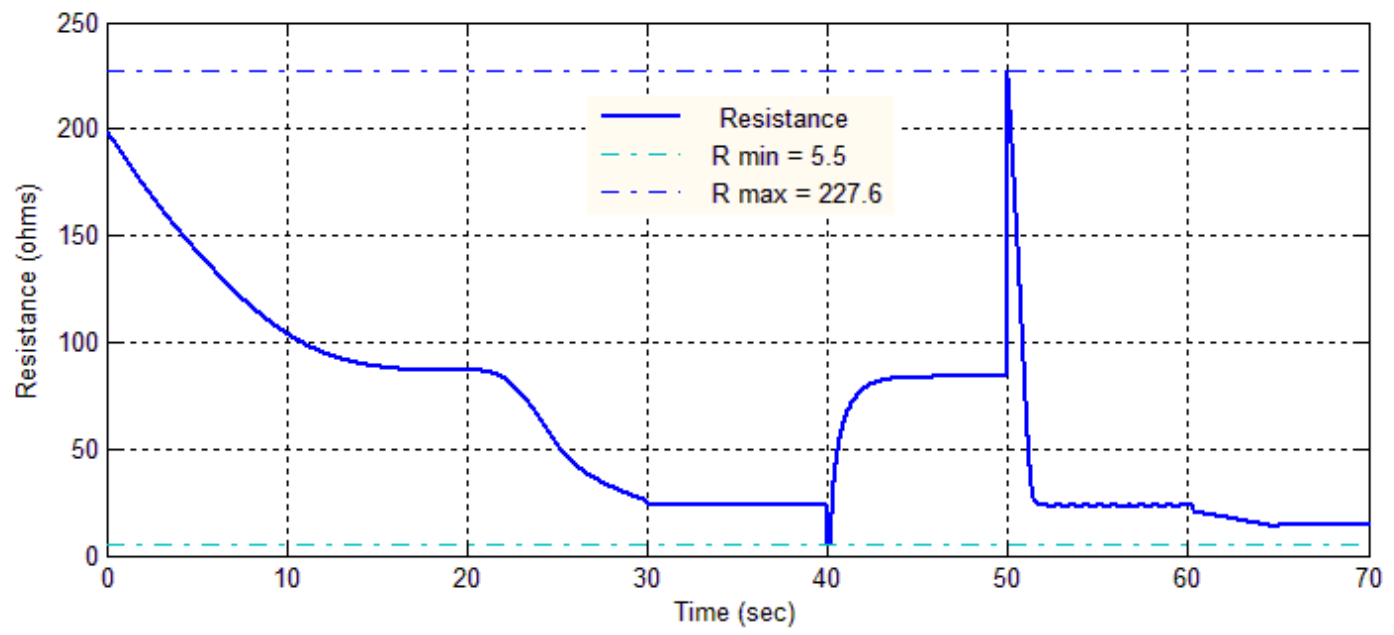

Figure 4.16 Resistance control signal connected to the generator

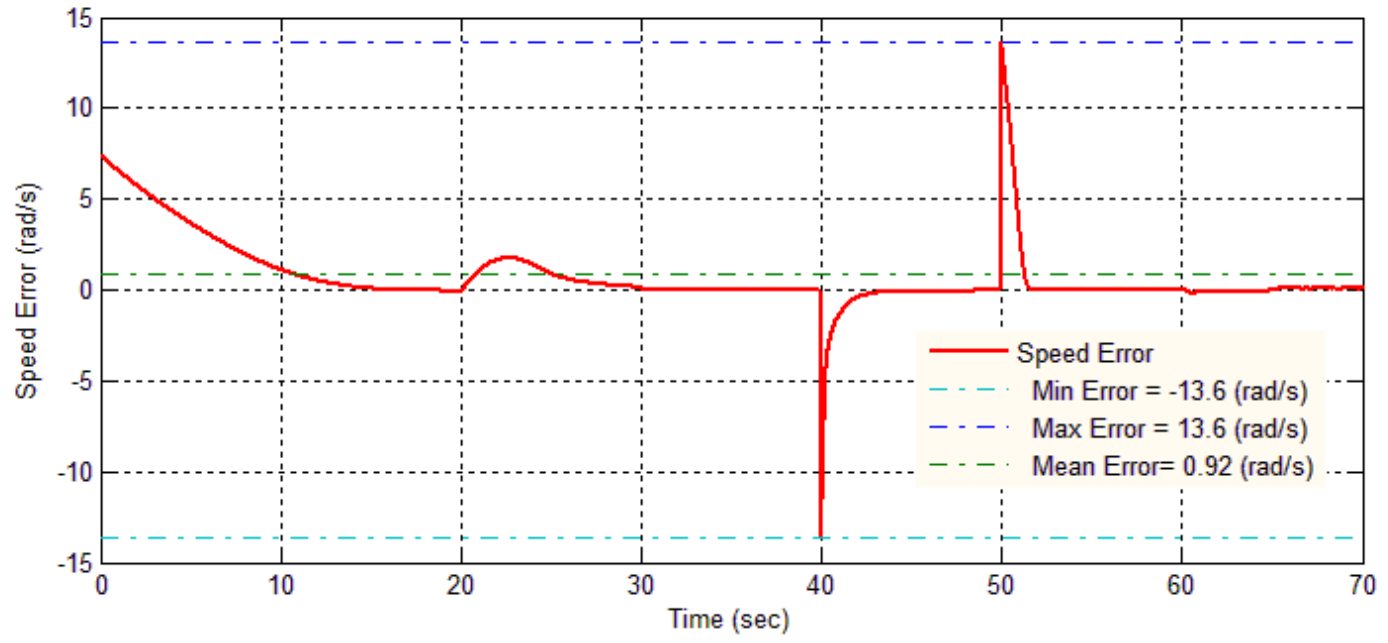

Figure 4.17 Speed error signal and PID input 


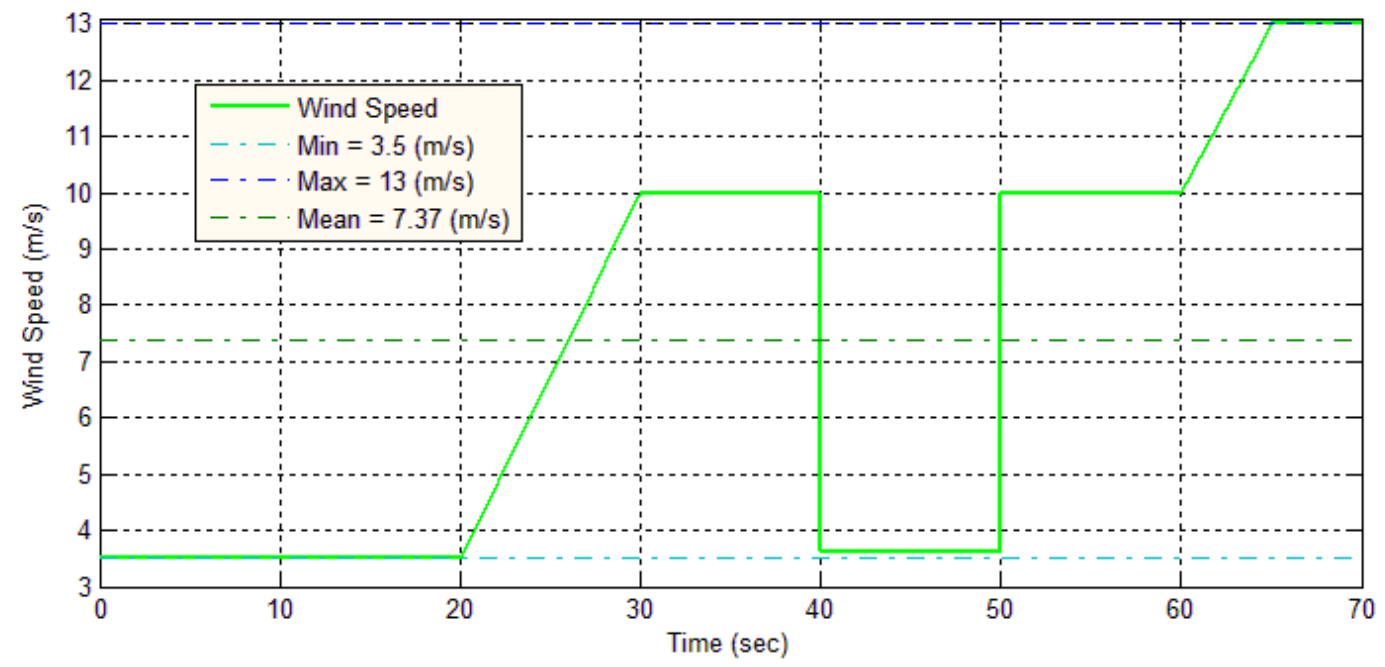

Figure 4.18 Wind Speed input vs. time

Figures 4.19 and 4.20 show the generator torque and rotor torque. The rotor torque is smooth because it is fed directly from the aerodynamic block. The generator torque is the electromechanical torque produced by the generator. Most of the torque oscillations come from the rectifier which is discussed in section 3.3 but a large and undesirable torque spike occurs from the controller at time $\mathrm{t}=40$ (sec) when the wind speed suddenly drops.

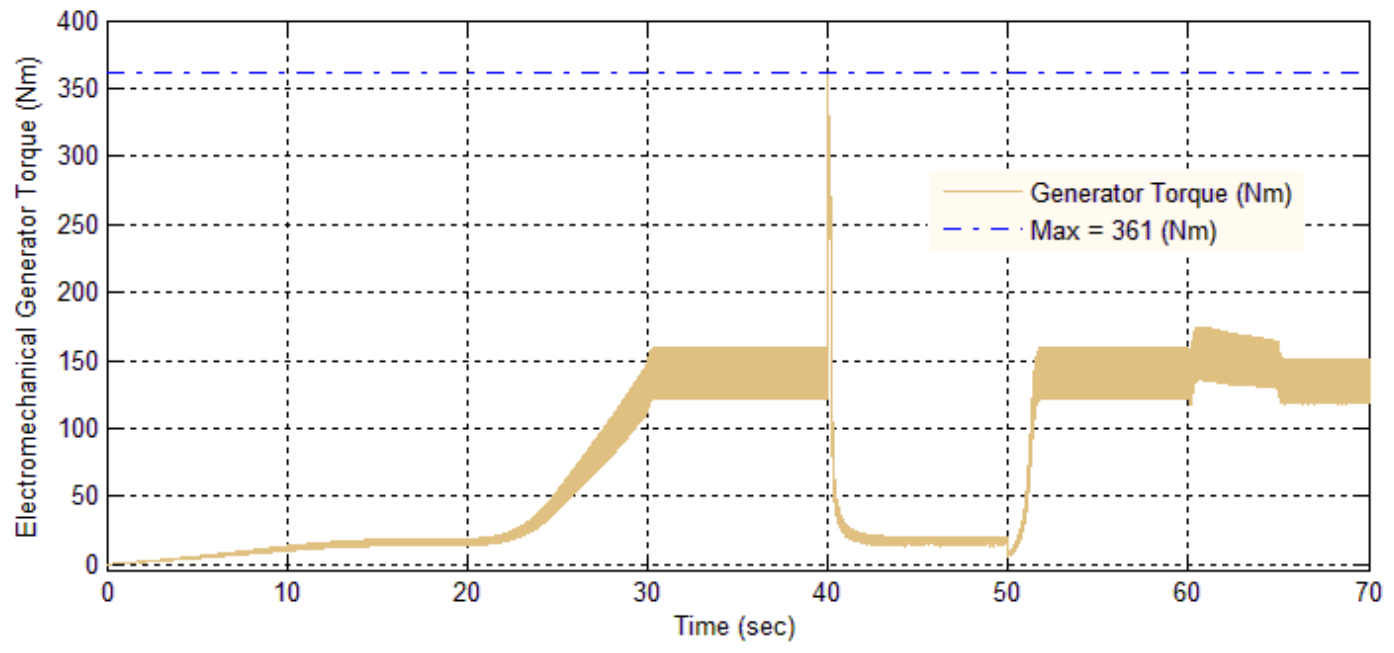

Figure 4.19 Generator Electromechanical Torque 


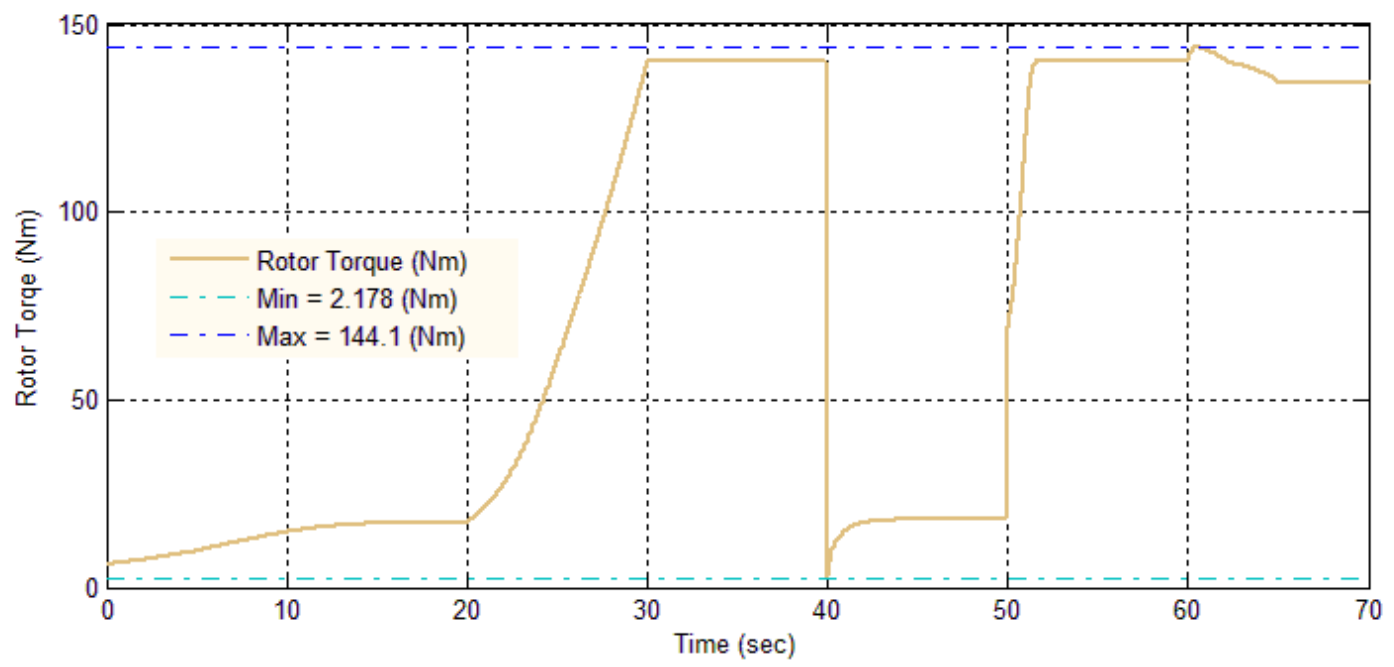

Figure 4.20 Rotor Torque

Figure 4.21 and Figure 4.22 show the electrical consequences of the torque spike. At time $t=30 \mathrm{~s}$ a fast voltage transient occurs, and the current increases to a peak value of 27.63(A), which is about 3 times the steady state limit but it decays in about 0.35 s. A quick current spike of this magnitude does not exceed the thresholds established in Appendix F - Figure 0.9, so it is not a major concern.

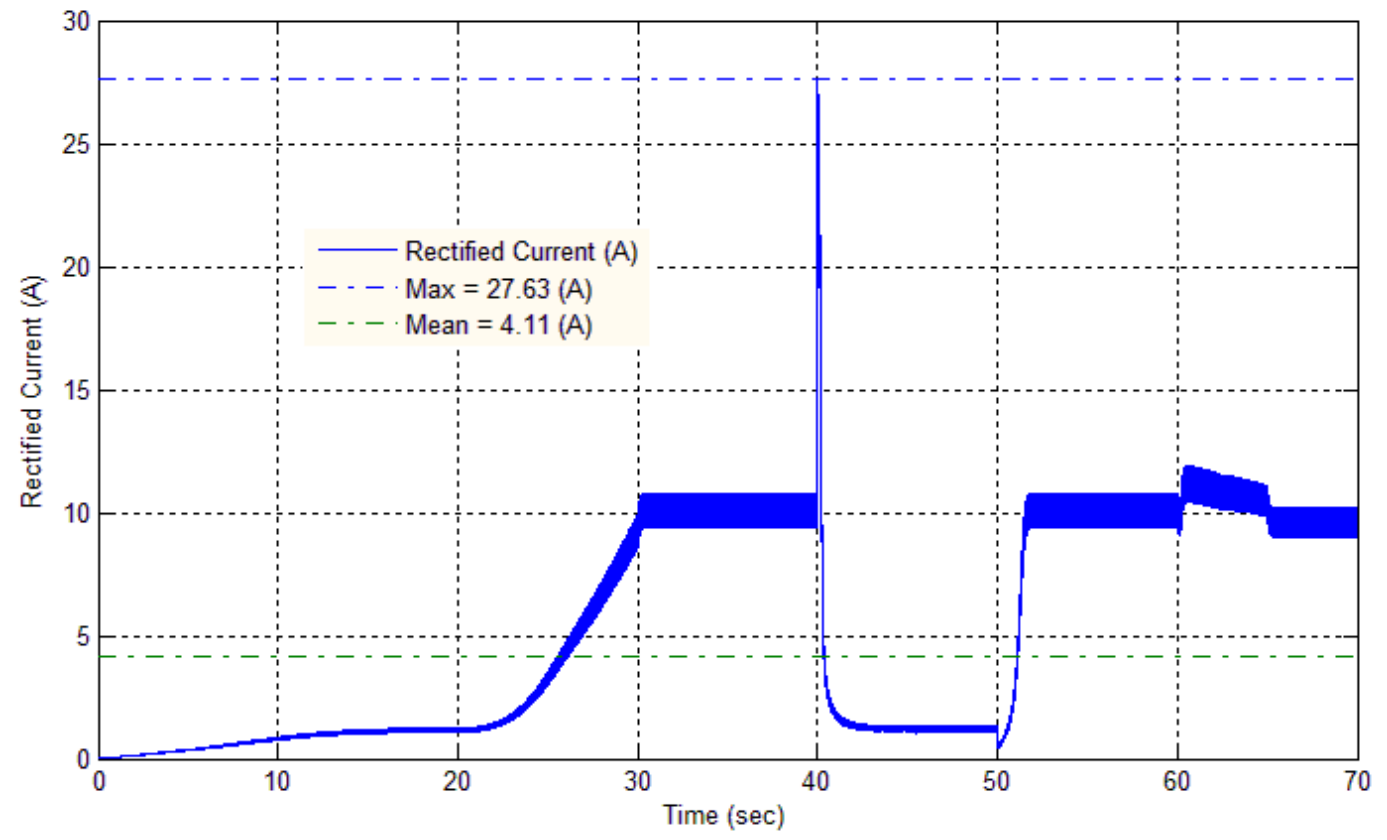

Figure 4.21 Rectified DC current vs. time (5.5ohm limit) 


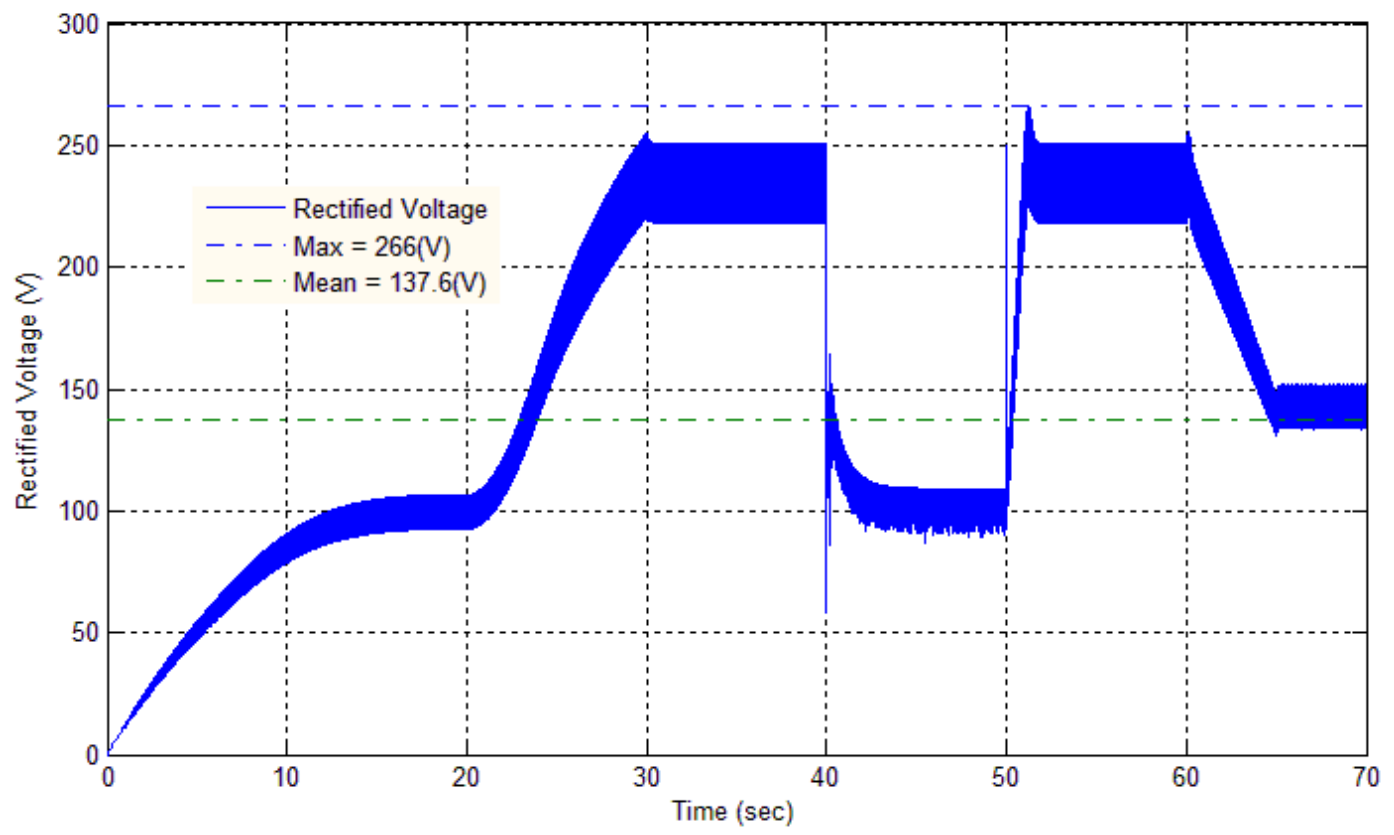

Figure 4.22 Rectified Voltage vs. time (5.50hm limit)

There are a few ways to address the torque spike problem. One way to reduce the torque spike is to raise the minimum resistance limit from 5.5[ohms] to 10 [ohms]. The affect of raising the minimum resistance limit is shown in Figure 4.23 and Figure 4.24. The magnitude of the torque spike is reduced and the current spike also decreases. A $10[0 \mathrm{hms}]$ limit is still lower than the lowest steady state resistance value (see Figure 4.25) so there will be no change to the operational range of the WECS. 


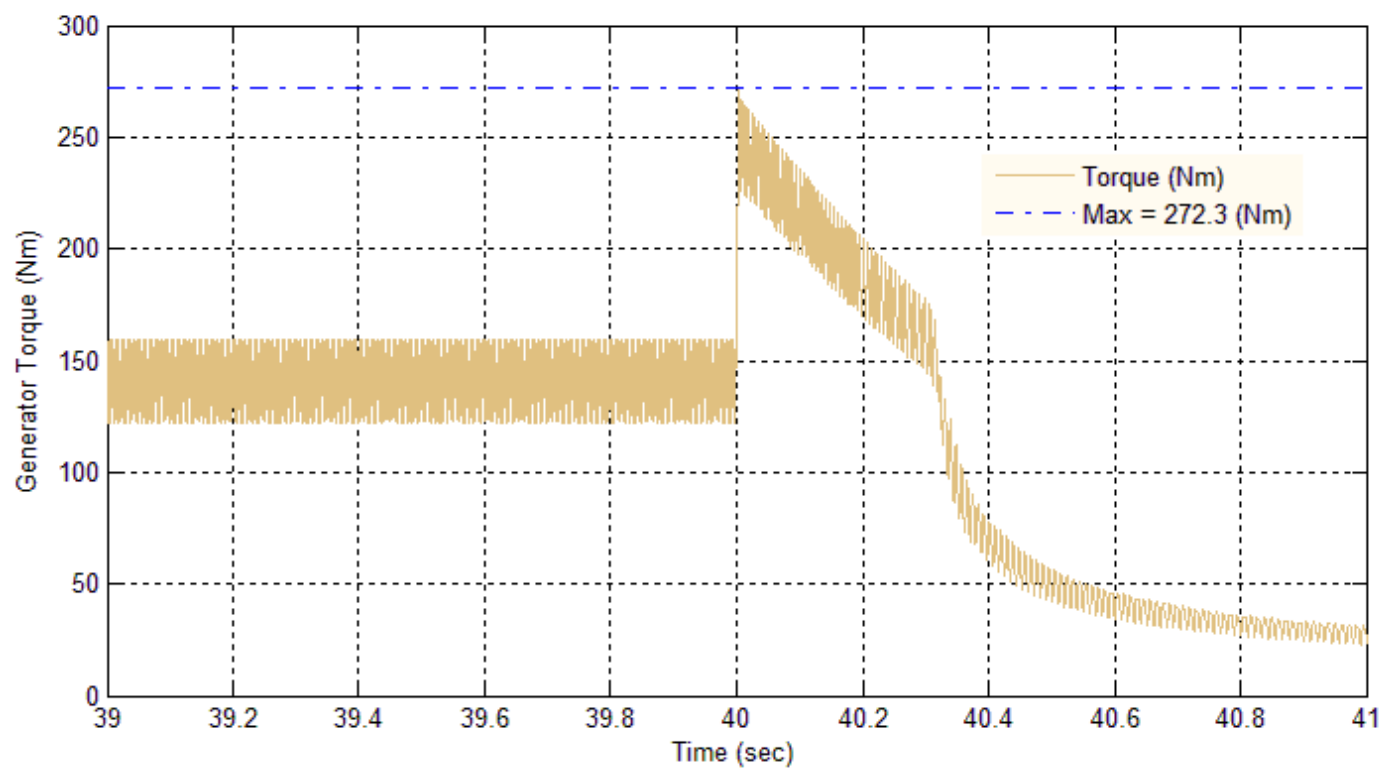

Figure 4.23 Generator Torque spike with minimum resistance limit of $100 \mathrm{hms}$

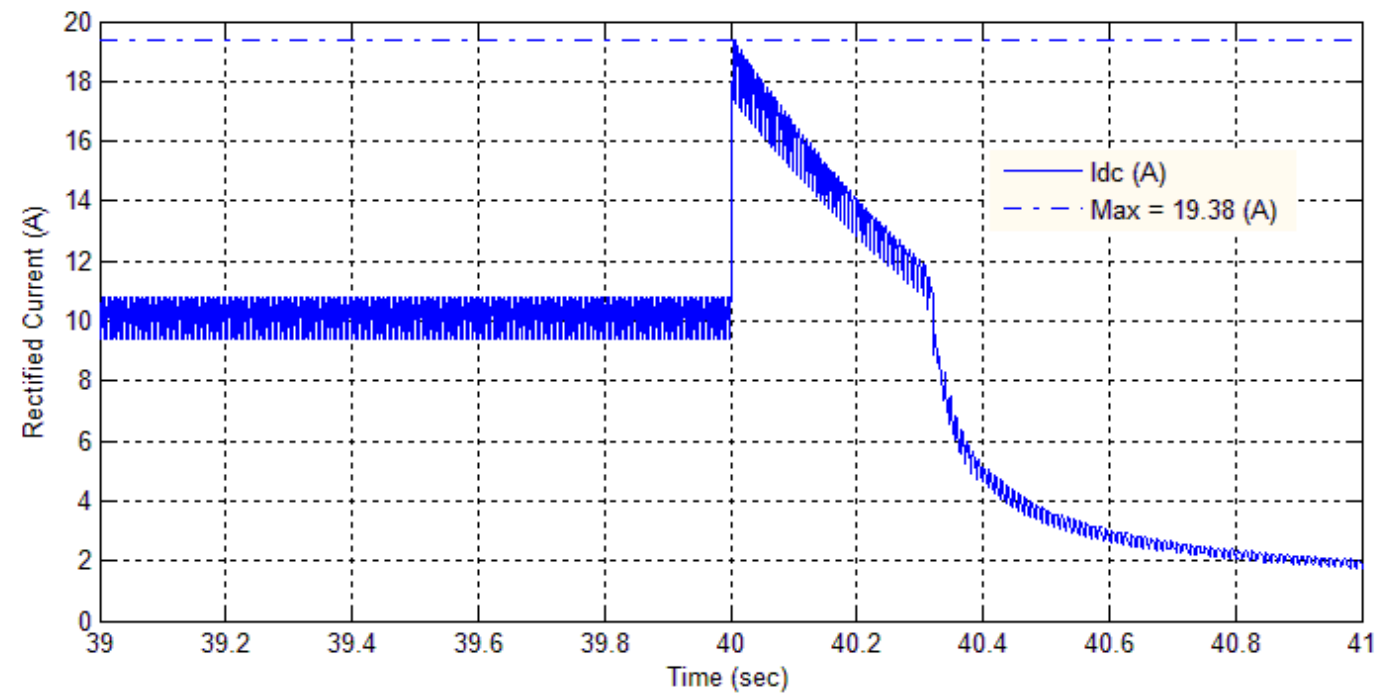

Figure 4.24 Idc with low resistance limit of $10 \mathrm{ohms}$ 


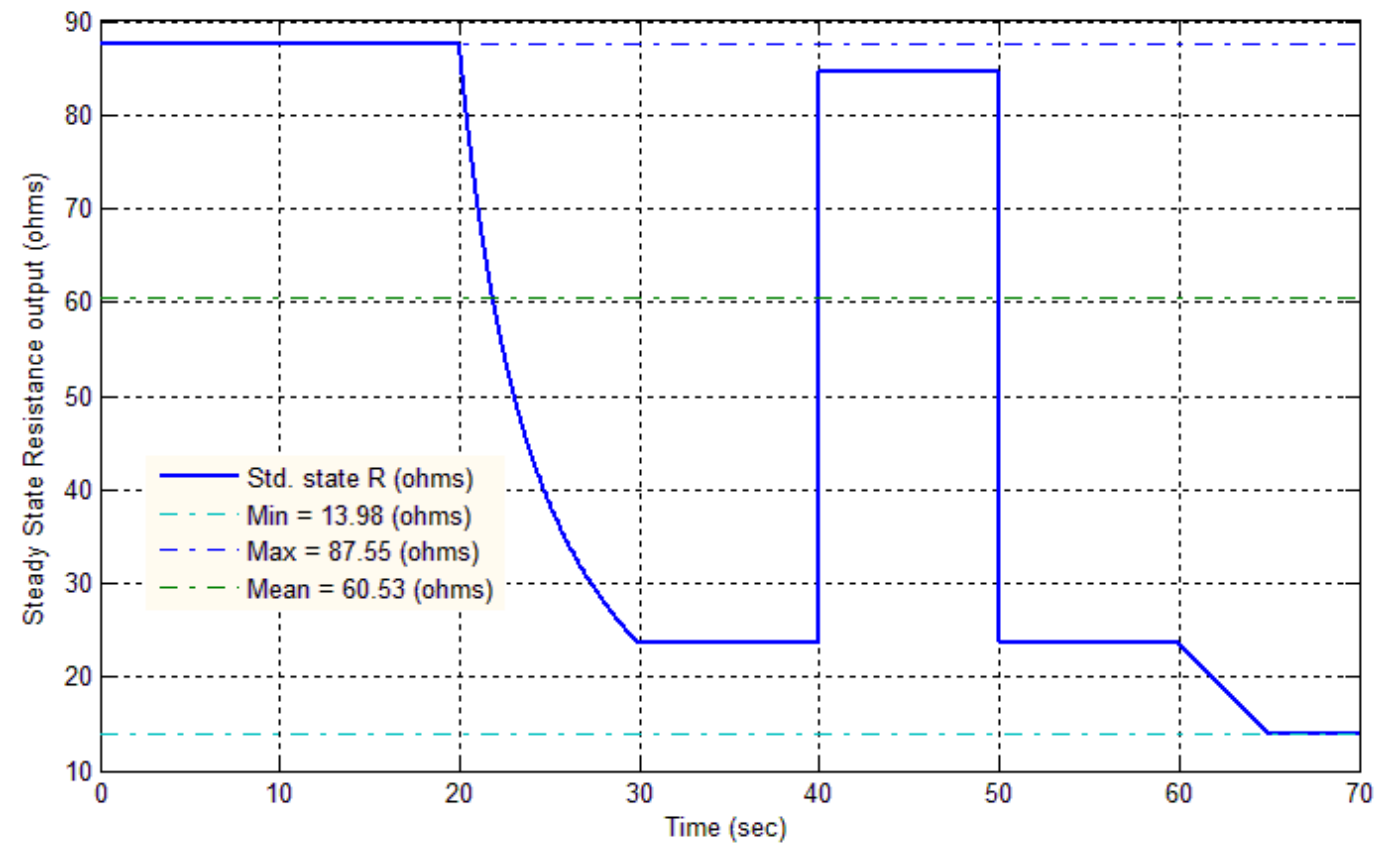

Figure 4.25 Steady State resistance output

Another possible way to reduce the torque spike is to use logic to selectively turn on or off the PID controller when the wind speed suddenly drops. In Figure 4.19 the torque spike only occurs when the wind speed drops, so the logic could include a rate of change detector that turns off the PID during predetermined negative wind speed acceleration. Figure 4.26 shows how the WECS responds to a change in wind speed from $10(\mathrm{~m} / \mathrm{s})$ to $3.5(\mathrm{~m} / \mathrm{s})$ when the PID controller is removed. It takes about $8(\mathrm{sec})$ for the WECS to reach steady state when the PID is removed, and it takes about 3(sec) for the WECS to reach steady state with the PID included. 


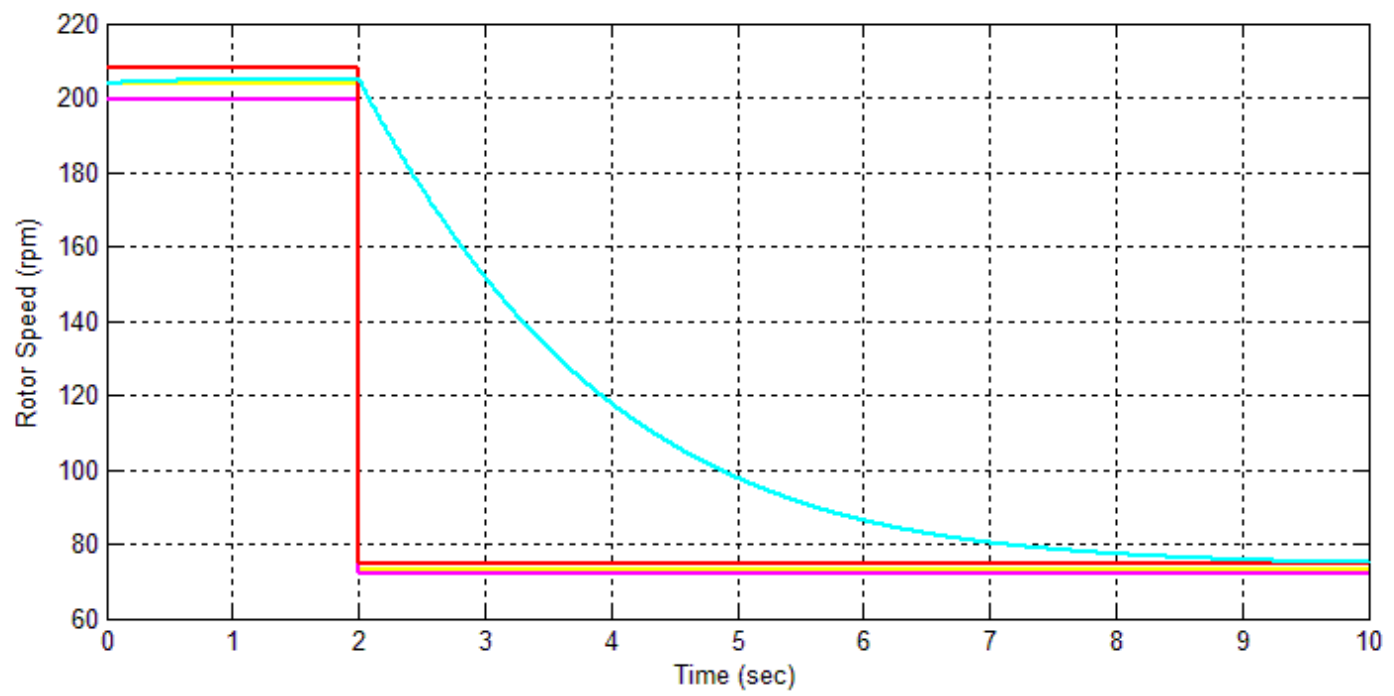

Figure 4.26 Rotor Speed vs. Time for wind speed drop - No PID

The most significant benefit of not using the PID during sudden wind speed drops is seen in Figure 4.27. The generator torque spike is eliminated when the WECS is only controlled by the steady state resistance compensator.

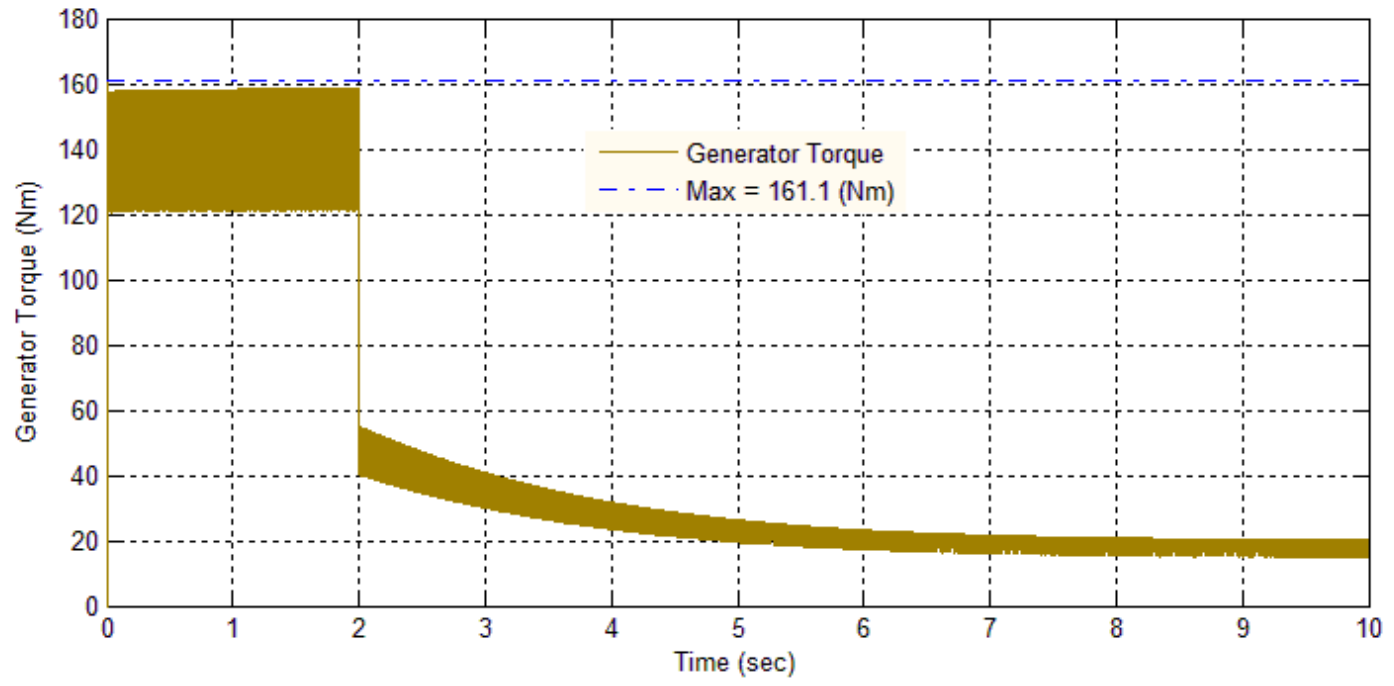

Figure 4.27 Generator torque during wind speed drop - No PID 


\subsubsection{Controller Stability}

Stability means that the output of the system must not grow without bound due to a bounded input, initial condition, or unwanted disturbance. For LTI systems there are classical methods to analyze stability such as the root locus method, but for non-linear time-variant systems the task is much more challenging. This thesis does not address any formal tests for non-linear system stability but the simulated control system shows no obvious signs of being unstable. The Ziegler Nichols method was used to experimentally find the ultimate gain $K_{u}$ at different wind speeds (see appendix D) which is the gain that causes the system to reach marginal stability. The trend shows that $K_{u}$ decreases as wind speed increases, and the lowest value of $K_{u \min }=245$, was found at a wind speed of $13.9(\mathrm{~m} / \mathrm{s})$. The proportional gain proposed for the PID controller is $K_{p}=15$ which is significantly smaller than $K_{u}$ min and should not cause stability issues. 


\section{CONCLUSIONS}

\subsection{Summary and Conclusions}

This project has covered a broad range of topics and has focused on the most important aspects of a control system to ensure that the proposed design is safe and economical. The most relevant WECS control strategies were studied before proposing a final design to fit a unique Cal Poly built system. The final design choice is based on a combined optimization of conflicting goals; to maximize energy efficiency and mitigate mechanical loads. In addition, the safe operating limits of the PMG were investigated, as well as potentially harmful electrical disturbances.

As discussed previously, two different sets of optimal operating points were defined. One set covers a narrow range of operational wind speeds but is capable of capturing power at full rated conditions, while the other set encloses a wider range of wind speeds but can never operate at fully rated conditions. The most favorable set depends on the distribution of the wind resource, which is specific to site location and conditions. Economic factors are ultimately behind all control system goals and strategies.

The PID speed loop gains proposed in this thesis can be generalized as being loosely tuned to minimize torque variations imposed by the generator. The conservative choice of low gains values is also justified due to the uncertainty around the true measure of reliability performance. The measure of reliability performance defined in this thesis is highly simplified compared to the true dependability of a machine which can only be measured at the end of its useful life and inevitably depends on a number of variables.

\subsection{Suggested Future Work}

1. Verify dynamic generator parameters of the Ginlong PMG-3500

2. Apply wind turbulence model to further investigate WECS dynamics and controller action

3. Measure actual voltage transients from full bridge rectifier

4. Measure actual torque oscillations on WECS from bridge rectifier

5. Investigate actual safe operating threshold of PMG

6. Simulate other controller designs and compare results

7. Build an actual controller and test with real time digital simulation

8. Apply an actual controller to the Cal Poly WECS and connect a useful load

9. Design and build a SCADA system for the Cal Poly WECS 


\subsection{Possible Solutions to Improve the Operational Range of the Fixed Pitch Cal Poly WECS}

The operational range of the fixed pitch Cal Poly WECS is severely limited by the $11 \mathrm{~A}$ current limit. There are a few ways to deal with this problem, but none of them are "quick fixes". One possible solution is to use a larger generator such as the Ginlong PMG-5000. A generator with a larger current rating could also solve the problem, or a generator with the same power rating that produces higher voltage at lower rotational speeds. For example, an electrically excited synchronous generator has the ability to adjust its output voltage independent of load current. It is however unlikely that a more suitable permanent magnet generator could be obtained without specifying a custom design because the Ginlong PMG-3500 is already specifically designed for small WECS applications.

Another possible idea to improve the operational range of the Cal Poly WECS is to add a gear system between the blades and the generator to increase the rotor speed of the PMG-3500. A higher rotor speed will produce a higher voltage and therefore less current, thus improving the useful operation range of the WECS. However, WECS with multi-pole generators do not typically use gear boxes because generators are already designed to operate at low rotor speeds. Adding a gear box to the Cal Poly WECS would likely require a significant design change to the mechanical system.

A better solution could stem from a new blade design with a larger optimum tip speed ratio. If the blades are designed with a higher optimum tip speed ratio, then the available power curves of Figure 4.1 will be shifted to the right with a higher optimum rotor speed. A higher rotor speed will produce a higher voltage and therefore less current, thus improving the useful operation range of the WECS. Improving the operational range may also increase the overall energy efficiency and make the system more economically viable. 


\section{APPENDICES}

\section{A. Non-Linear Control Strategies}

Non-linear control strategies are built around a non-linear WECS model.

\section{A.1 Maximum Power Point Tracking (MPPT)}

The goal of MPPT is to operate the WECS around the maximum power point within safe limits, by using information from the static power output and rated limits [1]. Most MPPT are used in applications when the power characteristic of the rotor is unknown, but the rated power, rated rotational speed, and inertia are known. The control typically takes inputs from the rotor speed and the active power, and the output is generator torque. To implement the MPPT algorithm, the controller determines the power derivative with respect to the rotor speed $\frac{d P}{d \Omega}$ and gradually adjusts the operating point towards the optimum point where the power derivative is equal to zero. A general block diagram for the MPPT can be seen in Figure 0.1.

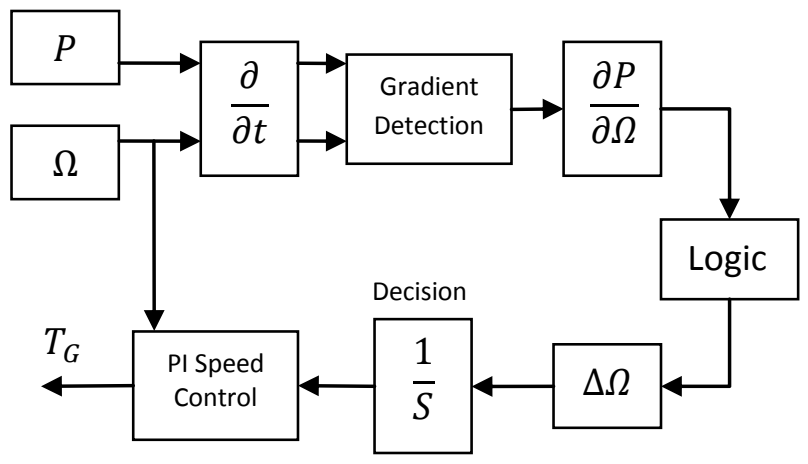

Figure 0.1 Max Power Point Tracking Block Diagram

MPPT are robust subject to WECS parameter uncertainties, which means they do not require much system information. A disadvantage of the MPPT strategy is that the actuating signal from the controller does not take a direct path to the optimum operation point. 


\section{A.2 Fuzzy-Logic Control}

Fuzzy logic control also aims at maximizing the power capture from the wind as an extension of MPPT. The goal of the control logic is to keep the operating point around small values of $\frac{d P}{d \Omega}$. Fuzzy logic controllers are more flexible than MPPT because the dynamic response is improved, but it has the disadvantage of being highly dependent on knowledge about the wind site features and turbine [1]. Figure 0.2 shows a block diagram for the fuzzy logic controller.

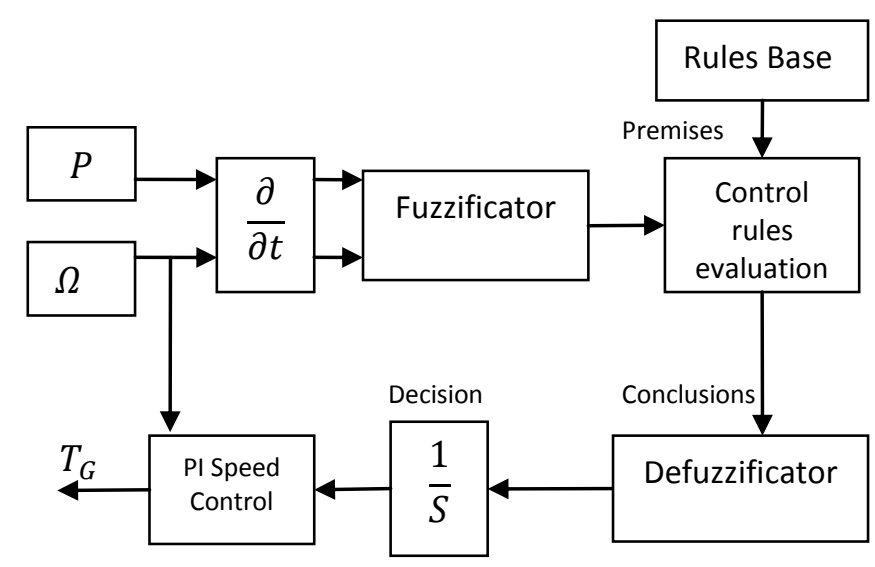

Figure 0.2 Fuzzy Logic Block Diagram

\section{A.3 Sliding-Mode Control (SMC)}

Sliding-Mode Control is a robust control method for non-linear systems that is composed of variable structures which switch at high frequency between several control laws [1]. The output is typically a pulsed signal for a Voltage Source Converter (VSC) which regulates the output power. The overall goal of the SMC control is to maximize power and minimize electromechanical torque variations. Sliding mode control has the advantage that it is intrinsically robust and requires little information about the WECS, as well as being insensitive to parametric variations, but the control algorithm is computationally complex. Another primary concern is the VSC switching frequency which could excite un-modeled mechanical dynamics and create destructive oscillations on the rotor. VSC switching must be designed at a high frequency to prevent destructive oscillations. 


\section{B. Linear Control Strategies}

The behavior of linear systems is much more intuitive and more generally understood than non-linear systems. Linear design methods are more popular because there is a large number of tools for the analysis and design of linear systems. However, these linear control strategies require an inherently non-linear model to be linearized which can lead to many difficulties and inaccuracies.

\section{B.1 Steady State Optimization}

The strategy of the steady state optimization controller is to maintain the optimum tip speed ratio by tracking the rotor speed and wind speed. This method is similar to the OOP controller and is typically based on the classical PID controller. The steady state optimization controller is different from the OOP controller, because the wind turbine model is linearized around the wind/torque expression. The linearization technique leads to a less accurate model, but its advantage is realized during the design stage. The design of a steady state optimization controller uses the methods of linear controls theory which allows a designer to use a pole placement procedure for the closed loop system [17]. The steady state optimization controller is only effective during slow wind speed variations and is limited by acceptable mechanical loads.

The PID controller is widely used in industry because of its relatively simple design and intrinsic robustness properties for plants with smooth models [1]. There are two types of PID control loops which are commonly implemented for the steady state optimization controller.

1. The Torque control loop utilizes measurements from the rotational speed only to produce a generator torque reference which is derived from the available torque equation (2.1)

$$
T_{G}=K \Omega^{2}
$$

Where $K$ is defined by

$$
K=\frac{1}{2} \frac{C_{p}\left(\lambda_{o p t}\right)}{\lambda_{o p t}^{3}} \rho \pi R^{5}
$$

This type of control loop is commonly referred to as the $K \Omega^{2}$ law. In addition, the torque variations are expected to be small in amplitude and slow, which is expected to result in poor energy efficiency. Poor energy efficiency is expected because the wind speed is not measured, so the optimum operating point is unknown.

2. The goal of the speed control loop is to minimize the error of the speed reference. The speed control loop usually has superior energy efficiency because the rotational speed and wind speed are used to determine the reference rotational speed in real time. The Figure below is an example of a possible speed control loop in the partial load region. 


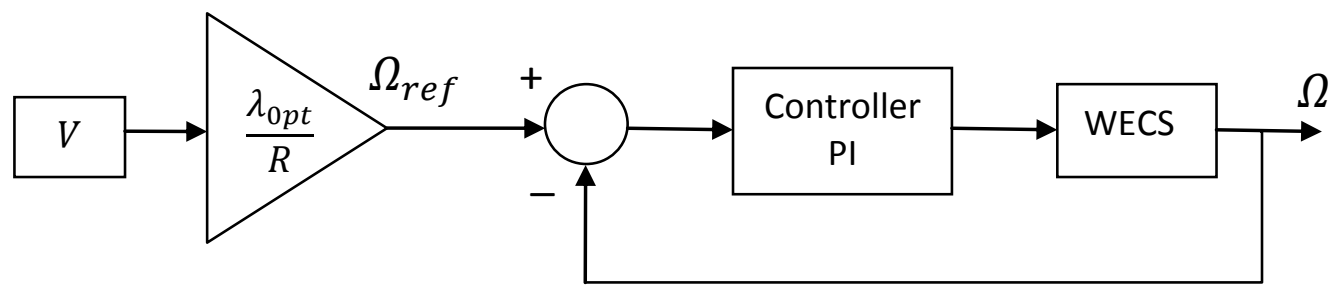

Figure 0.3 PI Speed control loop in partial load region

\section{B.2 Frequency Separation Principle}

The frequency separation control strategy is an approach that is designed to directly satisfy the mixed criteria goal of energy efficiency and performance reliability. [10] states that there are two spectral ranges of wind speed dynamics associated with WECS. The spectral ranges are classified as low frequency slow wind speed variations and high frequency turbulent wind speed variations. The proposed control system is composed of a two loop structure which acts on separate spectrums of the wind speed (see Figure 0.4). The low frequency loop has a goal of optimizing energy efficiency and determines the average operation point of the system. The optimization of this system is physically realizable because low frequency wind spectrum does not contribute to large torque variations or mechanical fatigue. In contrast, the high frequency wind spectrum can cause significant mechanical fatigue, so the goal is to minimize torque variations.

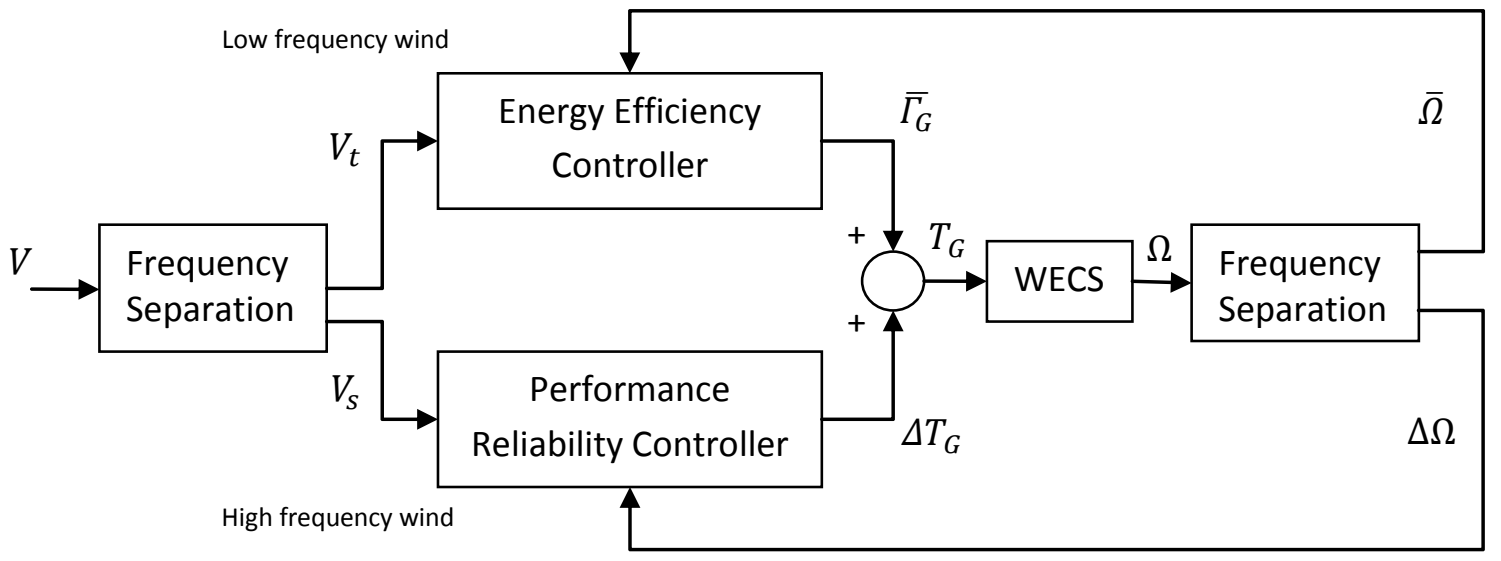

Figure 0.4 Frequency Separation Block Diagram

Each loop of the frequency separated controller sums together at the output to achieve a balance of energy efficiency and reliability performance. By this method, the output can be adjusted individually to achieve combined optimization as described by equation (2.25). However, the control algorithm is difficult to implement because of computational complexity. The optimal solution has been found to ultimately depend on how sharply the two wind spectrums can be separated [1]. 


\section{B.3 On-Off Controller}

The on-off controller uses the basic principal of the steady state controller by moving the steady state operating point towards the optimal tip speed ratio. The on off controller is different from the steady state controller because it also uses the high frequency component of the wind speed to produce self oscillations which stabilize the system around the steady state operating point. The On-off controller is robust to the parametric uncertainties that are present in most WECS. The first action of the controller is to take the difference between the optimal tip speed ratio and the actual tip speed ratio.

$$
\sigma(t)=\lambda_{\text {opt }}-\overline{\lambda(t)}
$$

The difference is then measured by the sample and hold and then the sign of the difference is determined. The sign(+1 or -1$)$ is multiplied by the gain $\beta$ which results in the high frequency component $u_{N}$.

$$
u_{N}=\beta \operatorname{sgn}(\sigma(t))
$$

The inner loop of the control system starts off by sampling the wind speed through a low-pass filter to obtain the low frequency component of the wind $V_{S} . V_{S}$ is then squared and multiplied with the gain $C$ to obtain the smooth component $u_{e q}$.

$$
u_{e q}=0.5 \pi \rho R^{3} v_{s}^{2} \frac{C_{p}\left(\lambda_{o p t}\right)}{i \lambda_{\text {opt }}}=C v_{s}^{2}
$$

Finally the summing junction combines the high and low frequency component to obtain the torque reference $u$.

$$
u=u_{e q}+u_{N}
$$

In addition, the time constant of the electro mechanical system (EMS) cannot be neglected before the actual torque is feed into the WECS.

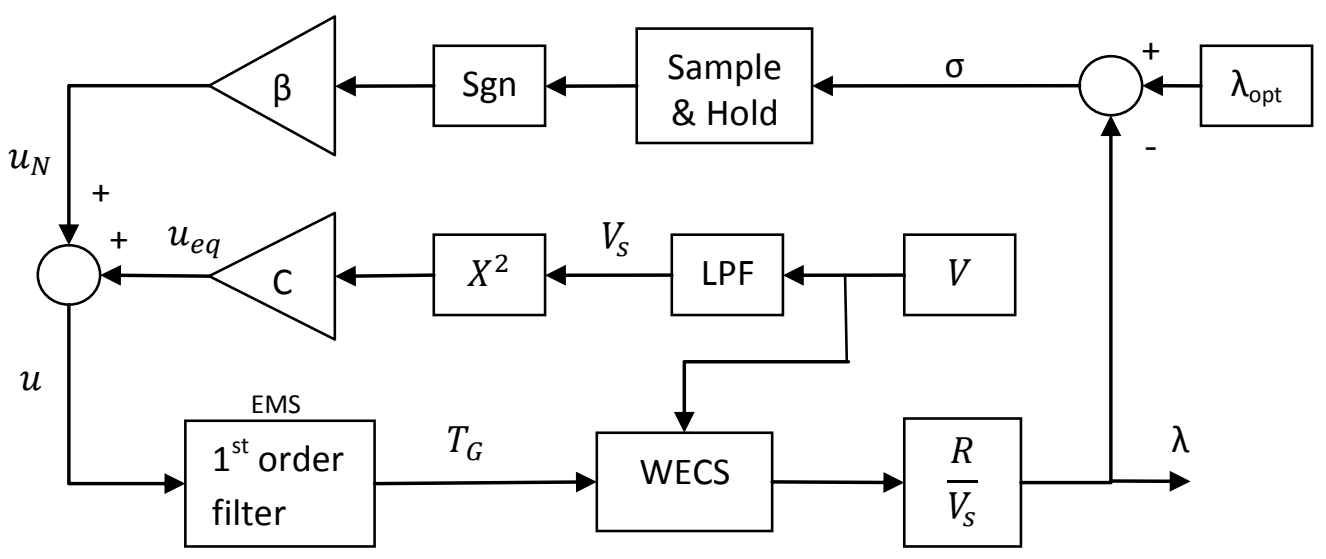

Figure 0.5 On-Off Control Block Diagram 


\section{B.4 Gain Scheduling for overall operation}

A Gain scheduling controller is under the family of linear time-invariant controllers (LTI), and is a widely used approach to control non-linear systems with the tools of linear control theory. Basically the control algorithm changes as the system tracks the locus of points which describe the optimum control strategy. Gain scheduling techniques vary in complexity. Simple algorithms switch between controllers at a selected threshold, while more complex algorithms use interpolation strategies [21]. Gain scheduling is popular because of its stability properties and because of possible simplifications associated with the design step. [8] demonstrates a method to design a gain scheduling controller using linear parameter varying systems (LPV).

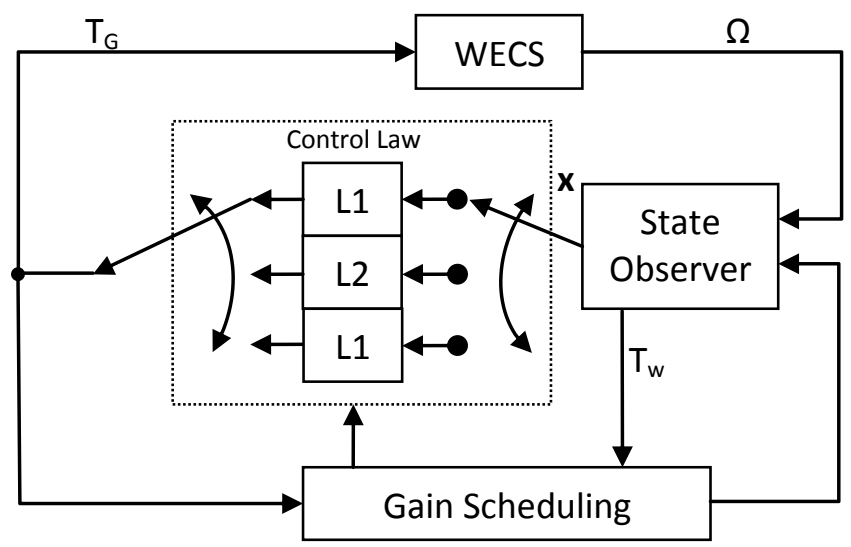

Figure 0.6 Typical Gain Scheduling Controller for overall operation

To better understand the gain scheduler, it is useful to look at the classical design process for the gain scheduled controller as presented by [8].

1. Select the locus of operating points representing the optimum WECS operation.

2. For each operating point, an LTI model is derived from the non-linear system. The family of LTI models is parameterized by the scheduling variables.

3. An LTI controller is then designed for each LTI model using techniques from linear control theory to ensure stability and performance.

4. Lastly, the gain scheduling operation is organized to switch between controllers based on scheduling variables.

The last step of the gain scheduling operation is of critical importance for multivariable high order controllers. The challenge involves ensuring stability over the entire operation locus, and that is where the use of LPV systems helps improve the classical gain scheduling design procedure. LPV models are described by the following equations:

$$
\begin{aligned}
& \dot{x}(t)=A(\theta(t)) x(t)+B(\theta(t)) w(t) \\
& z(t)=C(\theta(t)) x(t)+D(\theta(t)) w(t)
\end{aligned}
$$


Where $A(\cdot), B(\cdot), C(\cdot), D(\cdot)$ are known continuous functions of a vector $\theta(t)$, and $\theta(t)$ included time varying parameters within a bounded set.

In the context of gain scheduling controllers, the LPV model is typically found from step 1 of the gain scheduling design procedure. The variable $\theta$ becomes the parameterized scheduling variable and therefore the challenging fourth step of the classical gain scheduling design procedure is eliminated. The design procedure then follows a process similar to $\mathcal{H}_{\infty}$ synthesis where the design task is formulated as a convex optimization problem with linear matrix inequalities (LMIs).

\section{B.5 Adjusting ORC in Partial Load Region for Wind Turbulence}

As defined in section 2.2, the ORC in the partial load region describes the operating points when tracking $\lambda_{\text {opt }}$. When steady wind speeds are driving the turbine, maintaining the optimal tip speed ratio will produce the greatest energy efficiency, but when turbulent winds are considered it can be advantageous to adjust the ORC away from the optimal tip speed ratio. Turbulence or wind speed variations can cause non-symmetrical losses of energy efficiency depending on the shape of $C_{p} v s . \lambda$ curve [8]. This can be realized when looking at Figure $2.2 \mathrm{Cp}$-Power Coefficient vs. $\lambda$ for the Cal Poly WECS. The slope to the left of $C_{p M a x}$ is much steeper than the slope to the right, which means that wind variations with equal magnitude around $\lambda_{\text {opt }}$ will not cause equal measures of energy loss.

It has been determined that adjusting the ORC slightly to the right of $C_{p M a x}$ between approximately $99 \%$ to $95 \%$ can improve the overall energy efficiency of the WECS [1]. The exact determination depends on the turbulent nature of the wind, but this technique is a relatively simple way to increase energy efficiency. 


\section{Ginlong GL-PMG-3500 Data Sheet}

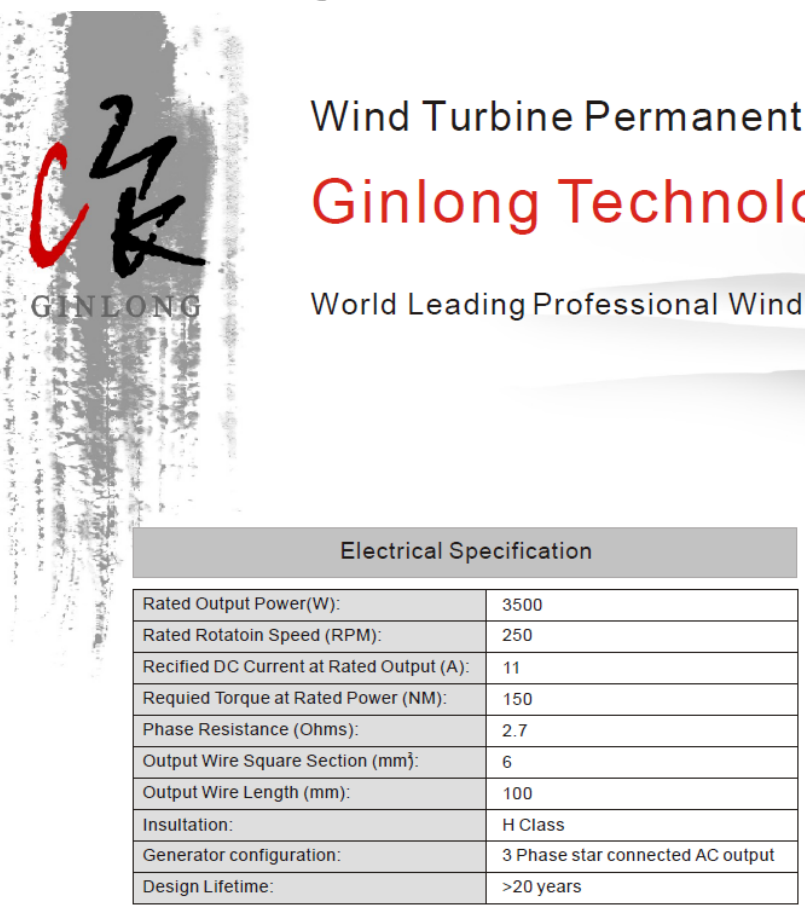

Mechanical Specification
\begin{tabular}{|l|l|}
\hline Mounting Type: & Horizontal \\
\hline Weight (Kgs): & 78 \\
\hline Starting Torque (NM): & $<2.0$ \\
\hline Rotor Inertia (Kg.m): & 0.066 \\
\hline Bearing Type: & $\begin{array}{l}\text { High standard NSK 6209DDU } \\
\text { (Front) NSK 6309DDU (Rear) }\end{array}$ \\
\hline
\end{tabular}

\begin{tabular}{l}
\multicolumn{2}{|c|}{ Material Specification } \\
\begin{tabular}{|l|l|}
\hline Shaft Material: & $\begin{array}{l}\text { Nickle plated 40 Cr Steel with } \\
\text { quenching and tempering treatment }\end{array}$ \\
\hline Shaft Bearing: & High standard SKF or NSK bearing \\
\hline Outer Frame Material: & Steel with anti-corrosion treatment \\
\hline Fasteners (nuts and bolts): & High standard Stainless Steel \\
\hline Windings Temperature Rating: & 180 degrees Celsius \\
\hline Magnet Material: & NdFeB (Neodymium Iron Boron) \\
\hline Magnets Temperature Rating: & 150 degrees Celsius \\
\hline Lamination Stack: & High specification cold-rolled Steel \\
\hline
\end{tabular}
\end{tabular}

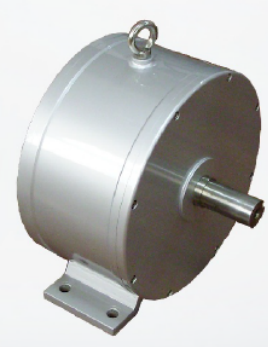

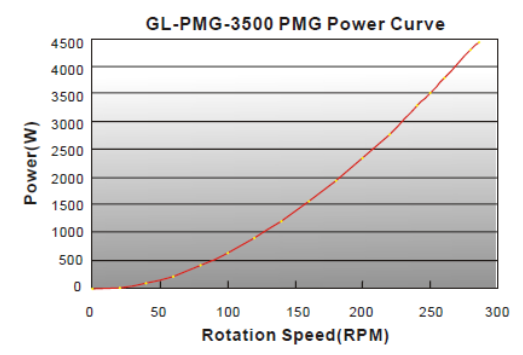

GL-PMG-3500 PMG Open Circuit Voltage
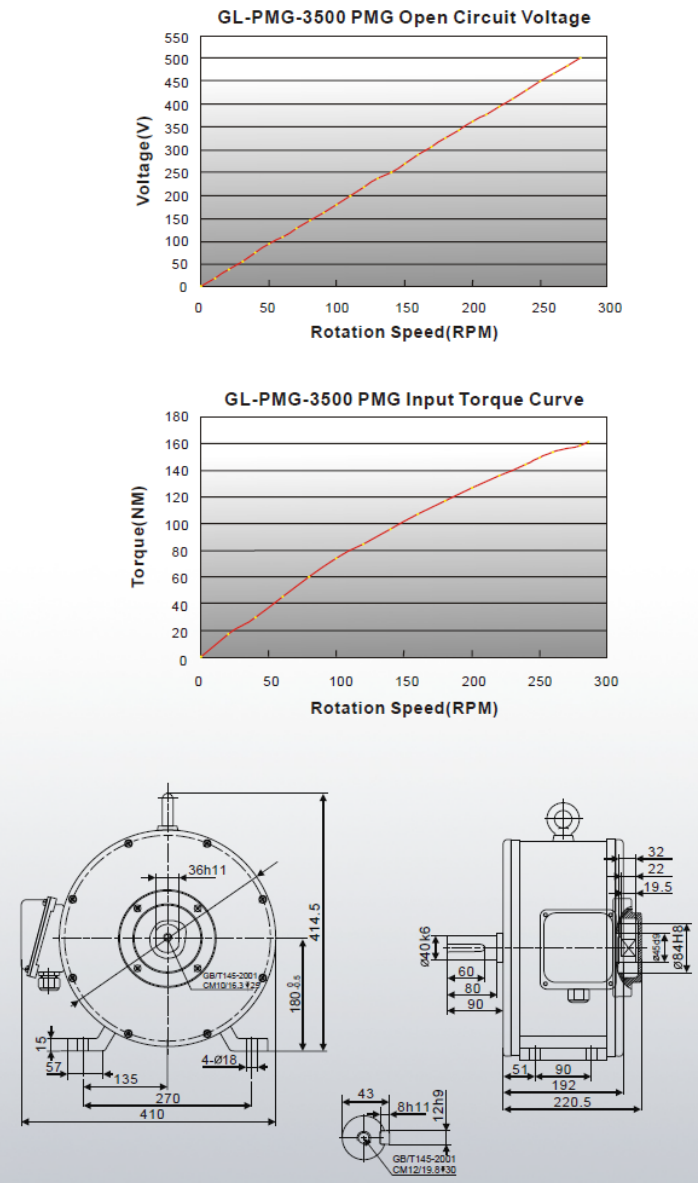


\section{Ziegler Nichols Frequency Response Tuning for PID}

The Ziegler Nichols method is a classic tuning method to determine the gain constants of the PID equation. The first step is to determine if the required proportional gain must be positive or negative. Using speed control loop the control variable $u$ is the resistive load for the generator, and the output of the plant is the generator rotor speed. If the resistance of the generator in increased, the load on the generator will decrease, which will cause the rotor speed to increase so the required proportional gain is positive. The next step for Ziegler Nichols tuning is to turn off the integral and derivative actions by setting $T_{d}=0$, and $T_{i}=\infty$. Next, the ultimate gain is determined by increasing the proportional gain until the system becomes marginally stable and begins to oscillate. The gain at marginal stability is the ultimate gain $K_{u}$ and the period of oscillation is $T_{u}$. The Ziegler-Nichols criteria can be applied to $\mathrm{P}, \mathrm{PI}$, or PID controllers as follows from Table 0.1.

Table 0.1 Ziegler-Nichols Frequency Response Tuning Parameters [17]

\begin{tabular}{|l|l|l|l|l|}
\hline Controller & \multicolumn{1}{|c|}{$K / K_{u}$} & \multicolumn{1}{|c|}{$T_{i} / T_{u}$} & $T_{d} / T_{u}$ & $T_{p} / T_{u}$ \\
\hline $\mathbf{P}$ & 0.5 & - & - & 1 \\
\hline PI & 0.4 & 0.8 & - & 1.4 \\
\hline PID & 0.6 & 0.5 & 0.125 & 0.85 \\
\hline
\end{tabular}

Table 0.1 also gives an estimate for the period of dominant plant dynamics represented by $T_{p}$. The gains determined by Ziegler Nichols tuning are not usually optimum controller gains, but a good starting point for initial tuning. Further tuning usually results in improved performance.

\section{D.1 Tuning the Cal Poly WECS with the Ziegler Nichols Frequency Method}

With the goal of stability in mind, the WECS is evaluated throughout its operational range with wind speeds from $3.5 \mathrm{~m} / \mathrm{s}$ to $13.9 \mathrm{~m} / \mathrm{s}$. The evaluation shows that the WECS is more susceptible to marginal stability at high wind speeds. The following table shows the results of simulating the WECS at different wind speeds with only proportional gain. The trend shows that $K_{u}$ decreases when wind speed increases.

Table 0.2 Marginal Stability for given wind speed, and ultimate gain

\begin{tabular}{|c|c|c|c|c|}
\hline V wind $[\mathrm{m} / \mathrm{s}]$ & $\mathrm{Ku}$ & $\mathrm{Ts}[\mathrm{s}]$ & $\mathrm{Tu}[\mathrm{s}]$ & {$[\mathrm{rpm}]$ peak-peak } \\
\hline 3 & 3000 & 0.01 & 0.02 & 0.17 \\
\hline 10 & 365 & 0.01 & 0.02 & 0.2 \\
\hline 13.9 & 245 & 0.01 & 0.02 & 0.27 \\
\hline
\end{tabular}


Table 0.3 shows the results of adjusting the sampling period of the PID controller. The wind speed was set to a constant value of $10 \mathrm{~m} / \mathrm{s}$.

Table 0.3 Marginal Stability at $\mathrm{V}=10 \mathrm{~m} / \mathrm{s}$ for given sampling period

\begin{tabular}{|l|l|l|l|}
\hline$T_{s}[\mathrm{~s}]$ & \multicolumn{1}{|c|}{$K_{u}$} & $T_{u}[\mathrm{~s}]$ & \multicolumn{1}{|c|}{$T_{u} / T_{s}$} \\
\hline 0.01 & 365 & 0.02 & 2 \\
\hline 0.05 & 500 & 0.01 & 2 \\
\hline 0.1 & 2536 & 0.2 & 2 \\
\hline
\end{tabular}

As shown in Table 0.3, a pattern was found relating the sampling period to the period of oscillation.

$$
T_{u} / T_{s}=2
$$

This relation makes sense because at marginal stability the output oscillates above and below steady state at a rate equal to 2 times the sampling period. Figure 0.7 shows the oscillation at marginal stability for a sample time of $T_{S}=0.01 \mathrm{~s}$.

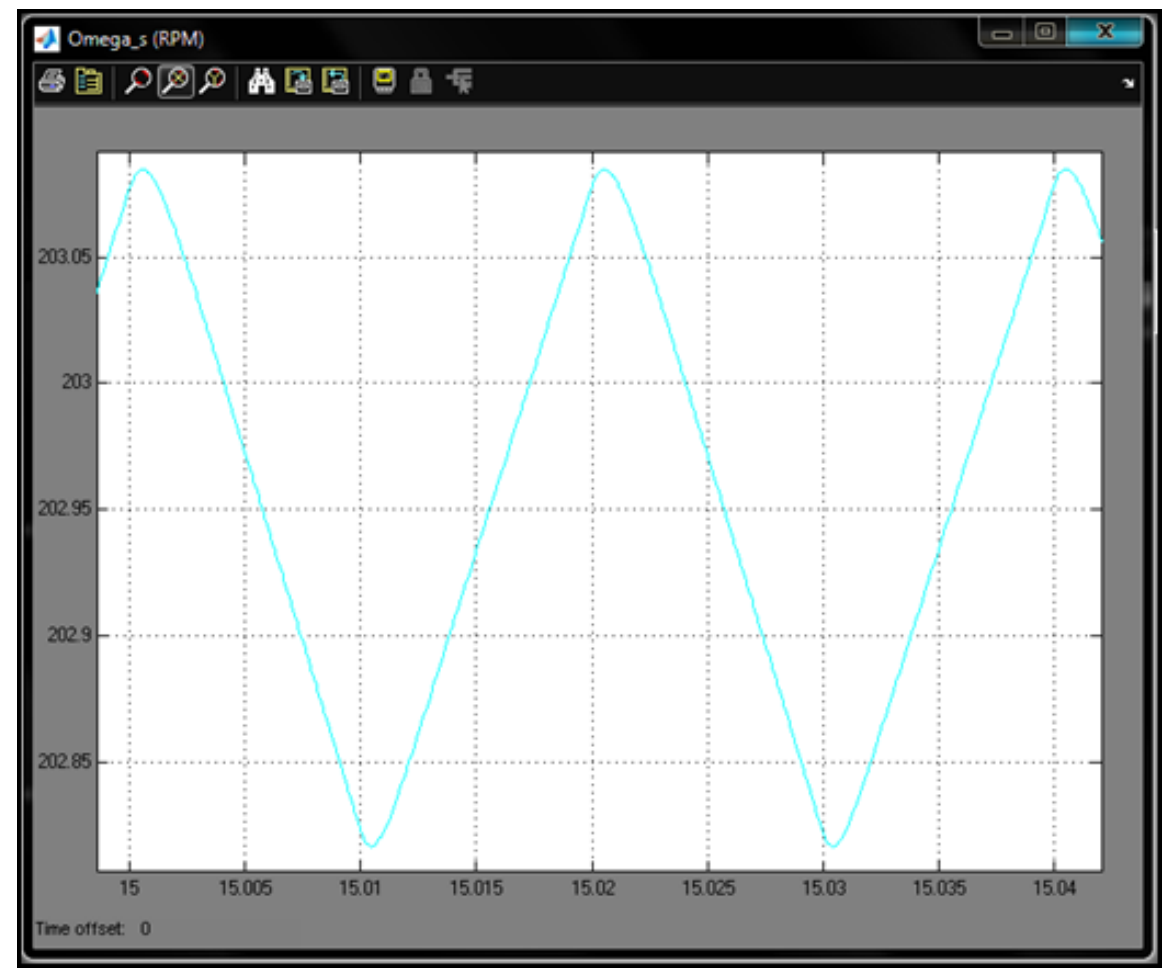

Figure 0.7 Marginal stability of rotor speed using discrete controller with $\mathrm{Ts}=0.01 \mathrm{~s}$

From the tuning method above, the proposed PID gains for the controller are as follows. 
Table 0.4 Ziegler Nichols suggested gains for Ts $=0.01 \mathrm{~s}$

\begin{tabular}{|l|c|c|l|}
\hline Controller & $K$ & \multicolumn{1}{|c|}{$T_{i}$} & \multicolumn{1}{|c|}{$T_{d}$} \\
\hline $\mathbf{P}$ & 182.5 & - & - \\
\hline $\mathbf{P I}$ & 146.0 & 0.016 & - \\
\hline PID & 219.0 & 0.010 & 0.0025 \\
\hline
\end{tabular}




\section{E. Classical Method for Determining Aerodynamic Limitations}

\section{E.1 Cut-in Wind Speed}

The cut-in wind speed is the minimum speed at which the WECS will deliver useful power. Useful power is delivered when the power produced by the generator is greater than the power used to control the wind turbine.

$$
P_{\text {useful }}=P_{G}-P_{\text {control }}
$$

The estimated power required to control the turbine is listed in the table below.

Table 0.5 Estimated Control Power

\begin{tabular}{|c|c|}
\hline Control power usage & Power (W) \\
\hline PLC Controller & $30-40$ \\
\hline Power Electronics load & 10 \\
\hline (Future) Data acquisition system & $30-40$ \\
\hline Miscellaneous & 10 \\
\hline Estimated Total Control Power & $\mathbf{1 0 0}$ \\
\hline
\end{tabular}

According to equation (1.8) and Table 0.5 the generator produces useful power when

$$
P_{G}>P_{\text {control }}
$$

Therefore the estimated minimum power produced by the generator must equal $P_{G}=100[\mathrm{w}]$ the cutin wind speed. The ideal cut-in wind speed can be calculated from available power from the wind which is defined by equation (2.2).

$$
V_{\text {cut-in ideal }}=\sqrt[3]{\frac{P_{G}}{\frac{1}{2} C_{\text {pMax }} \rho \pi \mathrm{R}_{\mathrm{t}}^{2}}}
$$

This calculation assumes a losses mechanical and electrical system. The max power coefficient $C_{p \text { Max }}=0.45$ and the aerodynamic constants are described in Table 2.1. The ideal cut-in wind speed is calculated in equation (1.11).

$$
V_{\text {cut-in ideal }}=\sqrt[3]{\frac{100}{0.5 \cdot 0.45 \cdot 1.22 \cdot \pi \cdot 1.875^{2}}}=3.207[\mathrm{~m} / \mathrm{s}]
$$


In actuality, there will be some mechanical losses due to friction and windage, as well as power lost in the generator due to the stator winding resistance. Assuming these efficiency losses are small (<30w), the cut in wind speed is rounded up to:

$$
V_{\text {cut-in }}=3.5[\mathrm{~m} / \mathrm{s}]
$$

\section{E.2 Nominal Wind Speed}

According to [4], the nominal wind speed is $10.3 \mathrm{~m} / \mathrm{s}$. This is the wind speed where the input torque of generator at rated power $T_{G \text {-rated }}=150[\mathrm{Nm}]$ intersects the available torque from the aerodynamic system. The nominal wind speed is calculated from equation (2.1) with $C_{Q M a x}=0.133$.

$$
\begin{gathered}
V_{\text {nominal }}=\sqrt{\frac{T_{G-\text { rated }}}{\frac{1}{2} C_{Q M a x} \rho \pi R_{t}^{3}}} \\
V_{\text {nominal }}=\sqrt{\frac{150}{\frac{1}{2} \cdot 0.113 \cdot 1.22 \cdot \pi \cdot 1.875^{3}}}=10.25[\mathrm{~m} / \mathrm{s}]
\end{gathered}
$$

\section{E.3 Cut-out Wind Speed from Structural Limitations}

According to [4], the cut-out wind speed occurs at $18 \mathrm{~m} / \mathrm{s}$. This limitation is imposed by the design of the tower structure. At the cut-out wind speed the safety system should take over and apply the mechanical breaks to slowly stop the rotor before damage occurs. 


\section{F. Thermal Overload - Short-time Current Limit}

Thermal protection of the generator windings typically consists of time-overcurrent protection [29]. If high current persists for an extended period of time through the stator winding, thermal damage can occur. This condition can occur if the generator operates above rated load for an extended period of time. From the Ginlong manufacture data sheet (see Appendix $\mathrm{C}$ ) we know the following specifications about the generator.

Table 0.6 Selected electrical \& thermal specifications from Ginlong PMG data sheet

\begin{tabular}{|c|c|}
\hline Rated output power & $3500(\mathrm{~W})$ \\
\hline Rectified DC current at rated output & $11(\mathrm{~A})$ \\
\hline Phase Resistance & $2.7(\Omega)$ \\
\hline Generator configuration & 3-phase Y connected \\
\hline Insulation & H class \\
\hline Winding temperature rating & 180 degrees (C) \\
\hline Magnet temperature rating & 150 degrees (C) \\
\hline
\end{tabular}

According to IEEE Std C37.102 Guide for AC generator protection [30], during emergency conditions it is permissible to exceed the continuous output capability for a short time. The IEEE emergency capability curve is defined by the following equation.

$$
I=100 \sqrt{\frac{k}{t}+1}
$$

Where $I$ is the stator current in percent rated current, and $k$ is the gain factor. IEEE specifies $k=37.5$ which corresponds to IEC 60034-1 which is the international standard for the rating and performance for rotating electrical machines. IEC 60034-1 section 9.3.2 describes the occasional excess current capability for generators stating "AC generators having rated outputs not exceeding 1200 MVA shall be capable of withstanding a current equal to 1.5 times the rated current for not less than $30 \mathrm{s."}$. For the application of the Cal Poly wind turbine, there is no reason to operate the turbine in an emergency situation because there are no critical loads connected to the system. With this consideration, a much more conservative curve will be used to limit the short term continuous output current. The Figure below has been adopted from the IEEE standard described above. 


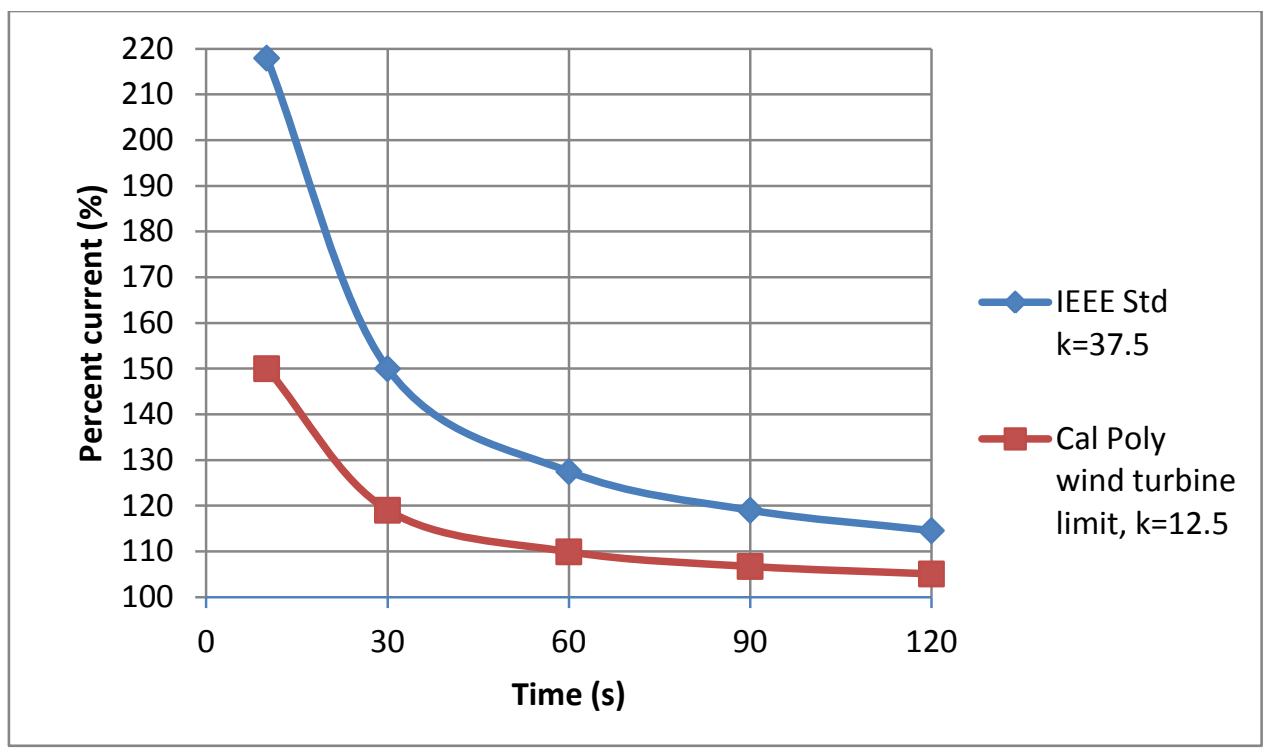

Figure 0.8 Stator short-time current limit as percent of rated current

With a new gain factor of $k=12.5$ the current is limited to $150 \%$ for a time of $10 \mathrm{~s}$, or $120 \%$ for 30 s. This conservative approach should cause no damage to the insulation of the generator. It is also reassuring to note that the Ginlong PMG uses class-H insulation which has the highest allowable continuous temperature rating [31]. The $0.1 \mathrm{sec}$ instantaneous current value (1122) listed in row 1 of Table 0.7 is a product of equation (1.15). See the following section for the instantaneous overcurrent limit.

Table 0.7 Short-time current limit as percent of rated current

\begin{tabular}{|c|c|c|}
\hline Time (s) & IEEE std k=37.5 & Cal Poly Wind turbine limit, k=12.5 \\
\hline 0.1 & 1939 & 1122 \\
\hline 1 & 620 & 367 \\
\hline 10 & 218 & 150 \\
\hline 30 & 150 & 119 \\
\hline 60 & 127 & 110 \\
\hline 90 & 119 & 107 \\
\hline 120 & 115 & 105 \\
\hline
\end{tabular}




\section{G. Instantaneous Overcurrent}

Instantaneous overcurrent is defined as an abrupt spike of current through the stator winding, which can be caused by an external electrical fault. The controller proposed in this report has the ability to control the electrical load of the generator, so it is important to investigate the threshold of instantaneous current which could cause damage to the generator.

The direct axis sub-transient reactance is typically the most conservative value used for the calculation of the maximum fault current. Maximum fault currents are typically in the order of 10 to 100 times the normal operating current [29].

As stated in the Ginlong PMG Data sheet, the GL-PMG-3500 is capable of withstanding temporary short circuit condition as required for braking.

For the Cal Poly wind turbine, it is very conservative to limit the instantaneous overcurrent to 4 times the normal operating current because IEC 60034-1 section 9.8 Short-circuit current for synchronous machines, states "the peak value of the short-circuit current for synchronous Machines...shall not exceed 15 times the peak value or 21 times the r.m.s. value of the rated current." Figure 0.9 below summarizes the suggested instantaneous and short time stator current limits for the Ginlong PMG-3500.

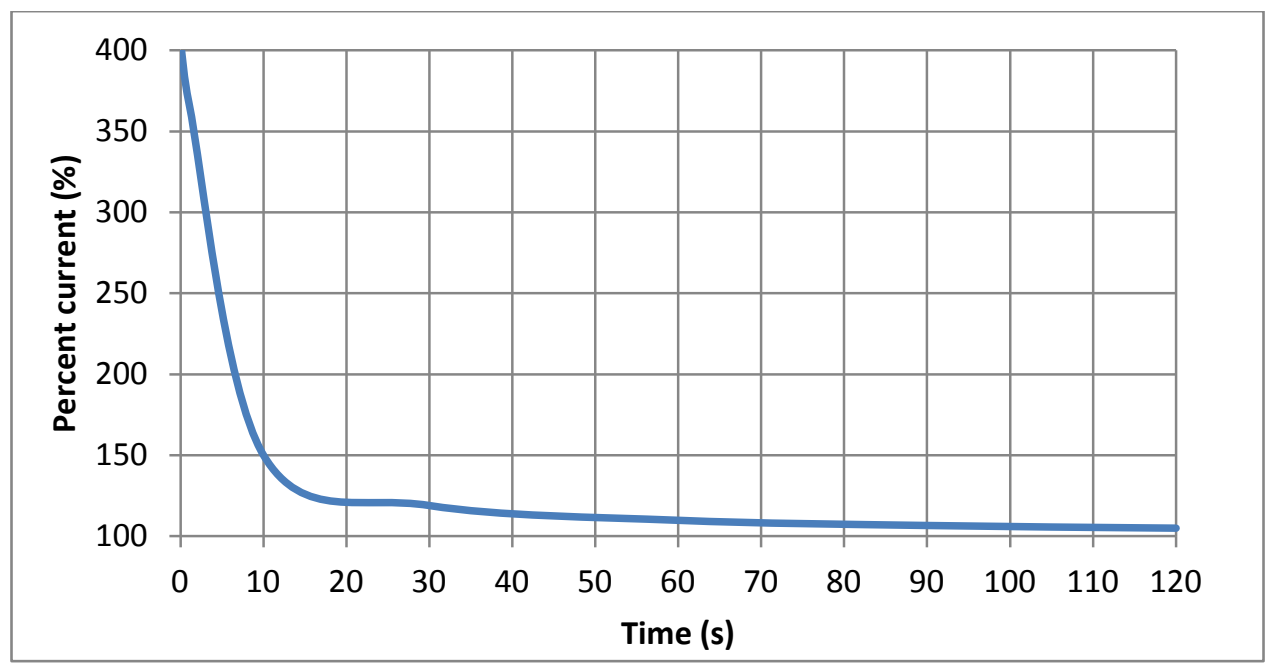

Figure 0.9 Instantaneous and short-time stator current limit for Ginlong PMG-3500 


\section{H. MDS60-16B Bridge Rectifier Datasheet

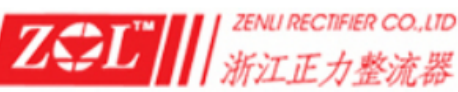

Bridge Rectifier Module

$\begin{array}{ll}\text { Bridge Rectifier Module } & \\ \text { Features } & \text { Applications } \\ \text { - Base \& chip insulation AC voltage 2500V } & \text { - Instrument's DC powers upply } \\ \text { - International standard packing } & \text { - PWM frequency transformet } \\ \text { - Excellent temperature feature } & \text { - Input rectificate power supply } \\ \text { - Easy to install } & \text { - DC motor field power supply } \\ \text { - Popular size } & \text { - Switch power supply input rectificate } \\ \text { - Low VFM } & \end{array}$

- Low VFM

Part number type \& circuit
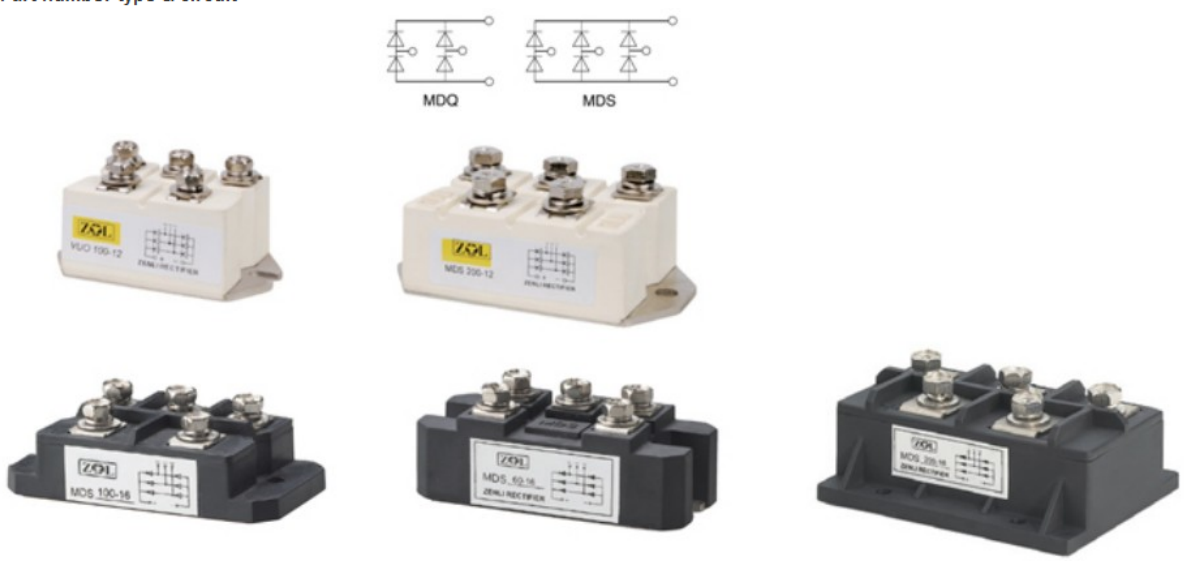

THREE-PHASE BRIDGE RECTIFIER MODULES (MDS)

\begin{tabular}{|c|c|c|c|c|c|c|c|c|c|c|c|c|c|}
\hline \multirow{2}{*}{ Type } & \multicolumn{2}{|c|}{ Id@Tc } & \multirow{2}{*}{$\begin{array}{c}\text { VRRM } \\
\mathrm{V}\end{array}$} & \multicolumn{2}{|c|}{ VFM@IFM } & \multirow{2}{*}{$\begin{array}{c}\text { IRRM } \\
\text { mA }\end{array}$} & \multirow{2}{*}{$\begin{array}{c}\mathrm{I} F(\mathrm{AV}) \\
\mathrm{A}\end{array}$} & \multirow{2}{*}{$\frac{\mathrm{I} \text { (RMS) }}{\mathrm{A}}$} & \multirow{2}{*}{$\begin{array}{l}\text { ITSM } \\
A \times 10^{3}\end{array}$} & \multirow{2}{*}{$\begin{array}{c}\mathrm{Rjc}_{\mathrm{jc}} \\
\mathrm{C} / \mathrm{W}\end{array}$} & \multirow{2}{*}{$\begin{array}{l}\mathrm{T}_{\mathrm{jm}} \\
\mathrm{C} \mathrm{C}\end{array}$} & \multirow{2}{*}{$\begin{array}{c}V_{\text {iso }} \\
V(A C)\end{array}$} & \multirow{2}{*}{ Outline } \\
\hline & A & ${ }^{\circ} \mathrm{C}$ & & v & A & & & & & & & & \\
\hline MDS60 & 60 & 100 & $600-2000$ & 1.55 & 60 & 8 & 20 & 39 & 0.75 & 0.55 & 150 & 2500 & \multirow{3}{*}{$\begin{array}{l}\text { M16/ } \\
\text { M17/ } \\
\text { M18 }\end{array}$} \\
\hline MDS80 & 80 & 100 & $600-2000$ & 1.47 & 80 & 8 & 25 & 47 & 1.00 & 0.32 & 150 & 2500 & \\
\hline MDS100 & 100 & 100 & $600-2000$ & 1.53 & 100 & 10 & 33 & 51 & 1.50 & 0.24 & 150 & 2500 & \\
\hline MDS150 & 150 & 100 & $600-2000$ & 1.50 & 150 & 10 & 50 & 71 & 2.50 & 0.15 & 150 & 2500 & \multirow{3}{*}{$\begin{array}{l}\text { M19/ } \\
\text { M20 }\end{array}$} \\
\hline MDS200 & 200 & 100 & $600-2000$ & 1.47 & 200 & 10 & 75 & 105 & 2.50 & 0.15 & 150 & 2500 & \\
\hline MDS250 & 250 & 100 & $600-2000$ & 1.47 & 250 & 10 & 100 & 157 & 2.75 & 0.14 & 150 & 2500 & \\
\hline MDS300 & 300 & 100 & $600-2000$ & 1.48 & 300 & 9 & 125 & 200 & 2.90 & 0.14 & 150 & 2500 & \multirow{2}{*}{ M21 } \\
\hline MDS400 & 400 & 100 & $600-2000$ & 1.45 & 400 & 10 & 150 & 240 & 2.95 & 0.13 & 150 & 2500 & \\
\hline MDS500 & 500 & 100 & $600-2000$ & 1.49 & 500 & 10 & 200 & 320 & 3.15 & 0.12 & 150 & 2500 & \multirow{2}{*}{ M22 } \\
\hline MDS600 & 600 & 100 & $600-2000$ & 1.49 & 600 & 10 & 250 & 400 & 3.50 & 0.10 & 150 & 2500 & \\
\hline
\end{tabular}

The LT-Spice model uses the following model definition. All other parameters not defined below become default values in LT-Spice.

.$M O D E L$ DI_MDS60 D (Ilimit=60 Revilimit=0.008 Vj=1.55 BV=1600 Isr=5e-4 ) 


\section{References}

[1] Antoneta Iuliana Bratcu, Nicholaos-Antonio Cutululis, Emil Ceanga Iulian Munteanu, Optimal Control of Wind Energy Systems. Verlag London, England: Springer, 2008.

[2] Dinghui Wu, Yan Wang,Zhicheng Ji Wei Wang, "H infinite Gain Scheduling Control of PMSG-based Wind Power Conversion System," Institute of Electrical Automation, Jiangnan University, Wuxi, China, 5th IEEE Conference on Industrial Electronics and Applications 978-1-4244-5046-6/10, 2010.

[3] American Wind Energy Association. (2011, September) AWEA U.S. Wind Industry Fast Facts. [Online]. http://www.awea.org/learnabout/industry stats/index.cfm

[4] Richard Sandret, "Cal Poly Wind Turbine Modeling and Speed Control," San Luis Obispo, CA, 2010.

[5] Ka-Wah Li, Travis Robinson-Carter, and Michael Kulgevich, "Cal Poly Wind Turbine Off-Grid Load Bank and Emergency Speed Controller," San Luis Obispo, CA, 2009.

[6] Theda Silver-Pell, "DC chopper for electronic speed control of a small off-grid wind turbine," San Luis Obispo, CA, 2009.

[7] Kent Burnett, "Cal Poly Wind Turbine Speed Controller," San Luis Obispo, CA, 2010.

[8] Hernán De Battista, Ricardo J. Mantz Fernando D. Bianchi, Wind Turbine Control Systems: Principles, Modelling and Gain Scheduling Design. London: Springer, 2006.

[9] P.F. Puleston, P.E. Battaiotto, R.J. Mantz F. Valenciaga, "An adaptive feedback linearization strategy for variable speed wind energy conversion systems," INTERNATIONAL JOURNAL OF ENERGY RESEARCH, no. 24:151-161, p. 2, 2000.

[10] David Sharp, Nick Jenkins, Ervin Bossanyi Tony Burton, Wind Energy Handbook. West Sussex, England: John Wiley \& Sons, 2008.

[11] Ningbo Ginlong Technologies Co., Ltd. (2006) Ginlong GL-PMG-3500 data sheet. [Online]. www.ginlong.com

[12] Charles Kingsley, Jr. ,Stephen D. Umans A. E. Fitzgerald, Electric Machinery, 6th ed. New Delhi: Tata McGraw Hill, 2003.

[14] Nick Jenkins, Janaka Ekanayake, Phill Cartwright, Mike Hughes Olimpo Anaya-Lara, Wind Energy Generation; Modeling and Control. West Sussex, United Kingdom: John Wiley \& Sons, 2009. 
[15] Muhammad H. Rashid, Power Electronics-Circuits, Devices and Applications, 2nd ed. Englewood Cliffs, NJ, USA: Prentice Hall, 1993.

[16] Elkund T, "Modeling an linear quadratic optimal control of wind turbines," Chalmers University, Goteborg Sweden, Ph.D Thesis 1997.

[17] Tore Hagglundl Karl J. Astrom, Advanced PID Control. Research Triangle Park, NC, USA: ISAInstrument, Systems, and Automation Society, 2006.

[18] IEEE, "IEEE Guide for Test Procedures for Synchronous Machines," Electric Machinery Committee, New York, NY, Standard Std. 115-2009, 2010.

[19] J.E. Fletcher N.E.A.M. Hassanian, "Steady State performance assessment of three and five phase permanent megnet generators connected to a diode bridge rectifier under open circuit faults," The Institution of Engineering and Technology, IET Renew. Power Gener. 2010, Vol.4 Iss. 5, pp.420-427, 2010.

[20] J.E. Fletcher N.A.M Hassanian, "Analysis three and five phase permament magnet machines supplying diode bridge rectifiers for small scale generators," POWERENG 2007 Conf., Setubal, Portugal, 2007.

[21] JS Shamma, "Linerization and gain-scheduling," in Levine WS (ed.) The control handbook, IEEE Press, Ed.: CRC Press, 1996, pp. 388-398.

[29] Thomas J Domin J. Lewis Blackburn, Protective Relaying: Principals and Applications, 3rd ed., Taylor and Francis Group, Ed. Boca Raton, USA, FL: CRC Press, 2007.

[30] IEEE , "IEEE Guide for AC Generator Protection," Power Engineering Society, New York, Standard IEEE Std C37.102-2006, 2006.

[31] The Engineering Tool Box. (2011, April) NEMA Insulation Classes. [Online]. http://www.engineeringtoolbox.com/nema-insulation-classes-d 734.html 